NBER WORKING PAPER SERIES

\title{
THE WELFARE EFFECTS OF COORDINATED ASSIGNMENT: EVIDENCE FROM THE NYC HS MATCH
}

\author{
Atila Abdulkadiro lu \\ Nikhil Agarwal \\ Parag A. Pathak \\ Working Paper 21046 \\ http://www.nber.org/papers/w21046
NATIONAL BUREAU OF ECONOMIC RESEARCH
1050 Massachusetts Avenue
Cambridge MA 20138
March 2015, Revised June 2017

We thank Neil Dorosin, Jesse Margolis, Sonali Murarka, and Elizabeth Sciabarra for their expertise and for facilitating access to the data used in this study. Special thanks to Alvin E. Roth for his collaboration, which made this study possible. Jesse Margolis provided extremely helpful comments. We also thank Josh Angrist, Steve Berry, Stefan Bonhomme, Eric Budish, Francesco Decarolis, Matt Gentzkow, Arda Gitmez, Jerry Hausman, Phil Haile, Ali Hortacsu, Peter Hull, Yusuke Narita, Derek Neal, Alex Olssen, Ariel Pakes, Amy Ellen Schwartz, Jesse Shapiro, and seminar participants at the University of Chicago, Harvard University, Federal Reserve Bank of NY, London School of Economics, Yale University, and the NBER Market Design conference for input. We received excellent research assistance from Alonso Bucarey, Red Davis, Weiwei $\mathrm{Hu}$, Danielle Wedde, and a hard-working team of MIT undergraduates. Agarwal acknowledges support from the National Science Foundation (grant SES-1427231). Pathak acknowledges support from the Alfred P. Sloan Foundation (grant BR2012-068), National Science Foundation (grant SES-1056325), and the William T. Grant Foundation. Abdulkadiroglu and Pathak are on the Scientific Advisory Board of the Institute for Innovation in Public School Choice. The authors declare that they have no relevant or material financial interests that relate to the research in this paper. The views expressed herein are those of the authors and do not necessarily reflect the views of the National Bureau of Economic Research.

At least one co-author has disclosed a financial relationship of potential relevance for this research. Further information is available online at http://www.nber.org/papers/w21046.ack

NBER working papers are circulated for discussion and comment purposes. They have not been peer-reviewed or been subject to the review by the NBER Board of Directors that accompanies official NBER publications.

(C) 2015 by Atila Abdulkadiro lu, Nikhil Agarwal, and Parag A. Pathak. All rights reserved. Short sections of text, not to exceed two paragraphs, may be quoted without explicit permission provided that full credit, including $(\subset$ notice, is given to the source. 
The Welfare Effects of Coordinated Assignment: Evidence from the NYC HS Match Atila Abdulkadiro lu, Nikhil Agarwal, and Parag A. Pathak

NBER Working Paper No. 21046

March 2015, Revised June 2017

JEL No. C78,D47,D50,D61,I21

\section{ABSTRACT}

Coordinated single-offer school assignment systems are a popular education reform. We show that uncoordinated offers in NYC's school assignment mechanism generated mismatches. Onethird of applicants were unassigned after the main round and later administratively placed at less desirable schools. We evaluate the effects of the new coordinated mechanism based on deferred acceptance using estimated student preferences. The new mechanism achieves $80 \%$ of the possible gains from a no-choice neighborhood extreme to a utilitarian benchmark. Coordinating offers dominates the effects of further algorithm modifications. Students most likely to be previously administratively assigned experienced the largest gains in welfare and subsequent achievement.

Atila Abdulkadirolu

Department of Economics

Duke University

213 Social Sciences Building

Durham, NC 27708

and NBER

atila.abdulkadiroglu@duke.edu

Nikhil Agarwal

Department of Economics, E52-460

MIT

77 Massachusetts Ave

Cambridge, MA 02139

and NBER

agarwaln@mit.edu
Parag A. Pathak

Department of Economics, E52-426

MIT

77 Massachusetts Avenue

Cambridge, MA 02139

and NBER

ppathak@mit.edu

A Online appendix is available at http://www.nber.org/data-appendix/w21046 


\section{Introduction}

In recent years, market design theory has inspired dramatic changes in how children are assigned to public schools across numerous American cities and around the world. The first new system adopted was for placing 8th graders into high schools in New York City (NYC). NYC's new system has not only received widespread scientific and popular acclaim (Nobel 2012, Tullis 2014, Roth 2015), but also became a template for reforms in other cities. ${ }^{1}$ Despite widespread adoption of and apparent consensus on the value of market-design-inspired centralized assignment schemes, there is remarkably little evidence on whether, why, and how much a coordinated assignment system affects pupil allocation to schools or the extent to which the new system created losers as well as winners. The empirical performance of alternatives to NYC's deferred acceptancebased scheme, the quantitative aspects of particular design trade-offs, and whether the new mechanism is associated with improvements in downstream educational outcomes also remain open questions. ${ }^{2}$

Characterizing the state of the market prior to the new mechanism is a major challenge because decentralized and uncoordinated systems do not usually generate systematic data. This paper surmounts this hurdle by exploiting new data on the system used in New York before 2003 to study the effect of moving from an uncoordinated assignment system to a coordinated single-offer system for allocating students to schools. Using our rich micro-data on applications, assignments, and enrollments, we describe high school student placement in both systems and assess whether students receive one of their preferred choices. Tracking students from application to assignment allows us to comprehensively describe the drawbacks of NYC's previous system, but still leaves unanswered questions. First, we do not know whether the reform realized most of the possible gains associated with a new assignment system or how those gains were distributed across applicants. Second, we know little about the magnitude of further algorithmic improvements, as considered by the market design literature compared to other design aspects. Our paper addresses these questions using an estimated model of student preferences exploiting the straightforward incentive feature of New York's new system.

Prior to 2003, rising NYC high school students applied to five out of more than 600 school programs; they could receive multiple offers and be placed on wait lists. Students were allowed to accept only one school and one wait list offer, and the cycle of offers and acceptances was repeated two more times. The vast majority of students not assigned in these rounds went through an administrative process that manually placed them at schools close to their residences. Since admissions offers were not coordinated across schools, we refer to this as the uncoordinated mechanism. ${ }^{3}$ In Fall 2003, this system was replaced by a single-offer assignment system, based

\footnotetext{
${ }^{1}$ Cities that adopted new coordinated matching systems following NYC include Camden, Denver, New Orleans, Newark, and Washington DC.

${ }^{2}$ There is an active scholarly and policy debate about alternative designs. The OneApp process used in the Recovery School District in New Orleans is based on an entirely different assignment algorithm that relaxes the stability constraint in New York's system (Abdulkadiroğlu, Che, Pathak, Roth, and Tercieux 2017). Abdulkadiroğlu, Che, and Yasuda (2015) argue that ordinal strategy-proof mechanisms may not lead to improvements in cardinal utility.

${ }^{3}$ Although the offer timetable and number of rounds was uniform across schools, there was no coordination among schools during admissions decisions.
} 
on the student-proposing deferred acceptance algorithm (DA) for the main round. Applicants were allowed to rank up to 12 programs for enrollment in 2004-05, and a supplementary round placed students unassigned in the main round. Since the central office coordinated all schools into a single offer, we refer to this new system as the coordinated mechanism. The mechanisms could produce different allocations for three main reasons: 1) the new mechanism allows students to rank up to 12 choices, whereas the old mechanism only allowed for five; 2) the old mechanism's limited number of offer and acceptance rounds led to congestion, as students held on to lesspreferred choices while waiting to be offered seats at more preferred schools after others decline; and 3) unlike the new mechanism, the old mechanism invited strategic considerations on student ranking, as schools were able to see the entire rank ordering of applicants in the old mechanism, and some advertised they would only consider those who ranked them first.

Offer processing and matriculation patterns provide rich details on how and why the new mechanism improves on the old one. In the old mechanism, $18.6 \%$ of students matriculate at schools different from their assignment at the end of the match compared to $11.4 \%$ under the new mechanism. Multiple offers and short rank-order lists in the old mechanism advantage few students but leave many without offers. Roughly one-fifth of students obtain multiple offers, while half of applicants receive no first round offer, and 59\% of these applicants are administratively assigned. The take-up rates for administratively-assigned students are similar across mechanisms, but the number of students assigned in that round is three times larger in the old mechanism. In addition, in the old mechanism, 8.5\% of applicants left the district after assignment in the old mechanism while only $6.4 \%$ left under the new mechanism. Students are willing to travel 0.69 miles further to attend the schools they are assigned by the new mechanism. While these observations suggest welfare improvements, it is nevertheless necessary to estimate a model of school demand to quantify the distribution of student welfare effects and the relevance of design issues that are central to the school matching market design literature.

The new mechanism is based on DA, which is strategy-proof. This fact motivates treating stated preferences as true preferences and sidesteps challenges associated with inferring preferences from highly manipulable systems. ${ }^{4}$ As far as we know, our paper is the first to fit econometric models of school demand using data generated by DA, though many have argued for strategy-proof mechanisms because they generate credible preference data for guiding policy. ${ }^{5}$ Our preference estimates characterize the heterogeneous nature of student preferences and allow us to quantify which aspects of school choice market design are most important for allocative efficiency. That our estimates are robust to variations on our assumptions about ranking behavior and evidence of in-sample and out-of-sample fit reassures us that using stated preferences is suitable for welfare analysis.

We use these estimates to evaluate the allocative and distributional aspect of various assignment mechanisms, an exercise that provides a quantitative counterpart to the theoretical literature on matching market design. To scale the magnitude of welfare effects, we first

\footnotetext{
${ }^{4}$ In section 9.2 probes this assumption in greater detail.

${ }^{5}$ The fact that strategy-proof mechanisms generate reliable demand data is a common argument in their favor (see, e.g., Abdulkadiroğlu, Pathak, Roth, and Sönmez (2006), Abdulkadiroğlu, Pathak, and Roth (2009), Sönmez (2013)). Following our paper, Pathak and Shi (2014) examine the out-of-sample performance of school demand forecasts using data from Boston's DA-based system.
} 
measure aggregate welfare from two benchmark cases: a neighborhood assignment allocation, wherein each student was assigned to the closest school subject to capacity constraints, and the utilitarian optimal assignment, which maximizes the equally weighted average of distanceequivalent utility. The coordinated scheme achieves $80 \%$ of this idealized benchmark. Next, we find relatively modest gains from relaxing the mechanism design constraints emphasized by a large theoretical market design literature (Erdil and Ergin 2008, Abdulkadiroğlu, Pathak, and Roth 2009, Kesten 2010, Kesten and Kurino 2012). Had the mechanism produced a studentoptimal stable matching, the average student welfare would have improved by another $0.6 \%$ of this range. An ex post Pareto efficient matching, which abandons the stability constraints in the current mechanism, results in a further improvement of about $2.7 \%$ of the range. While these alternatives are infeasible without sacrificing some appealing features of the mechanism, this exercise shows that the magnitude of student welfare gains from any potential algorithmic improvements are swamped by the effect of simply having choice in a coordinated system implemented by deferred acceptance, as measured by the range between neighborhood assignment and the assignment from the coordinated mechanism assignment.

We then deploy several approaches to use our demand estimates to evaluate the transition from an uncoordinated to a coordinated mechanism. The first approach evaluates welfare changes by treating student behavior in the two mechanisms symmetrically, and the second approach approximates the best-case scenario for the uncoordinated mechanism in which students behave optimally. We find the new mechanism has made it easier for students to obtain a choice they want, and this result is robust to how we interpret data from the uncoordinated mechanism. Even though the coordinated mechanism produces school assignments that are geographically further away, our estimated distribution of preferences indicates the degree to which students prefer these assignments more than compensates for this difference. Under our estimate of an approximate best-case for the uncoordinated mechanism, we estimate that admissions coordination represents about a $45 \%$ improvement in the range for no choice to utilitarian optimum. Students across all demographic groups, boroughs, and baseline achievement levels receive a more preferred assignment on average from the new mechanism. The largest gains are for student groups that were more likely to be unassigned after the old mechanism's main round, a result that suggests that the old mechanism's congestion and ad-hoc placement of unassigned students are primarily responsible for misallocation. This comparison also shows that eliminating congestion through offer coordination via DA dominates the allocative effect of further modifications to the matching algorithm within the coordinated system. Finally, we show both test scores and graduation rates increase for students who were most likely to be administratively assigned in the old mechanism.

This paper relates to two distinct literatures on school choice and matching mechanisms. Our focus aligns with research interested in understanding how choice affects student assignment and sorting (Epple and Romano 1998, Urquiola 2005) rather than the competitive effects of choice on student achievement (Hoxby 2003, Rothstein 2006). Further, we concentrate on allocative efficiency, and only briefly examine subsequent achievement (Abdulkadiroğlu, Angrist, Dynarski, Kane, and Pathak 2011, Deming, Hastings, Kane, and Staiger 2014, Walters 2014, Neilson 2014). The allocative issues on which we focus are likely important for understanding potential long-term effects on residential choices and school productivity. A number of recent 
papers use micro data from assignment mechanisms to understand school demand (Hastings, Kane, and Staiger 2009, He 2012, Ajayi 2017, Agarwal and Somaini 2014, Calsamiglia, Fu, and Guell 2014, Hwang 2014, Burgess, Greaves, Vignoles, and Wilson 2015), typically using data from highly manipulable mechanisms like the Boston mechanism based on specific models of student information and sophistication. While some of these papers have compared the Boston mechanism and DA, ours is the first to examine congestion in an uncoordinated school assignment system. An approach based on estimated preferences complements survey data for comparing mechanisms. For instance, Budish and Cantillon (2012) use survey data on a multi-unit course allocation mechanism and find that more students are assigned to preferable choices in a strategyproof mechanism than in the strategic draft mechanism used at the Harvard Business School. Finally, our work relates to comparisons of decentralized and centralized medical labor markets by Niederle and Roth (2003), who show the distance between a gastroenterologist's medical school and residency location increases with a centralized clearinghouse.

\section{High School Choice in NYC}

\subsection{School Options}

Aspiring high school students may apply to any school or program throughout New York City. A single school may host several programs that have curricula ranging from the arts to sciences to vocational training. The 2002-03 High School directory describes program types. Specialized High Schools, such as Stuyvesant and Bronx Science, have only one type of program, which admits students by admissions test performance on the Specialized High Schools Admissions Test (SHSAT). ${ }^{6}$ There are three ways in which student screening differs for non-Specialized high schools. Unscreened programs admit students by random lottery, in some cases giving priority to students from specific residential zones or to students who attend the school's open house. Screened programs evaluate students individually using an assortment of criteria, including grades, standardized/diagnostic test scores; attendance and punctuality; interviews; and essays. Such programs might also evaluate students for proficiency in specific performing or visual arts, music, or dance. Education Option programs also evaluate students individually, but only for half of their seats. The other half is allocated by lottery. Seat allocation in each half targets the following student ability distribution as measured by citywide 7th grade English language arts scores: $16 \%$ of seats should be allocated to high performing readers, $68 \%$ percent to middle performers, and $16 \%$ to low performers.

Throughout the last decade, the NYC Department of Education (DOE) closed and opened new small high schools throughout the city, each with roughly 400 students. A big push for these small high schools came as part of the New Century High Schools Initiative launched by Mayor Bloomberg and Chancellor Klein. Eleven new small high schools were opened in 2002, 23 new small schools were opened in 2003, and small high school openings peaked in 2004 (Abulkadiroğlu, Hu, and Pathak 2013). Most of these schools are small and have about 100 students per entering class. As a result, the new small high schools have a relatively minor effect

\footnotetext{
${ }^{6}$ Abdulkadiroğlu, Angrist, and Pathak (2014) describe their admissions process in more detail.
} 
on overall enrollment patterns during our study period, which focuses on school options available in 2002-03 and 2003-04.

\subsection{Uncoordinated Admissions in 2002-03}

Forms of high school choice have existed in New York City for decades. Before 2002, high school assignment in New York City featured many choice options, mostly controlled by borough-wide high school superintendents. Significant admissions power resided with school administrators, who could directly enroll students. Admissions to the Specialized High Schools and the LaGuardia High School of Music \& Art and Performing Arts, however, have been traditionally administered as a separate process, which did not change with the new mechanism. ${ }^{7}$ Our study therefore focuses on admissions to non-Specialized public schools.

About 80,000 students interested in regular high schools visit schools and attend city-wide high school open houses before submitting their preferences in the fall. In the Main round in 2002-03, students could apply to at most five regular programs in addition to the Specialized High Schools. Programs receiving a student's application were able to see the applicant's entire preference list, including where their program was ranked. Programs then decided whom to admit, place on a waiting list, or reject. Applicants were sent a decision letter from each program to which they had applied, and some obtained more than one offer. Students were allowed to hold on to at most one admission and one wait-list offer. After receiving responses to the first letters, programs with vacant seats could make new offers to students from waiting lists. After the second round, students who did not have a zoned high school were allowed to participate in a Supplementary round known as the variable assignment process. In the Supplementary round, students could rank up to eight choices and were assigned based on seat availability negotiations between the enrollment office and high school superintendents. After replies to the second letter were received, a third round of letters were mailed. New offers did not necessarily go to rejected or wait-listed students in a predetermined order. Unassigned students were either placed at their zoned programs or administratively placed as close to home as possible by the central office. We refer to this final stage as the Administrative round. ${ }^{8}$

Three features of this assignment scheme motivated the NYC DOE to abandon it in favor of a new mechanism. First, there was inadequate time for offers, wait list decisions, and acceptances to clear the market for school seats. DOE officials reported that in some cases, highachieving students received acceptances from all of the schools to which they applied, while many other students received none (Herszenhorn 2004). Comments by the Deputy Schools Chancellor summarized the frustration: "Parents are told a school is full, then in two months, miracles of miracles, seats open up, but other kids get them. Something is wrong" (Gendar 2000).

\footnotetext{
${ }^{7}$ The 1972 Hecht-Calandra Act is a New York State law that governs admissions to the original four Specialized High Schools: Stuyvesant, Bronx High School of Science, Brooklyn Technical, and Fiorello H. LaGuardia High School of Music \& Performing Arts. City officials indicated that this law prohibits including these schools within the common application system without action by the state legislature.

${ }^{8}$ Students who are new to New York City or did not submit an application participate in an "over-the-counter" round over the summer. Our analysis follows applicants through to assignment and therefore does not consider students who joined the process after the high school match. Arvidsson, Fruchter, and Mokhtar (2013) provide further details on the over-the-counter round.
} 
Second, some schools awarded admissions priority to students who ranked them first on their application forms. The high school directory advises that when ranking schools, students should "determine what [their] competition is for a seat in this program" (DOE 2002). This recommendation reflects strategic incentives for ranking decisions. Students have to consider both the limited number of potential applications and whether the school only considers firstchoice applicants.

Third, a number of schools managed to conceal capacity to fill seats later on with more preferred students. For example, the Deputy Chancellor stated, "before you might have a situation where a school was going to take 100 new children for ninth grade, they might have declared only 40 seats, and then placed the other 60 outside the process" (Herszenhorn 2004). Overall, critics alleged that the old mechanism disadvantaged low-achieving students and those without sophisticated parents (Hemphill and Nauer 2009).

\subsection{Coordinated Admissions in 2003-04}

The new mechanism was designed with input from economists (see Abdulkadiroğlu, Pathak, and Roth (2005) and Abdulkadiroğlu, Pathak, and Roth (2009)). When publicizing the new mechanism, the DOE explained that its goals were to utilize school places more efficiently and reduce the gaming involved in obtaining school seats (Kerr 2003). As in previous years, in the first round, students apply to Specialized High Schools when they take the SHSAT. Offers are produced according to a serial dictatorship with priority given by SHSAT scores. ${ }^{9}$

In the Main round, students can rank up to twelve regular school programs in their applications, which are due in November. The DOE advises parents: "You must now rank your 12 choices according to your true preferences," because this round is built on Gale and Shapley (1962)'s student-proposing deferred acceptance algorithm. Schools with programs that prioritize applicants based on auditions, test scores or other criteria are sent lists of students who ranked the school, but these lists do not reveal where on the preference lists the schools were ranked. Schools return orderings of applicants to the central enrollment office. Schools that prioritize applicants using geographic or other criteria have those criteria supplied by the central office. That office uses a single lottery to break ties among students with the same priority, thus generating a strict student order at each school.

The centralized clearinghouse assigned schools using DA with inputs that include student preferences, school capacities, and schools' strict ordering. After lottery numbers are drawn, DA works as follows:

Step 1) Each student proposes to her first choice. Each school tentatively assigns seats to its proposers one at a time, following their priority order. The student is rejected if no seats are available at the time of consideration.

In general, in

\footnotetext{
${ }^{9}$ There is very limited overlap between the specialized round and subsequent rounds. In 2003-04, 4,175 out of 4,553 of students offered a Specialized High School placement accepted that offer.
} 
Step k) Each student who was rejected in the previous step proposes to her next best choice. Each school considers the students it has tentatively assigned together with its new proposers and tentatively assigns its seats to these students one at a time following the school's priority order. The student is rejected if no seats are available when she is considered.

The algorithm terminates either when there are no new proposals or when all rejected students have exhausted their preference lists.

DA is run for all students in February. In this first round, only students who receive a Specialized High School offer receive an offer letter from a regular school, and they are asked to choose. After they respond, students who accept are removed from the pool, school capacities are adjusted, and the algorithm is re-run with the remaining students. After the Main round, all students receive a letter notifying them of their assignment or whether they are unassigned after the Main round.

Students unassigned after the Main round receive a list of programs with vacancies and are asked to rank up to twelve of these programs. In 2003-04, the admissions criteria at the remaining school seats were ignored in this Supplementary round. Students are ordered by their random number, and DA is run with this ordering in place at each school. Students who remain unassigned in the Supplementary round are assigned administratively. These students and any appealing students are processed on a case-by-case basis in the Administrative round.

\section{$3 \quad$ Data and Sample Restrictions}

\subsection{Students}

For this study, the NYC DOE provided us with several data sets: student choices and assignments, student demographics, and October student enrollment. Each student has a unique identification number used across all data sets. For 2002-03, the assignment files record students' Main round rank-order list, their offers and rejections for each round, whether they participate in the Supplementary round, and their final assignment at the conclusion of the assignment process as of July 2003. For 2003-04, the assignment files contain students' choice schools in order of preference, priority information for each school, assignments at the end of each round, and final assignment as of early August 2004. The student demographic files for both years contain information on home address, gender, race, limited English proficiency status, special education status, and performance on 7th grade citywide tests. We use addresses to compute the road distance between each student and his/her school and to place each student in a census block group. ${ }^{10}$ We also have access to similar files for 2004-05. Further details are in the Data Appendix.

Our analysis sample makes two restrictions. First, since we do not have demographic information for private school applicants, we restrict the analysis to students in NYC's public middle schools in the year prior to application. Second, we focus on students who are not assigned to

\footnotetext{
${ }^{10}$ Though we use road distance, we also computed subway distance using the Metropolitan Transportation Authority GIS files; the overall correlation between driving distance and subway commuting distance for all student-program pairs is 0.96 .
} 
Specialized High Schools because that part of the assignment process did not change in the new mechanism. Given these restrictions, we have two main analysis files: the mechanism comparison sample and the demand estimation sample.

The mechanism comparison sample is used to compare the assignment across the two mechanisms. This sample is the largest set of students assigned through the high school assignment mechanism to a school that exists when the high school directory is printed. A key property of the mechanism comparison sample is that every student has an assignment. Columns 1 and 2 of Table 1 summarize student characteristics in the mechanism comparison samples across years. 3,500 fewer students are involved in the mechanism comparison sample in the coordinated mechanism, a difference mainly due to the students assigned either to schools created after the high school directory was printed or to closed schools (as shown in Appendix Table C2).

New York City is the nation's largest school district, and like many urban districts, the majority of students are low-income and non-white. Nearly three-quarters of students are black or Hispanic, and about 10\% of students are Asian. Brooklyn has the largest number of applicants, followed by Queens and the Bronx, both of which account for roughly one quarter of students. Manhattan and Staten Island account for a considerably smaller shares of students at about $13 \%$ and $7 \%$, respectively. Consistent with the sudden announcement of the new mechanism, applicant characteristics are similar across years.

The demand sample, drawn from the assignment files, contains participants in the Main round in the new mechanism. These students' school choices represent the overwhelming majority of students. From the set of Main round participants, we exclude a small fraction of students who are classified as the top 2 percent because these students are guaranteed a school only if they rank it first, and this may distort their incentives to rank schools truthfully. Additional details on the sample restrictions are in the Data Appendix.

\subsection{Schools}

School data were taken from New York State report card files provided by NYC DOE. Program information comes from the official NYC High School Directory made available to students before they submit an application. Table 2 summarizes school and program characteristics across years. The number of schools increases from 215 to 235, and the number of students enrolled in 9th grade per school decreases by about 14 students. This decrease is driven by the replacement of some large schools with smaller schools that took place concurrently in 2003-04, as described above. Despite these shifts, there is little change in either average school achievement level or school demographic composition as measured by the report card data. We are not aware of other significant changes in school inputs, recruitment campaigns, or materials, including the format of the high school directory. ${ }^{11}$

Students can choose from among roughly 600 programs throughout the city. Programs vary substantially in focus, post-graduate orientation, and educational philosophy. For instance, the Heritage School in Manhattan is an Educational Option program where the arts play a substantial role in the curriculum, while Townsend Harris High School in Queens is a Screened program

\footnotetext{
${ }^{11}$ Appendix Figure A3 shows that the market share of most programs, except for about 20 rarely-ranked programs in the uncoordinated mechanism, is similar across years.
} 
with a rigorous humanities department, making it among the most competitive in the city. Using information from high school directories, we identify each program's type, language orientation, and specialty. With the new mechanism, there are more Unscreened programs and fewer Educational Option programs, a change driven by converting many Educational Option programs to Unscreened programs. This change in labeling was due to overlapping admissions criteria and similarity of educational programming. We code language-focused programs as Spanish, Asian, or Other, and we categorize program specialties as Arts, Humanities, Math and Science, Vocational, or Other. Not all programs have specialties, though about $70 \%$ fall into one of these categories. (Details on our classification scheme are in the Data Appendix). The menu of language program offerings and program specialties changes little across years.

\section{Congestion and Changes in Assignments}

The similarity of student and school attributes in Tables 1 and 2 suggest that there were few major systematic changes in either participant attributes or school supply across years. Moreover, there is no large-scale change in student location across years, as shown in Figure 1, which maps both student and school locations. Taking these facts into consideration, we attribute differences in allocations between 2002-03 and 2003-04 primarily to the assignment mechanism rather than changes in student participation or range of school options.

\subsection{Congestion in the Main Round}

Table 3 reports the number of students assigned across rounds of the uncoordinated and coordinated mechanisms. The most noteworthy pattern is that, in the uncoordinated mechanism, more students obtain their final assignments in the Administrative round than in the first round. Panel A of the Table shows that $37 \%$ of students are assigned administratively, compared to $34 \%$ in the first round. Panel B shows that only 33,894 students obtained one or more first-round offers. This is consistent with application patterns that are concentrated at relatively few schools and conservative yield management practices. As a consequence, only 23,867 students received their final assignment in the first round; 10,027 students with a first round offer were finalized with offers made in subsequent rounds. These students were processed as schools revised offers based on first-round rejections and made new offers in the second and third rounds. However, the relatively small number of students placed in the second and third round indicates that three rounds were insufficient to process all students. That only half of the students were placed in the Main round of the old mechanism contrasts sharply with the new mechanism, wherein $82 \%$ of students were placed in the Main round. ${ }^{12}$

These observations about the old mechanism are characteristic of congestion, as described in Roth and Xing (1997)'s study of the labor market for entry-level clinical psychologists. In that market, training position offers were made in an uncoordinated fashion during a 7-hour window, and Roth and Xing (1997) argue that uncoordinated processing and a small market-clearing window led to mismatch. In NYC, holding few rounds and serially processing batches of offers,

\footnotetext{
${ }^{12}$ The marked shift in the number assigned in the Main round also appears in the second year of the coordinated mechanism, where even more students, 87.3\%, were placed in the Main round (shown in Appendix Table B1).
} 
so that programs waited for previous offers to be rejected before making new offers, combined to have similar effects. In addition to insufficient offer processing, the small number of applications allowed in the old mechanism also led to situations where students who applied to oversubscribed schools fell through the cracks. Since rank-order lists were short, the mechanism considered a smaller number of alternate choices for these students than a mechanism that allowed students to rank more choices. Had more applications been allowed, schools where these students were ultimately placed may have been assigned in the Main round.

The new mechanism relieved congestion by increasing both the number of choices students can rank and the number of rounds of offer processing. To investigate the role of these two forces - short rank order lists and limited offer processing - in producing administrative assignments, we used data from the coordinated mechanism to simulate two variations: 1) the Main round, with only the top five choices considered and no restriction in the number of rounds, and 2) the Main round with twelve choices, but only three sets of proposals from the deferred acceptance algorithm. The first simulation is intended to illustrate the role of five choices, while the second illustrates the role of few offer-processing rounds. Since we do not model student behavioral responses, we only intend this exercise to shed light on mechanical features generating administrative assignments in the uncoordinated mechanism. The five-choice constraint with an unlimited number of rounds leaves about one quarter of applicants unassigned. The unconstrained mechanism with three proposal rounds leaves roughly half of applicants unassigned. Relative to the uncoordinated mechanism, then, the new coordinated mechanism appears to reduce administrative assignments by computerizing offer processing and avoiding the need for active student and school participation once preferences are submitted. Short rank-order lists also generate administrative assignments, but perhaps less so than fewer offer processing rounds.

\subsection{Distance, Exit, and Matriculation}

Across mechanisms, there are stark differences in distance to assigned school and offer takeup. Figure 2 reports the distribution of distance between students' residences and their assigned schools in both mechanisms. New York City spans a large geographic range, with nearly 45 miles separating the southern tip of Staten Island from the northernmost areas of the Bronx, and 25 miles separating the western edge of Manhattan near Washington Heights from Far Rockaway at the easternmost tip of Brooklyn. ${ }^{13}$ The closest school for a typical student is 0.82 miles from home, and students in the uncoordinated mechanism on average traveled 3.36 miles to their assigned school. In the coordinated mechanism, the average distance is 4.05 miles. Panels A and $\mathrm{C}$ of Table 3 show that average distances were lower in the uncoordinated system because a large number of students were administratively assigned to schools close to their homes.

The increased distance between home and assigned school parallels Niederle and Roth (2003)'s study of the gastroenterology labor market, wherein physician mobility increased following a centralized match. While these observations may suggest that coordinated mechanisms expand market scope, in the school choice context daily travel to school imposes a cost on students. It

\footnotetext{
${ }^{13}$ Our analysis focuses on road distance, which correlates highly with subway distance. Appendix B presents a detailed comparison of both measures.
} 
is therefore essential to measure how students value proximity relative to other aspects of their school choices to assess whether improved assignments compensate for the distance increase.

Student enrollment patterns documented in Table 3 indicate that student assignments in the uncoordinated mechanism, particularly those made in the Administrative round, are less desirable than assignments made in the coordinated mechanism. After receiving an assignment, a student may opt for a private school, leave New York, or even drop out. Families may switch schools after their final assignments are announced, but before the school year starts. ${ }^{14}$ In the uncoordinated mechanism, principals had greater discretion to enroll students, and the DOE officials quoted above alleged that students with sophisticated parents might just show up at a school in the fall and ask for a seat at the school. The exit rate from city public schools is higher in the uncoordinated mechanism (8.5\% compared to $6.4 \%)$, and the fraction of students who enroll at a school other than their assignment is higher (18.6\% compared to $11.4 \%$ ).

In the uncoordinated mechanism, students assigned in earlier rounds appear more satisfied with their assignments than those assigned in later rounds. The fraction of students who exit NYC public schools is $13.3 \%$ among administrative placements, compared to $5.2 \%$ among those assigned in the first round. More than a quarter of students assigned in the Administrative round who are still in NYC public schools matriculate at schools other than those to which they were assigned. By comparison, the take-up of offered assignments is much higher for those assigned in the first three rounds. Based on exit and matriculation, students with multiple offers in the first round are more satisfied with their assignment than students with zero or one offers. Students with multiple offers also travel further to their final assignments or enrolled schools. In contrast, the majority of students with no offers are assigned through the Administrative round, which likely accounts for their higher rates of exit and enrollment at a school other than their assignment. Even though the coordinated mechanism has substantially fewer administratively assigned students, the exit rates are highest and the matriculation rates are lowest for the participants in that round. ${ }^{15}$

\subsection{Mismatch in Administrative Round}

To further evaluate student assignments in the Administrative round, we compare the attributes of schools that students wanted (i.e. ranked) to the attributes of schools to which they were assigned. Students processed in earlier rounds are assigned to schools with attributes more similar to the schools they ranked than students processed in later rounds. Table 4 shows that, in both mechanisms, students assigned in the Main round generally ranked schools with similar or better attributes, with the exception of distance, than the schools they received. For instance, ranked schools have higher Math and English performance, more students attending four-year colleges, and higher attendance rates. Ranked and assigned schools are similar in terms of teacher experience, poverty (as measured by the percent of students receiving subsidized lunch), and racial make-up.

\footnotetext{
${ }^{14}$ Narita (2016) theoretically and empirically studies mechanisms to handle post-match reassignments.

${ }^{15} \mathrm{In}$ the second year of the mechanism, the average distance to the assigned school is 4.07 miles and the average exit rate is $6.6 \%$ (shown in Table B1). The take-up rate is higher than the first year and the fraction in the Administrative round decreases to $5.4 \%$.
} 
For students placed in the Supplementary round, assigned schools are also less desirable than ranked schools, and many of the gaps are wider than in the Main round. In the uncoordinated mechanism, for instance, the Math performance gap between ranked and assigned schools is 0.7 percentage points for those assigned in the Main round and 2.5 points in the Supplementary round. The gap between ranked and assigned alternatives for 9th grade size is quite pronounced under both mechanisms. For example, in the uncoordinated mechanism, ranked schools have about 200 fewer 9th graders than the schools where students are assigned. Since students who participate in the Supplementary round when they did not obtain a Main round assignment, it is not surprising that the difference between what students wanted and what they received widens.

The most striking pattern in Table 4, however, is for students who are administratively assigned. As noted above, the uncoordinated mechanism produces three times more students assigned in this round in the uncoordinated mechanism. Panel $\mathrm{C}$ shows that, in the uncoordinated mechanism, administratively-assigned students ranked schools, on average, 5.1 miles away from home and were assigned to schools only 1.6 miles away in the uncoordinated mechanism, a much larger gap than in either the Main or Supplementary round. For other school characteristics, the difference between what students wanted and what they were assigned widens relative to the Supplementary round, suggesting that mismatch is greatest for students in the Administrative round. For instance, the 2.5 point spread in Math achievement in the Supplementary round is 4.4 points in the Administrative round, and the fraction of students going on to four-year colleges similarly widens. The difference in 9 th grade size is also considerable for the administratively assigned: ranked schools have more than 400 fewer students than assigned schools.

In the coordinated mechanism, the difference between ranked and assigned schools also widen for later rounds. Rank and assigned schools differences in Math and English achievement and four-year college going are narrower for the Administrative round of the coordinated mechanism than for the uncoordinated one. On the other hand, assigned schools are not as close to home in the coordinated mechanism. Therefore, it is not possible to assert which mechanism's Administrative round generates better matches. What is clear, however, is that being processed in the Administrative round is undesirable for students in both mechanisms. As a result, it is reasonable to expect that significant changes in student welfare produced by the coordinated mechanism will be driven by reducing the number of administratively assigned students.

\subsection{Offer Processing by Student Characteristics}

Table 5 reports student attributes across rounds compared to the overall applicant population. Students from Manhattan, those with high math baseline scores, and those who have applied to exam schools (as indicated by taking the SHSAT) tend to obtain offers earlier in the uncoordinated mechanism. These applicants are also overrepresented among students who receive multiple first round offers (not shown). Students from Staten Island, students who are white, and those from high income neighborhoods tend to systematically obtain offers later in the process. Compared to the overall population, these groups are overrepresented in the Administrative round.

The coordinated mechanism distributes school access more evenly across rounds. That is, the differences in the types of students assigned in each round are not as pronounced under 
the coordinated mechanism. This can be seen by comparing students across boroughs or racial groups in column 4 of Table 5. The fraction of students assigned in the Main round is similar across all five boroughs, as is the racial composition of students. Higher baseline applicants are more likely to be assigned in the Main round in the new mechanism than low baseline applicants, but are not as overrepresented as in the old mechanism.

The coordinated mechanism assigned fewer students to schools that were undersubscribed in the uncoordinated mechanism. Figure 3 reports the change in the number of students assigned to a school compared to a measure of how oversubscribed the school was in the uncoordinated mechanism. For example, in 2002-03, 1,455 students were assigned to the Louis Brandeis High School, a struggling Manhattan high school with four-year graduation rates were among the lowest in the city, but in 2003-04 only 911 students were assigned there. ${ }^{16}$ The upward sloping line indicates that if a school is more oversubscribed in the old mechanism, the new mechanism tends to assign more students to that school. This phenomenon suggests that the coordinated mechanism was able to use the submitted preferences to more effectively place children into their desired schools. The extent to which this change represents an improvement in student welfare depends on the heterogeneity of student preferences, an issue we turn to next.

\section{$5 \quad$ Estimating Student Preferences}

\section{$5.1 \quad$ Student Choices}

Families in NYC obtain information about high school programs from many sources including guidance counselors, teachers, and other families. Each year the DOE publishes the NYC High School Directory, a booklet with information about school size, course offerings, Regents and graduation performance, the school's address, the closest bus and subway, and a description of each program, including its extracurricular activities and sports teams. Families can also learn about schools at high school fairs and open houses and from local newspapers, online guides, and books (e.g., Hemphill (2007)).

While a family may rank a school for reasons that we do not observe, the observable dimensions of their choices display consistent regularities: students prefer closer and higher quality schools as measured by student achievement levels, shown in Table $6 .{ }^{17}$ The first row of the table shows that only $20 \%$ of applicants rank 12 school choices; the majority rank nine or fewer choices, and nearly $90 \%$ rank at least three choices. A student's top choice is on average 4.43 miles away from home. Since the closest school is on average 0.82 miles away, the school closest to home is not most students' first choice. The typical student's first choice is 0.38 miles closer to home than her second choice, and her second choice is 0.24 miles closer than her third choice. Distance increases monotonically until the 9 th choice, which is 5.65 miles away.

\footnotetext{
${ }^{16}$ The NYC DOE announced the closure of this school in 2009. The largest size reduction is the Evander Childs High School in the Bronx, which went from 1,739 to 453 9th graders. This high school had a longstanding reputation for violence and disorder, and it was eventually closed in 2008.

${ }^{17}$ Table B3 provides additional information on school assignments. $31.9 \%$ of students receive their top choice, $15.0 \%$ receive their second choice, and $2.4 \%$ receive a choice ranked 10 th, 11 th, or 12 th. $17.5 \%$ of students are asked to participate in the Supplementary round because they are unassigned in the Main round.
} 
Lower-ranked schools are also less desirable on other measures of school quality. Math performance decreases going down rank-order lists. (English performance exhibits the same trends as Math and is therefore not reported.) Other measures of performance (also not reported) such as the percent of students attending a four-year college and the fraction of teachers classified as inexperienced change monotonically going down rank-order lists. Schools enrolling lower shares of poor students or a higher proportions of white students tend to be ranked higher.

Using requests for individual teachers, Jacob and Lefgren (2007) find that parents in lowincome and minority schools value a teacher's ability to raise student achievement more than parents in high income and non-minority schools. In contrast, Hastings, Kane, and Staiger (2009) report that higher-SES families are more likely than lower-SES parents to choose higherperforming schools than lower-SES ones based on stated reports under Charlotte's school choice plan. This difference across groups motivates our investigation of how baseline ability and neighborhood income influence ranking behavior. High-achieving students tend to rank schools with higher Math achievement relative to low achievers, though both groups place less emphasis on achievement as they move further down their preference list. Similarly, students from low-income neighborhoods tend to put less weight on Math achievement than do students from high-income neighborhoods, but both groups prefer higher achieving schools higher. These differences suggest the importance of allowing for preferred school achievement levels to differ by baseline achievement and income groups in the demand model.

Proxies for the quality of schools ranked in the uncoordinated mechanism, also shown in Table 6, decrease with school achievement and income. For distance, however, the gradient is lower relative to the coordinated mechanism. For instance, in the uncoordinated mechanism, the distance to a students' first choice school is 4.80 miles, while it is 4.79 miles for their fifth choice. In the coordinated mechanism, the fifth choice is about one mile further than the first choice. Such a pattern is consistent with students being more expressive with their choices in the new mechanism, which would be expected given that more choices can be ranked.

All else being equal, based on their submitted preferences, students prefer attending a school closer to home. The fact that students in the new mechanism are assigned to schools further from home might suggest that school assignments are worse on average than in the old mechanism. On the other hand, students may prefer schools outside their neighborhood because these schools are a better fit. To assess the new mechanism, we must therefore weigh the greater travel distance in the new mechanism against changes in other aspects of the assigned school. Our next task is to quantify how students evaluate distance relative to school attributes, including average achievement levels, demographic composition, and size, based on their submitted preferences in the coordinated mechanism.

\subsection{Model and Estimation}

Comparing the characteristics of schools ranked higher, lower, or not at all reveals students' tastes over these characteristics. To quantify these trade-offs, we estimate a random utility model, which represents the ordinal rankings in cardinal terms. Let $i \in \mathcal{I}$ index students and 
$j \in \mathcal{J}$ index programs. The indirect utility of student $i$ from program $j$ is:

$$
u_{i j}=v\left(\mathbf{x}_{j}, \mathbf{z}_{i}, \xi_{j}, \gamma_{i}, \varepsilon_{i j}\right)-d_{i j}
$$

where $\mathbf{x}_{j}$ is a vector of program $j$ 's observed characteristics, $\mathbf{z}_{i}$ is a vector of observed student characteristics, $\xi_{j}$ is a program-specific unobserved vertical characteristic, $\gamma_{i}$ captures idiosyncratic tastes for program characteristics, $\varepsilon_{i j}$ captures idiosyncratic tastes for programs, and $d_{i j}$ is distance between student $i$ 's address and program $j$, measured in miles. Our main assumption is

$$
\left(\gamma_{i}, \varepsilon_{i j}\right) \Perp d_{i j} \mid \mathbf{z}_{i}, \mathbf{x}_{j}, \xi_{j}
$$

which states that, conditional on observed student and school characteristics, and the vertical school characteristics $\xi_{j}$, unobserved tastes for programs are independent of distance. This assumption may be violated if students systematically reside near schools they prefer, given our controls for student characteristics. In that case, we're likely to underestimate the value of being assigned to a nearby school. On the other hand, the assumption is plausible if the set of observed characteristics is sufficiently rich. The specification also treats distance as the numeraire. All else being equal, if students dislike traveling to school, then the coefficient of -1 on distance is a scale normalization, which allows us to measure utility in distance units, expressed as a "willingness to travel." We also normalize $v(\cdot)=0$ if all of its arguments are zero. ${ }^{18}$

To assist estimation in finite samples while allowing for a computationally tractable procedure, we parametrize $u_{i j}$ as follows:

$$
\begin{aligned}
u_{i j} & =\delta_{j}+\sum_{l} \alpha^{l} z_{i}^{l} x_{j}^{l}+\sum_{k} \gamma_{i}^{k} x_{j}^{k}-d_{i j}+\varepsilon_{i j}, \\
\text { with } \quad \delta_{j} & =\mathbf{x}_{j} \beta+\xi_{j} .
\end{aligned}
$$

We further assume that

$$
\gamma_{i} \sim \mathcal{N}\left(0, \Sigma_{\gamma}\right), \quad \xi_{j} \sim \mathcal{N}\left(0, \sigma_{\xi}^{2}\right), \quad \varepsilon_{i j} \sim \mathcal{N}\left(0, \sigma_{\varepsilon}^{2}\right)
$$

The vector of random coefficients, $\gamma_{i}$, capture idiosyncratic tastes for program characteristics. It is worth noting that for our welfare calculations, we do not interpret the coefficients on school characteristics as measuring the causal effect of different school characteristics. Throughout the welfare comparisons, we examine the effects of different assignments on utility holding school attributes fixed. This parametrization is an ordered choice version of the model in Rossi, McCulloch, and Allenby (1996), who show that these distributional assumptions allow for estimation via Gibbs' sampling. ${ }^{19}$ To this end, we specify conjugate priors for $\theta=\left(\alpha, \beta, \Sigma_{\gamma}, \sigma_{\xi}^{2}, \sigma_{\varepsilon}^{2}\right)$. For additional details on the procedure and the specification of priors, see the Computational Appendix.

\footnotetext{
${ }^{18}$ These scale and location normalizations are without loss of generality and equivalent to other normalizations since the additively separable form of utilities is well defined only up to positive affine transformations.

${ }^{19}$ We use Gibbs' sampling rather than simulated maximum likelihood because of biases in datasets with a large number of choices (Train 2009). The posterior means we report have the same asymptotic distribution as maximum likelihood estimates (see chapter 10.1 in van der Vaart (2000)).
} 
Intuitively, the degree to which otherwise identical students' propensity to rank a school changes with distance reveals how important distance is relative to other factors. Since our model is non-parametrically identified, these assumptions are made for tractability. ${ }^{20}$

Our specification allows for students to have idiosyncratic tastes for schools that are not captured by the student characteristics in our dataset. To exploit the richness of rank-ordered data, we do not restrict the correlation across the dimensions of $\gamma_{i}$. Berry, Levinsohn, and Pakes (2004) show that data on top and second choices improves on estimates that only use first choice by revealing common characteristics between subsequent rankings for a given student. Rankordered data also allow us to relax the common assumption that random coefficients on choice characteristics are independently distributed.

We do not explicitly model an outside option because our primary interest is studying the allocation within inside options rather than substitution outside of the NYC public school system. Moreover, the commonly-used model of the outside option, which infers that a school is unacceptable if not ranked, would require us to assume that students who have not ranked all 12 choices prefer their outside option to a NYC high school. ${ }^{21}$ To normalize the location of utilities, we set the mean of $u_{i j}$ to zero if all observables are zero.

The demand sample for 2003-04 contains the rankings of 69,907 participants across 497 programs in 235 schools, for a total of 542,666 school choices. Our specifications follow other school demand models and include average school test scores and racial attributes as characteristics (see, e.g., Hastings, Kane, and Staiger (2009)). We focus on four main school characteristics: high Math achievement, percentage of students receiving subsidized lunch, percent white, and 9 th grade size.

We start by assuming that rankings reflect true preferences. For rank-order list $\mathbf{r}_{i}=\left(r_{i 1}, \ldots, r_{i K_{i}}\right)$, let $r_{i k}$ be the $k^{\text {th }}$ choice and $K_{i}$ is the number of choices $i$ ranks. In terms of indirect utilities, we assume that

$$
\begin{aligned}
u_{i r_{i k}} & >u_{i i_{i k+1}} \\
u_{i r_{i K_{i}}} & >u_{i j} \quad \text { for all } k<K_{i}, \\
\text { for all } j \neq r_{i k} & \text { and } k \leq K_{i} .
\end{aligned}
$$

This benchmark is motivated by the mechanism's straightforward incentive properties and by the advice the NYC DOE provided in the 2003-04 High School Directory and through their information and outreach campaign. For instance, the DOE guide advises participants to "rank your twelve selections in order of your true preferences" with the knowledge that "schools will no longer know your rankings." 22

\footnotetext{
${ }^{20}$ In particular, under our assumption that there is one characteristic (distance) that is additively separable and independent of the unobservable $\left(\gamma_{i}, \epsilon_{i j}\right)$, we can use variation in distance to trace out the distribution of utility. Identification for binary and multinomial models is studied by Ichimura and Thompson (1998), Lewbel (2000), and Briesch, Chintagunta, and Matzkin (2002). Ordered choice data contains strictly more information than in these settings. Agarwal and Somaini (2014) study identification in the school choice context with a potentially manipulable mechanism. Non-parametric identification results in these settings apply to our case.

${ }^{21}$ Table B3 shows that only about 14,000 students submit all 12 ranks and that students with incomplete lists are also more likely to remain unassigned. Table B4 shows that the majority of these students enter the supplementary round and are likely to accept an assignment in this round. This suggests that the choice of the number of schools to rank is not directly related to preferences.

${ }^{22}$ As mentioned above, this formulation ignores potential information about the relative value of schools less
} 
This model assumes that all programs are available to applicants, though in practice, 193 programs have an eligibility restriction whereby applicants are only eligible for a program if they reside in particular boroughs. We therefore also consider a model in which each applicant's choice set only comprises the programs for which she is eligible. About $5 \%$ of students rank a program for which they are ineligible and this corresponds to about $1 \%$ of all submitted choices. In those cases, we include the ineligible program as part of the choice set. ${ }^{23}$ Section 9 reports on variations on these assumptions.

\subsection{Preference Estimates}

We report select estimates for four different specifications in Table 7 and a larger set of specifications in Table A3. ${ }^{24}$ The first specification includes school characteristics (high Math achievement, percent subsidized lunch, percent white, and 9th grade size), but does not incorporate interactions between school and student characteristics (i.e. $\alpha^{l}=0$ for all $l$ ). Further, we do not include additional achievement characteristics examined in Table 4, such as high English achievement and percentage of students later attending a four-year college, because these both closely relate to high Math achievement.

The next three specifications include student-school interactions. Each specification includes dummies for Spanish, Asian and Other Language Programs, which are interacted with students' English proficiency status and whether they are Hispanic or Asian. The model in column 2 assumes that there are no random coefficients $\left(\gamma_{i}=0\right)$, while the model in column 3 places no restriction on $\gamma_{i}$. Column 4 reports estimates wherein the choice set for each applicant is restricted to the set of schools for which she is eligible.

There are three main patterns in Table 7. First, student-school interactions are often estimated precisely; for instance, high baseline math students tend to prefer higher-achieving schools and minority students tend not to prefer schools with high white percentages. Second, the estimates are similar between the model with no restriction on the choice set and the model where the choice set only contains programs for which the student is eligible. Third, many of the random coefficients are significant, thereby suggesting the importance of a flexible specification in accounting for the underlying heterogeneity in student preferences. We further report on model fit in Section 9. We use the estimates in column 3 for our primary calculations, because these fully exploit all choice data in the most flexible model, and discuss other specifications in Section 9 .

preferable than the $K_{i}$-th most preferred school. It is consistent with a model in which the student ranks all schools that are preferable to an outside option, but does not require this to be the case.

${ }^{23}$ This specification is similar in spirit to methods in Fack, Grenet, and He (2015) who advocate for restricting the student choice set based on the set of schools that may be achievable for that student. Their setting has the additional advantage that admission criteria for all schools are known, whereas we do not have direct information on admissions criteria used for all screened schools.

${ }^{24}$ Due to computational constraints, models presented in Table A3 to assess robustness of our results are estimated from a $10 \%$ random sample of the data with containing about 7,000 students. 


\section{Comparing Alternative Mechanisms}

\subsection{Measuring Welfare}

Our estimates allow us to compute measures of welfare for an assignment using the distribution of student preferences. Let $\mu: \mathcal{I} \rightarrow \mathcal{J} \cup \mathcal{I}$ denote a matching, such that each student is assigned either to only one program or is unassigned (here, assigned to herself), and no program's matches exceed its capacity. $\mu(i)$ denotes student $i$ 's assignment. The average student welfare under $\mu$ is

$$
W(\mu)=\frac{1}{|\mathcal{I}|} \sum_{i \in \mathcal{I}} u_{i \mu(i)}
$$

where $u_{i j}$ is the (indirect) utility student $i$ associated with assignment to program $j$. Given the normalization in equation (1), welfare is measured in the same distance (in miles).

Since individual student utility not directly observed, we compute the expectation of the utility for each student, $\mathbb{E}\left[u_{i \mu(i)} \mid \mathbf{r}_{i}, \mathbf{z}_{i}, \mathbf{x}_{j}, \mathbf{d}_{i} ; \theta\right]$, given the rank-order list $\mathbf{r}_{i}$, the observed characteristics $\left(\mathbf{z}_{i}, \mathbf{x}_{j}, \mathbf{d}_{i}\right)$, and the estimated distribution of preferences parameterized by $\theta$. In what follows, we drop the conditioning on $\left(\mathbf{z}_{i}, \mathbf{x}_{j}, \mathbf{d}_{i}\right)$ and $\theta$ to simplify the notation. With this convention, we estimate the average student welfare $\bar{W}(\mu)$ as the expectation of the expression in the last display:

$$
\bar{W}(\mu)=\frac{1}{|\mathcal{I}|} \sum_{i \in \mathcal{I}} \mathbb{E}\left[u_{i \mu(i)} \mid \mathbf{r}_{i}\right]
$$

Evaluating the expectation of each student's utility requires an assumption about the relationship between utilities and observed rank-order lists. If preferences are truthfully submitted to coordinated mechanism, the $k^{\text {th }}$ ranked program yields the $k^{\text {th }}$ highest utility. This assumption restricts values of unobserved tastes $\gamma_{i}$ and $\varepsilon_{i j}$. The expectation

$\mathbb{E}\left[u_{i j} \mid \mathbf{r}_{i}\right]= \begin{cases}\mathbb{E}\left[\begin{array}{l|l}\left.u_{i j} \mid u_{i r_{i 1}}>\ldots>u_{i r_{i k-1}}>u_{i j}>u_{i r_{i k+1}}>\ldots>u_{i r_{i K_{i}}}\right] & \text { if program } j \text { ranked } k^{\text {th }}, \\ \mathbb{E}\left[u_{i j} \mid u_{i r_{i 1}}>\ldots>u_{i r_{i k}}>\ldots>u_{i r_{i K_{i}}}>u_{i j}\right.\end{array}\right] & \text { if program } j \text { not ranked, }\end{cases}$

where $K_{i}$ is the number of programs listed on rank-order list $\mathbf{r}_{i}$. The conditioning events in equation (3) translate observed rank-order lists $\mathbf{r}_{i}$ into restrictions on unobserved tastes $\varepsilon_{i j}$. Intuitively, if program $j$ is ranked among the top 12, it must yield higher utility than all unranked programs. Since there are many unranked programs, this means that idiosyncratic tastes for ranked programs are likely to be high. We compute the expression in equation (3) by fixing the estimated parameters at their posterior means, and using a Gibbs sampler to draw from the distribution of utilities given the rank order list. ${ }^{25}$ For a student who did not submit a rankorder list in the Main round, we compute the mean utility conditional only on $\left(\mathbf{z}_{i}, \mathbf{x}_{j}, \mathbf{d}_{i}, \theta\right)$. This simulated value of the expectation of utility is fixed for welfare comparisons across assignments.

The difference in average student welfare between two matchings, $\mu$ and $\mu^{\prime}$, is given by:

\footnotetext{
${ }^{25}$ For each applicant, we use 20,000 draws after burning the first 1,000 draws. This step is identical to the first step in the Gibbs sampler in Appendix A.
} 


$$
\bar{W}(\mu)-\bar{W}\left(\mu^{\prime}\right)=\frac{1}{|\mathcal{I}|} \sum_{i \in \mathcal{I}}\left(\mathbb{E}\left[u_{i \mu(i)} \mid \mathbf{r}_{i}\right]-\mathbb{E}\left[u_{i \mu^{\prime}(i)} \mid \mathbf{r}_{i}\right]\right) .
$$

To report differences in average welfare for particular demographic groups, we simply restrict the sample to the set of students with that demographic characteristic when computing equation (4).

\subsection{Evaluating Mechanism Design Features}

For organizing the school admissions process, there are several possible coordinated mechanisms that differ in how they deal with strategic considerations and school priorities. Before examining these alternatives quantitatively, we summarize their theoretical properties.

\subsubsection{Theoretical Mechanism Design Trade-offs}

A typical school choice problem can be modeled as a matching problem between students and schools. Each student ranks schools on her application. Each student is also granted an assignment priority at every school for which she is eligible. Priorities may differ among schools and may be determined, for instance, by whether the student resides in a particular borough or has attended the school's information session.

An assignment of students to schools matches each student with at most one school for which she is eligible, or leaves her unassigned, and capacity is not exceeded at any school. An assignment mechanism produces an assignment using students' reported preferences, school priorities, school capacities, and a lottery to break ties amongst equal priority students to produce an assignment. Once the ties are broken, every school ranks students in a linear order, first by priority at the school and then by lottery numbers, which we will also refer as tie-breaker. A mechanism is strategy-proof if submitting true preferences is a (weakly) dominant strategy for every student.

To facilitate comparison of alternative allocations, we consider two benchmarks. Neighborhood assignment is an allocation where students are assigned to the closest possible school subject to capacity constraints. We compute this assignment by running deferred acceptance (DA), described in Section 2.3, with applicants simply ranking schools in increasing order of distance and schools ranking students in increasing order of distance. This benchmark corresponds to an extreme without school choice, where the market's geographic scope is limited in a similar fashion as the Administrative round of the uncoordinated mechanism.

The second benchmark, utilitarian assignment, assigns students to obtain the greatest possible average student utility given school capacities. Given school capacities $c_{j}$ at each program $j$, it solves the following program:

$$
\max _{a} \sum_{i j} u_{i j} a_{i j} \text { s.t. } \sum_{j} a_{i j} \leq 1, \sum_{i} a_{i j} \leq c_{j}, a_{i j} \in\{0,1\},
$$

where $a$ is $|I| \times|J|$ matrix with $(i, j)$ element $a_{i j}$ denoting that student $i$ is assigned to program $j$. Since no other allocation can yield higher average utility, the utilitarian assignment represents an extreme, where a planner implements the best possible allocation with knowledge of the cardinal distribution of student preferences. 
While the utilitarian assignment yields the maximal possible student welfare, it is difficult to achieve for two reasons. First, there are over 200 screened programs in New York City, so implementing this allocation would ignore school-side rankings in those programs. For instance, the utilitarian assignment could allow a lower-scoring student or a student in a lower priority group to be assigned to a school over a student with a higher score or higher priority who also wanted that school. ${ }^{26}$ More formally, a student-school pair blocks an assignment if the student strictly prefers the school to his assignment, is eligible for it, and the school either has an available seat or is assigned another student with lower priority. An assignment is stable if it is not blocked by any student-school pair, and if every student prefers her assignment to remaining unassigned. The utilitarian assignment may not be stable.

Second, the utilitarian assignment uses cardinal information, which is not elicited by the coordinated mechanism. ${ }^{27}$ An alternative notion of efficiency would only consider students' ordinal rankings of schools. An assignment Pareto dominates another, if in the latter assignment every student is assigned to a weakly-preferred choice but some students are assigned to a strictly preferred choice than in the former assignment. An assignment is Pareto efficient if it is not Pareto dominated by another assignment; in other words, if there is space to match some students with better schools in their choice lists without hurting other students.

When priorities do not include any ties, the student-proposing DA used in the coordinated mechanism produces the unique student-optimal stable matching (Gale and Shapley 1962). That is, it produces a stable matching that is not Pareto dominated by any stable assignment. Furthermore, DA is strategy-proof (Dubins and Freedman 1981, Roth 1982). When priorities include ties, however, DA must include a tie-breaker. Tie-breaking opens the door to multiple studentoptimal stable matchings and DA may fail to find a student-optimal stable matching (Erdil and Ergin 2008, Abdulkadiroğlu, Pathak, and Roth 2009).

Based on this observation, Erdil and Ergin (2008) suggest an algorithm to find a studentoptimal stable matching when priorities include ties. The algorithm uses a stable matching (such as the one produced by DA) as its input and looks for stable improvement cycles to improve on this matching. A stable improvement cycle is an ordered set of students such that (i) every student is assigned a school but prefers the assigned school of the next student, and the last student prefers the assigned school of the first student (so that we obtain a cycle); (ii) moreover, each student in the set has the highest priority at the assigned school of the next student among all students who prefer that school to their assignment.

By modifying the original assignment by moving each student to the school to which the next student in this cycle is assigned, we can find an assignment that is both stable and Pareto dominates the original assignment. Consequently, they propose the following stable improvement cycles algorithm:

Step 1) Start with the assignment produced by the deferred acceptance algorithm.

Step $\mathrm{k}>1$ ) If a stable improvement cycle exists in the assignment produced by step $k-1$, obtain a

\footnotetext{
${ }^{26}$ Budish, Che, Kojima, and Milgrom (2013) and He, Miralles, Pycia, and Yan (2015) describe alternative utilitarian mechanisms that can take into account how programs rank students.

${ }^{27}$ Bogomolnaia and Moulin (2001) argue that focusing on ordinal mechanisms can be "justified by the limited rationality of agents participating in the mechanism."
} 
new stable assignment by moving each student to the assigned school of the next student in the cycle.

Since each step improves upon the assignment of each student in the cycle without creating blocking pairs, the resulting new assignment is stable and Pareto dominates the previous one. The algorithm terminates when no more stable improvement cycle is found. While the stable improvement cycles assignment is a student-optimal stable matching, no mechanism is student optimal stable and strategy-proof when priorities include ties (Erdil and Ergin 2008).

A student-optimal stable assignment may still fail to be Pareto efficient (Roth 1982), thus leaving room for improvement in student assignments at the expense of creating blocking pairs. In order to measure the efficiency loss from imposing stability, we find a Pareto efficient assignment that Pareto dominates the stable improvement cycles assignment by employing Gale's top trading cycles algorithm as follows: ${ }^{28}$

Step 1) Start with a student-optimal stable assignment. Initialize all students to be available.

Step $\mathrm{k}>1$ ) Given an assignment, each available student points to her most preferred school, each school points to the highest ranked available student that is assigned to the school, and if no available student is assigned the school, it points to the the highest ranked available student.

A top trading cycle is an ordered list of student-school pairs such that each student points to her paired school and the school points to the student of the next pair, where "next pair" for the last pair is the first pair in the ordered list.

Since the number of students and schools is finite, a top trading cycle exists, and each student in the cycle is assigned the school he points to and is then removed.

The algorithm terminates when no more top trading cycles are found.

This mechanism is not strategy-proof, and in general, there is no strategy-proof mechanism that Pareto dominates the deferred acceptance or stable improvement cycles mechanism with or without ties in school priorities (Abdulkadiroğlu, Pathak, and Roth 2009, Kesten 2010, Kesten and Kurino 2012).

\subsubsection{Quantifying Mechanism Design Trade-offs}

The first column of Table 8 shows that the difference in distance-equivalent utility between the neighborhood and utilitarian assignment is 18.96 miles. In other words, the average student is willing to travel 18.96 miles further for the school she is assigned under the utilitarian assignment compared to the neighborhood assignment. To compute the coordinated mechanism, we run DA for 100 different lottery draws. ${ }^{29}$ The coordinated mechanism achieves about $80 \%$ of the 18.96 mile range, since the difference in willingness to travel from the utilitarian assignment for the

\footnotetext{
${ }^{28}$ This version of the top trading cycles algorithm starts with the DA outcome in contrast to the version defined by Abdulkadiroğlu and Sönmez (2003).

${ }^{29}$ For students unassigned after the Main round, we implement NYC's Supplementary round by using preferences from the demand model and assigning students under a serial dictatorship according to the lottery number.
} 
average student is 3.73 miles shown in column $2 .{ }^{30}$ The gains from a choice system are smaller for whites and Asians compared to blacks and Hispanics. Gains are also considerably smaller for residents of Staten Island, which has on average better-performing schools than other boroughs.

As discussed above, DA does not produce a student-optimal stable matching when priorities involve ties, but no strategy-proof mechanism does. Any potential gains from a Pareto-dominant stable assignment can therefore be viewed as cost of providing straightforward incentives for students. We quantify this cost by computing a student-optimal stable assignment that Pareto dominates the DA assignment. To this end, we run the stable improvements cycle algorithm for each of the 100 lottery draws. Across these draws, 2,348 students on average obtain a better assignment in a student-optimal stable matching without harming other students. The difference in distance-equivalent utility is 0.11 miles on average compared to the assignment produced by the coordinated mechanism. Because the student-optimal matching Pareto dominates the DA assignment for every lottery draw, this difference is non-negative for every realization of utilities and is therefore statistically significant.

A stable assignment constrains student welfare through its treatment of school priorities and preferences. We next compute welfare from a Pareto-efficient assignment that dominates the student-optimal stable assignment via Gale's top trading cycles algorithm (Shapley and Scarf 1974). Since this mechanism does not produce a stable outcome, it is possible that schools benefit by offering students seats outside of the assignment process. The difference in aggregate student welfare under this Pareto-efficient assignment and the student-optimal stable matching may therefore be viewed as the cost of providing incentives for schools for participating in the system. ${ }^{31}$

For each of the 100 lottery draws, we calculate a Pareto-efficient matching that dominates each student-optimal stable matching and report the average welfare relative to the utilitarian assignment in column 4 of Table 8 . A total of 10,882 students obtain a more preferred assignment at a Pareto-efficient matching. An ordinal Pareto-efficient allocation still produces substantially lower welfare than the utilitarian optimum. The utility difference for the average student is 3.11 miles. Relative to the coordinated mechanism, the cost of limiting the scope for strategizing by schools (i.e. by imposing stability) is 0.62 miles.

In summary, these comparisons show that the difference in student welfare between having a choice system with the coordinated mechanism and neighborhood assignment is much larger than possible welfare gains from fine-tuning the algorithm used in coordinated mechanism. That is, the ability to choose schools generates substantial student welfare when preferences are heterogeneous. Further optimizing the matching algorithm in NYC is likely to produce relatively little gain in the best case, even if it were possible to implement cardinal allocation schemes. This conclusion does not imply that the matching scheme is unimportant especially in light of the large number administratively assigned in the uncoordinated mechanism. To see where the

\footnotetext{
${ }^{30}$ The standard error across parameter draws is 0.04 . For a fixed parameter draw, the variance of this difference is small because our sample has 69,907 students.

${ }^{31}$ Balinski and Sönmez (1999) and Abdulkadiroğlu and Sönmez (2003) provide an alternative equity rationale for stability. Note that no stable mechanism eliminates strategic participation issues for schools (Sönmez 1997, Ekmekci and Yenmez 2016), although this may not be an issue in markets with many participants (Kojima and Pathak 2009).
} 
uncoordinated mechanism lies in the 18.96 mile range, we next turn to analyzing its properties.

\section{Comparing the Coordinated and Uncoordinated Mechanisms}

\subsection{Approach}

We use the estimated preference parameters and observed data to quantify the difference in welfare between assignments produced by the coordinated and uncoordinated mechanisms. Results presented in the previous section used information embedded in a student's submitted ranking when evaluating the expectation of her utility for the observed assignment using equation (3). This exercise relied on the fact that the coordinated mechanism has straightforward incentives. Interpreting rankings submitted in the uncoordinated system, however, is significantly more challenging since the uncoordinated mechanism is not strategy-proof and, consequently, submitted rankings depend on applicant beliefs and behavior. ${ }^{32}$ This difficulty is not unique to our setting and is likely a challenge in evaluating other assignment systems where the incentive properties of the mechanism are not well understood and agent behavior is difficult to model. We therefore analyze the uncoordinated mechanism using two extreme models of agents' behavior: truthful reporting and optimal reporting. Neither extreme is a plausible characterization of behavior under the uncoordinated mechanism, but the former is focal, and the latter represents a best-case analysis for the uncoordinated system and therefore represents a lower bound on the difference between the coordinated and uncoordinated mechanisms.

Truthful reporting parallels the assumption made for the coordinated mechanism. Although we do not presume all participants were truthful, it is a natural definition of unsophisticated behavior. ${ }^{33}$ Sub-optimal reporting is consistent with the fact that about one third of applicants who submitted preferences ended up unassigned, shown in Table 3. Had applicants anticipated they would be unassigned in the Main round, they may have ranked schools that would admit them.

To formally describe our approach, let $\mathcal{I}$ be the set of students in the coordinated mechanism and $\mathcal{I}^{\prime}$ be the set in the uncoordinated mechanism. Suppose $\mu$ is the matching produced by the coordinated mechanism and $\mu^{\prime}$ is the matching produced by the uncoordinated mechanism. Given our estimate of $\theta$ from the coordinated mechanism, we estimate the difference in average student welfare assuming truthful reporting in the uncoordinated mechanism as follows:

$$
\bar{W}^{T}(\mu)-\bar{W}^{T}\left(\mu^{\prime}\right)=\frac{1}{|\mathcal{I}|} \sum_{i \in \mathcal{I}} \mathbb{E}\left[u_{i \mu(i)} \mid \mathbf{r}_{i}\right]-\frac{1}{\left|\mathcal{I}^{\prime}\right|} \sum_{i \in \mathcal{I}^{\prime}} \mathbb{E}\left[u_{i \mu^{\prime}(i)} \mid \mathbf{r}_{i}\right],
$$

where each expectation is computed as equation (3). ${ }^{34}$

\footnotetext{
${ }^{32}$ Recent work by Kapor, Neilson, and Zimmerman (2016) surveys parents to elicit their beliefs about admissions probabilities in the New Haven choice mechanism and incorporate them as part of an empirical strategy to simulate alternative mechanisms. Budish and Cantillon (2012) utilize survey data from a manipulable mechanism to make statements about changes in mechanism design. Unfortunately, similar survey data does not exist in our setting.

${ }^{33}$ For experimental, empirical and theoreitical studies in a related context, the Boston mechanism, see, e.g., Chen and Sönmez (2006), Hastings, Kane, and Staiger (2009), Pathak and Sönmez (2008).

${ }^{34}$ Under the assumption of truthful reporting, it would be possible to estimate demand directly from rank-order lists submitted in the uncoordinated mechanism. We did not do that because some applicants may not have
} 
Optimal reporting assumes that applicant rank-order lists are optimal given their (correct) beliefs on admissions probabilities. While it is unlikely that all applicants are sophisticated enough to respond optimally, considering this alternative generates a lower bound on the difference in average student welfare between the coordinated and uncoordinated mechanism. To see why, let $O_{i}$ be the set of schools that make an offer to student $i$ in the Main round of the uncoordinated mechanism. For each applicant $i$, let $p_{i}^{j}\left(\mathbf{r}_{i}\right)$ be the probability that student $i$ is offered a seat at program $j$ given report $\mathbf{r}_{i}$ in the Main round. We assume that students have private information about their preferences, and correct forecasts about their admissions chances at various schools, which depend on the ranking strategies of all other students. We omit the dependence on these ranking strategies for notational simplicity. $p_{i}^{j}\left(\mathbf{r}_{i}\right)$ is zero if program $j$ is not ranked in $\mathbf{r}_{i}$. Since the uncoordinated mechanism is not a single-offer mechanism, $O_{i}$ may have more than one element. Each student picks her most preferred option in $O_{i}$. Therefore, given $O_{i}$, her utility from the most preferable assignment in the main round is $\max _{j \in O_{i}} u_{i j}$. If an applicant does not receive any offers, she expects to participate in the Supplementary and Administrative rounds. Let $\mathbf{q}_{i}$ be a probability vector giving the odds student $i$ is assigned to program $j, q_{i}^{j}$, in these rounds. The expected utility from submitting $\mathbf{r}_{i}$ is, therefore,

$$
E U\left(\mathbf{r}_{i} ; \mathbf{u}_{i}\right)=\mathbb{E}\left[\max _{j \in O_{i}} u_{i j} \mid \mathbf{r}_{i} ; \mathbf{u}_{i}\right]+\mathbb{P}\left(O_{i}=\emptyset \mid \mathbf{r}_{i}\right) \sum_{j} q_{i}^{j} u_{i j}
$$

The first term in the right-hand side of expression (6) reflects the fact that applicants obtain utility from their most preferred school when they have more than one offer. The second term represents the expected utility when an applicant is not offered any school in the Main round. Let $u_{i}^{(k)}$ be the utility for the $k^{\text {th }}$ best program given $\mathbf{u}_{i}$, and let $p_{i}^{(k)}$ be the probability of an offer at that program. Expression (6) can be written without the $O_{i}$ notation as

$$
E U\left(\mathbf{r}_{i} ; \mathbf{u}_{i}\right)=\sum_{k=1}^{J} u_{i}^{(k)} \prod_{\ell=1}^{k-1}\left(1-p_{i}^{(\ell)}\left(\mathbf{r}_{i}\right)\right) p_{i}^{(k)}\left(\mathbf{r}_{i}\right)+\left[\prod_{k=1}^{J}\left(1-p_{i}^{(k)}\left(\mathbf{r}_{i}\right)\right)\right] \sum_{j=1}^{J} q_{i}^{j} u_{i j} .
$$

Suppose a student knows the probability of receiving an offer from a program given her rank-order list. The rank-order list $\mathbf{r}_{i}^{*}$ is an optimal report if it maximizes her expected utility:

$$
\mathbf{r}_{i}^{*} \in \arg \max _{\mathbf{r}_{i}^{\prime}} E U\left(\mathbf{r}_{i}^{\prime} ; \mathbf{u}_{i}\right)
$$

The average student welfare of the uncoordinated assignment when each student submits an optimal report is

$$
\bar{W}^{*}=\frac{1}{\left|\mathcal{I}^{\prime}\right|} \sum_{i \in \mathcal{I}^{\prime}} \mathbb{E}\left[E U\left(\mathbf{r}_{i}^{*} ; \mathbf{u}_{i}\right)\right],
$$

where the expectation is calculated by drawing from the estimated distribution of $\mathbf{u}_{i}$ given

submitted truthful reports, and so we felt more comfortable using the preference estimates obtained from the coordinated mechanism. Instead, we interpret the results in this section as providing a range for the plausible answers. 
$\left(\mathbf{z}_{i}, \mathbf{x}_{j}, \mathbf{d}_{i}, \theta, \xi\right)$ and solving for $\mathbf{r}_{i}^{*}{ }^{35}$ The definition of $\mathbf{r}_{i}^{*}$ implies that

$$
\mathbb{E}\left[E U\left(\mathbf{r}_{i}^{*} ; \mathbf{u}_{i}\right)\right] \geq \mathbb{E}\left[E U\left(\mathbf{r}_{i} ; \mathbf{u}_{i}\right)\right] \quad \text { for any } \mathbf{r}_{i} .
$$

The average student welfare when each applicant submits an optimal report, therefore, provides a best-case scenario across possible application strategies in the uncoordinated mechanism.

This exercise assumes that students in 2002-03 were submitting optimal reports, and these reports generated $\mathbf{p}$ and $\mathbf{q}$, the equilibrium reduced-form admissions probabilities, which we estimate. The approach imposes consistency of the admissions probabilities in the data and ranking strategies. It does not imply that the welfare associated with the old mechanism is the best possible equilibrium given the 2002-03 mechanism. Students might have, for instance, all done better by coordinating and ranking the school they obtain from the student-optimal stable matching. However, such a strategy would not be optimal given the strategies and admissions rules that generated the data. This approach of computing $\bar{W}^{*}$ differs from our approach under truthful reporting, which uses data on applicant rank-order lists and assignments from the uncoordinated mechanism directly. Given the large number of choices and no analytic formula for what rankings imply about unobserved tastes in the uncoordinated mechanism, we only use data from the uncoordinated mechanism to measure $(\mathbf{p}, \mathbf{q})$.

While optimal reporting provides a valuable lower bound, we need to tackle two issues in solving the optimization problem given by equation (8). First, we must specify the information students have about $(\mathbf{p}, \mathbf{q})$. Second, given $(\mathbf{p}, \mathbf{q})$ solving equation (8) requires iterating through all possible rank orderings of length up to 5 to find the maximum for each applicant. When the number of schools is large, this is computationally infeasible. ${ }^{36}$

We estimate $(\mathbf{p}, \mathbf{q})$ using data from the uncoordinated mechanism, using a simple reduced form for school admissions decisions. Given a dataset of applications $\mathbf{r}_{i}$ and offers, we fit the logit equation

$$
p_{i}^{j}\left(\mathbf{r}_{i}\right)=G\left(\tau_{j}+\mathbf{z}_{i} \lambda_{1}+\sum_{l} \eta^{l} z_{i}^{l} x_{j}^{l}+1\left\{r_{i 1}=j\right\}\left(1, n_{j}^{r}, n_{j}^{a}\right) \lambda_{2}\right),
$$

where $G$ is the standard logistic function, $\tau_{j}$ is a program fixed-effect, $\mathbf{z}_{i}$ is a vector of the same student characteristics as in the demand models with comformable parameter $\lambda_{1}, \mathbf{x}_{j}$ are programtype dummies with parameter $\eta, 1\left\{r_{i 1}=j\right\}$ is an indicator if applicant $i$ ranked program $j$ first, $n_{j}^{r}$ and $n_{j}^{a}$ are the number of students that ranked and were admitted to program $j$, and $\lambda_{2}$ is a three-dimensional column vector. The admission probability depends on the program (via the program fixed effect), student characteristics, and their interaction (via the interaction of program type and student characteristics). Since schools could observe the student's rank-order lists, it also distinguishes between the probability of an offer from a school based on whether it was ranked first, and differentially so based on the number of students that ranked the program

\footnotetext{
${ }^{35} \theta$ is set to the posterior mean. For 423 programs that existed in 2003-04, $\xi$ is set to the posterior mean. For the remaining programs, $\xi$ is drawn from $\mathcal{N}\left(0, \sigma_{\xi}^{2}\right)$. For each applicant, we use 1,000 draws of $\left(\gamma_{i}, \epsilon_{i}\right)$ from their respective distribution given $\theta$.

${ }^{36}$ With 612 programs, this requires a search over $612^{*} 612^{*} 611^{*} 610^{*} 609$ (since it is possible to submit an incomplete list) or more than 85 trillion possible rank orderings.
} 
and were admitted. ${ }^{37}$ We estimate $\mathbf{q}_{i}$ as the empirical frequency of school assignments for unassigned students in the same geographic area defined by student $i$ 's zoned high school. For the vast majority of students, the student's zoned high school predicts a greater than a threequarters chance of assignment into a single program. The zone school is almost a perfect predictor of the school to which a student will be administratively assigned.

Given our estimate of $(\mathbf{p}, \mathbf{q})$, to solve the optimization problem, we approximate student welfare from optimal reports by limiting the set of reports a student considers to include only a subset of programs based on her preferences. In particular, we assume that agents consider the set of programs which give the highest utility for a student given our estimate $\theta$. Given a utility vector $\mathbf{u}_{i}$ for student $i$, let $J_{i \ell}$ be the set of the $\ell$-highest utility schools for applicant $i$. Define the optimal report, given that only the top $\ell$ choices are considered, as:

$$
\mathbf{r}_{i}^{*, \ell} \in \arg \max _{\mathbf{r}_{i}^{\prime}, r_{i k}^{\prime} \in J_{i \ell}} E U\left(\mathbf{r}_{i}^{\prime}, \mathbf{u}_{i}\right)
$$

and the corresponding student welfare as:

$$
\bar{W}^{*, \ell}=\frac{1}{\left|\mathcal{I}^{\prime}\right|} \sum_{i \in \mathcal{I}^{\prime}} \mathbb{E}\left[E U\left(\mathbf{r}_{i}^{*, \ell}, \mathbf{u}_{i}\right)\right] .
$$

As $\ell$ increases, the $J_{i \ell}$ approaches the set of all schools. Therefore, the expected utility of the optimal report from this restricted set, $\mathbf{r}_{i}^{*, \ell}$, approaches the expected utility from the optimal report when considering all programs, $\mathbf{r}_{i}^{*}$. As a result, our approximation of $\bar{W}^{*}$ improves as $\ell$ increases and equals the best-case average student welfare when $\ell$ equals the size of the choice set. In the analysis that follows, we consider three different values of $\ell=10,15$, and 20 . We have not been able to compute equation (10) for larger values of $\ell$, but seeing how the estimate changes for the three values of $\ell$ we can compute will be informative about what to expect from larger values of $\ell$.

\subsection{Estimates}

Under the truthful reporting assumption for the uncoordinated mechanism, the improvement in average student welfare between the uncoordinated and coordinated mechanism equals 10.62 miles with a standard error of 0.64 miles. ${ }^{38}$ Figure 4 shows the distribution of welfare from the two mechanisms. The bimodal distribution of utility in the uncoordinated mechanism is driven by students who are assigned in the Administrative round. In the coordinated mechanism, most of the mass in the first mode shifts rightward, a phenomenon driven by the sharp reduction in administrative placements. The shift in the distribution is broad-based: each student group shown in Table 9 experiences a positive gain from the coordinated mechanism.

\footnotetext{
${ }^{37}$ Specifications that allowed the probability to differ if a program is ranked second show little evidence of a systematic second-choice effect.

${ }^{38}$ To convert the willingness-to-travel metric into a dollar value, we translate 10.62 miles into roughly 30 minutes per day (15 minutes each way to and from school) using the travel time estimates from ArcGIS. For 70,000 students per year, 180 school days per year, and 4 years of high school, this corresponds to 25.2 million hours per cohort. The US DOT estimates the cost of commuting is $\$ 12$ an hour, resulting in a $\$ 300$ million estimate per cohort. The corresponding net-present value assuming a 5\% discount rate is $\$ 6$ billion.
} 
We've seen in Table 3 that the new mechanism assigned students 0.69 miles further from home. The magnitude of the difference in average student welfare far exceeds this increased travel distance. The lowest gains in Table 9 are for Manhattan residents, who experience no increase in travel distance. However, the welfare gains are not solely driven by changes in distance. For instance, Staten Island pupils only travel 0.34 miles further, but they experience the largest improvement of any borough at 22.62 miles. This suggests mismatch was particularly severe in Staten Island and is consistent with the substantially larger fraction of Staten Island residents who are administratively assigned in the uncoordinated mechanism. ${ }^{39}$

The welfare gains in the coordinated mechanism are larger for many disadvantaged groups, as seen in Table 9, a pattern consistent with Hemphill and Nauer (2009)'s claim that the uncoordinated mechanism advantaged high-achieving students and those with sophisticated parents. For instance, welfare gains are larger for low baseline math students than for high baseline math students. Gains are also higher for limited English proficient students than for SHSAT test-takers. However, the difference for Staten Island, which has a larger white population and wealthier neighborhoods, plays a significant role in the fact that whites and those from rich neighborhoods experience larger welfare gains than blacks, Hispanics, and those from poorer neighborhoods.

The estimates discussed above may be optimistic because they are not based on the bestcase scenario for the uncoordinated mechanism. Table 10 reports the extent to which truthful reporting may be biased in favor of the uncoordinated mechanism. Specifically, the Table reports

$$
\Delta^{\ell}=\frac{1}{\left|\mathcal{I}^{\prime}\right|} \sum_{i \in \mathcal{I}^{\prime}} \mathbb{E}\left[E U\left(\mathbf{r}_{i}^{*, \ell}, \mathbf{u}_{i}\right)\right]-\frac{1}{\left|\mathcal{I}^{\prime}\right|} \sum_{i \in \mathcal{I}^{\prime}} \mathbb{E}\left[E U\left(\mathbf{r}_{i}^{T}, \mathbf{u}_{i}\right)\right],
$$

for $\ell=10,15$, and 20 where $\mathbf{r}_{i}^{T}$ is the truthful report, i.e. $r_{i k}^{T}$ is the program with the $k^{\text {th }}$ highest utility in $\mathbf{u}_{i}$, and a student only ranks a school if it is preferred to remaining unassigned in the main round. The difference between our approximation of optimal reporting and truthful reporting in the uncoordinated mechanism indicates the the range under which our behavioral assumptions about rankings submitted in the uncoordinated mechanism may alter the conclusions about the two mechanisms. ${ }^{40}$

There is a large difference in behavior between estimates that assume truthful reporting and our approximation of optimal reporting. Using our approximation computed from the top 10 choices, only about one tenth of applicants submit the same rank ordering as they would if they

\footnotetext{
${ }^{39}$ The 22.62 mile difference in Staten Island is larger than the 13.82 mile difference between the neighborhood and utilitarian assignment in Table 8, a result that suggests the uncoordinated assignment is actually worse than neighborhood assignment in Staten Island. In the uncoordinated mechanism, there are 1,054 students who ranked Staten Island Technical, a highly sought-after screened school. Only $16 \%$ are assigned there, and about $75 \%$ do not obtain a Main round offer and are subsequently administratively assigned. In the coordinated mechanism, there is also a large reduction in the number assigned to four main Staten Island schools: New Dorp, Tottenville, Port Richmond, and Curtis. Staten Island students submitting rankings were unlikely to highly rank these schools.

${ }^{40}$ If applicants submitted truthful reports in the uncoordinated mechanism and ( $\left.\mathbf{p}, \mathbf{q}\right)$ represents the corresponding admissions probabilities, then

$$
\bar{W}^{T}\left(\mu^{\prime}\right)=\frac{1}{\left|\mathcal{I}^{\prime}\right|} \sum_{i \in \mathcal{I}^{\prime}} \mathbb{E}\left[E U\left(\mathbf{r}_{i}^{T}, \mathbf{u}_{i}\right)\right]
$$
}

where $\mu^{\prime}$ is assignment in the uncoordinated mechanism. 
submitted preferences truthfully. As we improve our approximation by considering larger choice sets, the fraction of applicants who have the same optimal report increases. Roughly half of applicants submit the same rank list when optimizing over their top ten choices compared to their top 15 choices. That is, $\mathbf{r}_{i}^{*, 10}=\mathbf{r}_{i}^{*, 15}$ for about half of the applicants. When we compare $\mathbf{r}_{i}^{*, 15}$ and $\mathbf{r}_{i}^{*, 20}$, nearly three quarters have the same choices. Consistent with this fact, the difference between truthful and optimal reporting from a menu of top 20 choices is $\Delta^{20}=2.08$ miles, which is only slightly larger than the difference with optimal reporting and a menu of top 15 choices $\Delta^{15}=1.94$. These findings suggest that we would not find a large difference if we were able to approximate optimal reports from the full choice menu.

The difference between assuming truthful reporting and our approximation of optimal reporting changes the 10.62 mile estimate in Table 9 by about 2.08 miles overall, or a $20 \%$ difference. The conclusion that the coordinated mechanism generated significant welfare improvement over the uncoordinated mechanism appears robust to a best-case analysis for the uncoordinated mechanism. The gains are largest for groups that experienced high rates of administrative assignment in the uncoordinated mechanism. Nearly all of the patterns across demographic groups remain the same when considering optimal reports among the top 20: Manhattan residents gained the least, while Staten Island residents gained the most; low baseline students gained more than SHSAT test takers. Since optimal reporting provides the best case for the uncoordinated mechanism and there is evidence that our approximation may be close to optimal reporting, the average improvement in student welfare is likely to be more than 8.6 miles.

The large gains associated with assignment offers need not correspond to differences in matriculation patterns observed earlier, especially if the uncoordinated mechanism's aftermarket is more flexible. ${ }^{41}$ Coordinating admissions occurred with greater central control over enrollment, which may mean the more rigid aftermarket in the coordinated mechanism is actually worse for students. Table 3 shows that students enrolled in schools further away on average than where they were assigned in the uncoordinated mechanism, but the opposite pattern is true in the coordinated mechanism. Column 2 of Table 9 also reports the utility associated with the schools at which students enroll in October of the following school year. Compared to assignments, the gains from the coordinated mechanism measured by enrollment are somewhat smaller, but they are still large. For instance, the distance-equivalent utility for the average student is 9.25 miles (with standard error 0.56 miles), which is $87 \%$ of the gain from the assignment. The change in travel distance to enrolled school is also lower than the change in travel distance to assignment. Though a smaller gain from enrollment suggests some of the old mechanism's mismatch was undone in its aftermarket, these facts weigh against the argument that post-market reallocation has undone a large fraction of misallocation. Relatedly, since the exit rate in the coordinated mechanism is lower than in the uncoordinated mechanism, more students preferred accepting their coordinated offer over enrolling in a high school outside of the system. This finding suggests that our welfare estimate may understate the overall effect for all public school $8^{\text {th }}$ graders.

Figure 5 summarizes the comparisons across the alternative mechanisms. The scale corresponds to 18.96 miles from neighborhood to utilitarian assignment. Under our approximation to

\footnotetext{
${ }^{41}$ Similar arguments are often made in the context of auction design in the presence of resale markets. See, e.g., Milgrom (2004).
} 
the best-case for the uncoordinated mechanism, the difference between it and the coordinated mechanism represents $45 \%$ of the total range. This is more than double the possible range associated with further tweaks to the matching algorithm, which is at most $20 \%$. This finding informs a broader debate in the market design literature about the importance of sophisticated market clearing mechanisms. In the context of auctions, Klemperer (2002) argued that "most of the extensive auction literature is of second-order importance for practical auction design," and that "good auction design is mostly good elementary economics." Consistent with this point of view, for school matching market design, coordinating admissions produces much larger gains than algorithm refinements within the coordinated system.

\section{Comparison for the Administratively Assigned}

A key difference between mechanisms is the number of students administratively assigned. Table 4 shows that being administratively assigned is undesirable: students are assigned to schools that differ substantially from the schools they ranked. These facts suggests that students who are administratively assigned loom large in comparisons between mechanisms. In this section, we investigate what our demand estimates imply for this group, and we also examine achievement outcomes.

To begin, we estimate the likelihood that a student is administratively assigned in the uncoordinated mechanism based on demographic characteristics and geographic location. Denote $a_{i}$ as an indicator if a student is administratively assigned. We fit a probit model:

$$
a_{i}=\Phi\left(\mathbf{z}_{i} \rho+\pi_{t}\right)
$$

where $\mathbf{z}_{i}$ is a vector of student characteristics (same as the demand model) with co-efficient vector $\rho, \pi_{t}$ are census tract effects for tracts indexed by $t$, and $\Phi$ is the standard normal CDF. The specification includes census tract dummies to account for neighborhoods that may or may not have zoned high schools, which are a guaranteed fallback option for some students.

Equation (13) allows us to construct an index, based on each student's observed characteristics, that quantifies a student's risk of being administratively assigned. With this index, we compare students from the uncoordinated mechanism with students in the coordinated mechanism that are similar on this dimension.

\subsection{Welfare}

Figure 6 shows that students who were likely to be administratively assigned in the old mechanism realized higher student welfare under the new mechanism. To produce this figure, we compute the expected utility for student $i$ under mechanism $m$, where $m \in$ \{coordinated, uncoordinated from equation (3). Then we relate the fitted values $\hat{a}_{i}$ to this expected utility using a flexible functional form:

$$
y_{i m}=g_{m}\left(\hat{a}_{i}\right)+\epsilon_{i m}
$$

where $g_{m}$ is estimated via local linear regressions with normal kernel, with twice Silverman's rule-of-thumb bandwidth. 
For a grid of points $a \in\left\{a_{1}, \ldots, a_{K}\right\}$, Figure 6 reports the difference in $g_{m}$ for the coordinated and uncoordinated mechanism. This provides a non-parametric estimate of the difference in utility for students with administratively assignment propensity $a{ }^{42}$ Consistent with the descriptive facts in Tables 3 and 4, there is a clear monotonic pattern between administrative assignment propensity and welfare improvement, whether comparing utility differences including either distance or net of distance.

\subsection{Test Scores and Graduation}

We next examine whether the allocative differences on which we've focused influence educational outcomes. This exercise not only complements our focus on allocative effects, but it is also of independent interest. As far as we know, there is no previous evidence on how changes in school assignment mechanisms translate into differences in downstream educational outcomes. Comparisons between mechanisms are challenging because they are aggregate market-wide shocks, making it difficult to disentangle changes in the mechanism from other contemporaneous changes. Our approach considers groups of students who are more likely to benefit from the new mechanism based their likelihood of being assigned administratively in the old mechanism. Because our findings suggest that effects are largest for those most likely to have been administratively assigned, we anticipate that the downstream consequences are largest for that group.

Figure 7 reports estimates of Math and English Regents and graduation based on the probability a student is administratively assigned, constructed in the same way as Figure 6 . The top panel shows the difference in Regents Math and English achievement is largest for students who were most likely to be administratively assigned in the uncoordinated mechanism, and the difference in achievement mirrors the difference in utility shown in Figure 6. The bottom panel shows that these differences translate into differences in graduation rates, with a nearly $10 \%$ graduation increase for students who were most likely to be formerly administratively assigned.

\section{Model Fit and Alternate Behavioral Assumptions}

\subsection{Model fit}

Since our goal is to make statements about welfare, it is important to examine how well our demand estimates match the data. We first investigate within-sample fit to see what our estimates imply for the aggregate patterns by rank in Table 6. Figure A2 reports on measures of fit using the main specification in column 3 of Table 7 . We plot the observed versus predicted pattern of three school characteristics - high Math achievement, percent subsidized lunch, and percent white - as we go down a student's choice list. The panels include three pairs of lines for the entire sample and for the low and high baseline math applicants. For these three characteristics, our estimates capture the broad pattern of the choices, matching both the level and slope of these characteristics. For instance, the average high math achievement is 10.0, and the range from the top choice to the 12 th choice is 16.7 to 10.4. Our estimates imply that for first choices, a school's

\footnotetext{
${ }^{42}$ These results are similar if the expected utility under the uncoordinated assignment mechanism is computed under the assumption of optimal reporting rather than under truthful reporting.
} 
fraction high math achievement is 18.4 , which drops to 11.8 for the 12 th choice. Our model also captures high baseline math applicants' greater sensitivity of high baseline math applicants to school math performance is also captured by our model. Furthermore, first choices for percent white are 19.1, while we predict them to be 19.8 on average, and the average percent white across New York's schools is only 10.8. Relative to the average attributes of schools, the model fit is much closer to the actual ranked distribution.

In the last panel of Figure A2, we report the fit for distance. Here, we find that while the increase in distance observed for lower-ranked choices mirrors that predicted by our model, there is a greater divergence in the level of distance. This pattern appears in all of the models we have estimated with random coefficients. It is worth noting that the difference in levels between our model and the data is small compared to the difference between the average distance to a high school in New York (12.7 miles from home) and the closest school (less than a mile from home).

Berry, Levinsohn, and Pakes (2004) emphasize the importance of mixture models in the context of rank data for automobiles. In particular, they emphasize that when examining the within-consumer relationship between the attributes of alternatives ranked first and second, models without random coefficients do a poor job. This concern may be particularly important in our context. For instance, a high correlation between the first and second ranked schools' size may indicate taste for large schools. In Table A1, we report on the correlation between the first and second choice, the first and third choice, and the second and third choice. Consistent with earlier work, we see that the observed correlation between choices is much closer in our preferred specification than in the simpler model within sample. When we examine a more demanding out-of-sample test, which compares the 2003-04 preference estimates to examine the correlation pattern of choice made in 2004-05, we also see that the correlation pattern in our main specification is closer to the observed pattern than that from a demand model without student interactions.

\subsection{Behavioral Assumptions on Ranking}

Motivated by the detailed information in school brochures and the incentive properties of the deferred acceptance algorithm, the preference estimates that we reported come from models that assume students are well-informed and truthful in the coordinated mechanism. We examine some potential objections to this assumption in this subsection.

\subsubsection{Stability of Preferences}

In an influential field experiment, Hastings and Weinstein (2008) sent Charlotte-area parents clear information about schools. The percentage of applicants who requested to change schools increased by about $6.6 \%$ (with a standard error of 3.6\%). ${ }^{43}$ The authors interpret this finding as showing that how school information is framed can influence school choices. In NYC, the information available to participants about school characteristics was similar in the uncoordinated mechanism and the first few years of the coordinated mechanism. Consistent with this fact,

\footnotetext{
${ }^{43}$ This paper also reports that when NCLB-eligible students are given additional information about schools, an additional $5 \%$ of applicants chose a different first choice.
} 
Figure A4 shows that school market shares are fairly stable in the first and second year of the new mechanism.

Enrollment patterns also support the idea that choices are deliberate and contain welfarerelevant information. Table B4 reports assignment and enrollment decisions for students who are assigned in the Main round. The table shows that $92.7 \%$ of students enroll in their assigned choice, and this number varies from $88.4 \%$ to $94.5 \%$, depending on which choice a student receives. Interestingly, take-up is higher for students who receive lower-ranked choices, while the fraction of students who exit is highest among students who obtain one of their top three choices. This suggests that either families are unconcerned with differences among later choices and simply enroll where they obtain an offer or that families deliberately investigate later choices and are therefore willing to enroll in lower-ranked schools. If families are more uncertain about lower-ranked choices, then using all submitted ranks may provide a misleading account of student preferences. To examine how sensitive our conclusions are to this assumption, we fit a demand model that considers only students' top three choices in column 4 of Table 7.

\subsubsection{Assumptions about Ranking Behavior}

A second concern with treating submitted rankings as truthful is that parents rank schools using heuristics carried over from the previous system. Despite the theoretical motivation and the DOE's advice, parents might still deviate from truth-telling because of misinformation. Table B3 shows that students are more likely to be assigned their last choice than their penultimate choice. This pattern may be caused by strategic behavior if students apply to schools that they like, and, as a safety option, rank last a school in which they have a higher admissions chance. For instance, Calsamiglia, Haeringer, and Kljin (2010) present laboratory evidence that a constraint on rank-order lists encourages students to rank safer options. However, it may also be fully consistent with truth-telling. For example, students usually obtain borough priority or zone priority for schools in their neighborhoods. Ranking these schools improves their likelihood of being assigned to them in case they are rejected by their higher choices. If students consider applying and higher-achieving schools further away from their neighborhoods, they may as well stop ranking schools below their neighborhood schools once such considerations no longer justify the cost of their commute. Alternatively, search costs may induce parents to stop their search for schools before they identify twelve schools for their children and rank their neighborhood school as last choice. This preference pattern would produce the observed assignment pattern. To examine how sensitive our conclusions are to this assumption, we fit demand models that drop the last choice of each student.

Another issue with assuming truthful preferences is that students can rank at most 12 programs on school applications. When a student is interested in more than 12 schools, she has to carefully reduce the choice set down to 12 schools. If a student is only interested in 11 or fewer schools, this constraint in principle should not influence ranking behavior (Abdulkadiroğlu, Pathak, and Roth 2009, Haeringer and Klijn 2009). It is a weakly dominant strategy to add an acceptable school to a rank-order list as long as there is room for additional schools on the application form. However, $20.3 \%$ of students in our demand sample rank 12 schools. Some of these students may drop highly-sought-after schools from the top of their choice lists because of this 
constraint. To examine how sensitive our conclusions are to this assumption, we fit a demand model that drops students who have ranked all twelve choices.

In Table A2, we report on our evaluation of mechanism design choices under these alternative specifications: 1) using choices among eligible programs, 2) using only the top 3 choices, 3) excluding applicants who have ranked all 12 programs, and 4) dropping applicants' last choice. Because of computational constraints, we only estimate the first model for the entire sample and estimate a 10\% random sample for the other three models. (Table A3 reports the corresponding preference estimates). The full sample is used to compute all counterfactuals. For all demand models, the coordinated mechanism in column 2 is more than three quarters of the way from the neighborhood assignment to the utilitarian assignment. It therefore appears that our conclusions on the value of choice relative to changes within the coordinated mechanism are robust to these alternative ways of using the submitted rank-order lists in the coordinated mechanism.

Panel B of Table A2 reports on how the comparison between mechanisms varies with our demand specification using participants' full ranking information. Given that Staten Island has the highest fraction of students who are assigned administratively and experiences the largest welfare gain, we re-estimate preferences excluding any applicant from Staten Island. Our conclusions are unaltered by this modification. The table does show, however, that preference heterogeneity generates a larger role for school choice compared to neighborhood assignment. This phenomenon can be seen by comparing the estimates from our main specification to those from specifications without student interactions and without random coefficients. The neighborhood assignment is more appealing according to those two demand models, since they are only 15.5 and 16.2 miles away from the utilitarian assignment, compared to 21.5 miles from the main specification in the $10 \%$ sample.

\section{Conclusion}

The reform of NYC's high school assignment system provides a unique opportunity to study, with detailed data on preferences, assignments, and enrollment, the effects of centralizing and coordinating school admissions. We find that the new coordinated mechanism is an improvement relative to the old uncoordinated mechanism in a variety dimensions. More than a third of students were assigned through an ad-hoc administrative process in the uncoordinated mechanism after multiple offers with few choices and few rounds of clearing left a large number of students without offers after the Main round. Students placed in the Administrative round were assigned to schools with considerably worse characteristics than the schools they ranked. The new mechanism relieved this congestion and assigned more students to schools where they applied.

The coordinated mechanism assigns students 0.69 miles further from home compared to the uncoordinated mechanism. However, the benefit of being assigned through the coordinated mechanism is significantly larger than the cost of additional travel. The gains are positive on average for students from all boroughs, demographic groups, and baseline achievement categories. Welfare improvements are also seen whether utility is measured based on assignments made at the end of the high school match or subsequent school enrollment. The largest gains are for students who were more likely to be processed in the Administrative round of the uncoordinated 
mechanism. These conclusions are robust to alternative behavioral assumptions on preferences submitted in both the uncoordinated and coordinated mechanism. Cross-sectional differences in Regents test performance and graduation also coincide with the fact that students who were most likely to be assigned administratively in the old mechanism experienced the largest gains.

These gains are measured by a rich specification of student demand that implies significant estimated heterogeneity in willingness to travel for school. Preference heterogeneity is important for measuring the allocative effects of choice when there is a shortage of good schools. Our estimates reveal that the benefits of coordinated choice with deferred acceptance are much larger than than those associated with modifications to the assignment algorithm within the coordinated mechanism. This does not imply that the mechanism design is not important, however, because the gap in average student welfare between the uncoordinated and coordinated mechanism is large.

The increase in student welfare due to the new mechanism illustrates that there are considerable frictions to exercising choice in poorly designed assignment systems. The 2003 change in NYC took place in an environment where participants already had some familiarity with choice since both the uncoordinated and coordinated system had a common application. In other cities, the school choice market is even less well organized, without readily available information on admissions processes and application timelines. For instance, admissions in Boston's growing charter sector are uncoordinated, and the schools have only recently adopted a standardized application timeline. Recently, there have been efforts to unify enrollment across school sectors (Vaznis 2013, Fox 2015). The relative value of policies such as common timelines, common applications, single vs. multiple offers, sophisticated matching algorithms, and good information and decision aides is an interesting avenue for future research. 
Table 1. Characteristics of Student Sample

\begin{tabular}{|c|c|c|c|}
\hline & \multicolumn{2}{|c|}{ Mechanism Comparison } & \multirow{2}{*}{$\begin{array}{c}\text { Demand Estimation } \\
\text { Coordinated } \\
\text { Mechanism } \\
\text { (3) }\end{array}$} \\
\hline & $\begin{array}{c}\text { Uncoordinated } \\
\text { Mechanism } \\
\text { (1) }\end{array}$ & $\begin{array}{l}\text { Coordinated } \\
\text { Mechanism } \\
\text { (2) }\end{array}$ & \\
\hline Number of Students & 70,358 & 66,921 & 69,907 \\
\hline Female & $49.4 \%$ & $49.0 \%$ & $49.0 \%$ \\
\hline Bronx & $23.7 \%$ & $23.3 \%$ & $23.7 \%$ \\
\hline Brooklyn & $31.9 \%$ & $34.1 \%$ & $33.3 \%$ \\
\hline Manhattan & $12.5 \%$ & $11.8 \%$ & $12.0 \%$ \\
\hline Queens & $25.0 \%$ & $24.8 \%$ & $24.7 \%$ \\
\hline Staten Island & $6.9 \%$ & $6.0 \%$ & $6.3 \%$ \\
\hline Asian & $10.6 \%$ & $10.9 \%$ & $10.6 \%$ \\
\hline Black & $35.4 \%$ & $35.7 \%$ & $35.7 \%$ \\
\hline Hispanic & $38.9 \%$ & $40.4 \%$ & $40.3 \%$ \\
\hline White & $14.7 \%$ & $12.6 \%$ & $13.0 \%$ \\
\hline Other & $0.4 \%$ & $0.4 \%$ & $0.4 \%$ \\
\hline Subsidized Lunch & $68.0 \%$ & $67.4 \%$ & $67.8 \%$ \\
\hline Neighborhood Income & 38,360 & 37,855 & 37,920 \\
\hline Limited English Proficient & $13.1 \%$ & $12.6 \%$ & $12.6 \%$ \\
\hline Special Education & $8.2 \%$ & $7.9 \%$ & $7.5 \%$ \\
\hline SHSAT Test-Taker & $22.4 \%$ & $24.3 \%$ & $23.9 \%$ \\
\hline
\end{tabular}

Notes: Means unless otherwise noted. Uncoordinated mechanism refers to the 2002-03 mechanism and coordinated mechanism refers to the 2003-04 mechanism based on deferred acceptance. Neighborhood income is the median census block group family income from the 2000 census: table reports the mean neighborhood income across students. SHSAT stands for Specialized High School Achievement Test. 
Table 2. Descriptive Statistics for Schools and Programs

\begin{tabular}{|c|c|c|}
\hline & $\begin{array}{c}\text { Uncoordinated } \\
\text { Mechanism } \\
\text { (1) }\end{array}$ & $\begin{array}{c}\text { Coordinated } \\
\text { Mechanism } \\
\text { (2) } \\
\end{array}$ \\
\hline & \multicolumn{2}{|c|}{ A. Schools } \\
\hline Number & 215 & 235 \\
\hline High Math Achievement & 10.2 & 10.0 \\
\hline High English Achievement & 19.1 & 19.3 \\
\hline Percent Attending Four Year College & 47.8 & 47.2 \\
\hline Fraction Inexperienced Teachers & 54.7 & 55.6 \\
\hline Attendance Rate (out of 100) & 85.5 & 85.7 \\
\hline Percent Subsidized Lunch & 62.5 & 62.6 \\
\hline Size of 9th grade & 465.7 & 451.3 \\
\hline Percent White & 10.9 & 10.9 \\
\hline Percent Asian & 8.7 & 8.6 \\
\hline Percent Black & 38.5 & 38.4 \\
\hline \multirow[t]{2}{*}{ Percent Hispanic } & 41.9 & 42.1 \\
\hline & \multicolumn{2}{|c|}{ B. Programs } \\
\hline Number & 612 & 558 \\
\hline Screened & 233 & 208 \\
\hline Unscreened & 63 & 119 \\
\hline Education Option & 316 & 119 \\
\hline Spanish Language & 27 & 24 \\
\hline Asian Language & 10 & 9 \\
\hline Other Language & 6 & 7 \\
\hline Arts & 80 & 80 \\
\hline Humanities & 89 & 93 \\
\hline Math and Science & 53 & 60 \\
\hline Vocational & 55 & 59 \\
\hline Other Specialties & 163 & 162 \\
\hline
\end{tabular}

Notes: Panel A reports means and Panel B reports counts, unless otherwise noted. Uncoordinated mechanism refers to the 2002-03 mechanism and coordinated mechanism refers to the 2003-04 mechanism based on deferred acceptance. The data appendix presents information on the availability of school characteristics. High Math and High English Achievement is the fraction of students who scored more than $85 \%$ on the Math A and English Regents tests in New York State Report Cards, respectively. Inexperienced teachers are those who have taught for less than two years. 
Table 3. Offer Processing across Mechanisms

\begin{tabular}{|c|c|c|c|c|c|}
\hline & & \multicolumn{2}{|c|}{ Distance to School (in miles) } & \multirow{2}{*}{$\begin{array}{l}\text { Exit from NYC Public } \\
\text { Schools } \\
\text { (4) }\end{array}$} & \multirow{2}{*}{$\begin{array}{l}\text { Enrolled in School Other than } \\
\text { Assigned } \\
\text { (5) }\end{array}$} \\
\hline & $\begin{array}{c}\text { Number of Students } \\
\text { (1) }\end{array}$ & $\begin{array}{c}\text { Assignment } \\
(2)\end{array}$ & $\begin{array}{l}\text { Enrollment } \\
\text { (3) }\end{array}$ & & \\
\hline & \multicolumn{5}{|c|}{ A. Uncoordinated Mechanism - By Final Assignment Round } \\
\hline Overall & 70,358 & 3.36 & 3.50 & $8.5 \%$ & $18.6 \%$ \\
\hline First Round & 23,867 & 4.23 & 4.11 & $5.2 \%$ & $9.6 \%$ \\
\hline Second Round & 5,780 & 4.55 & 4.44 & $4.8 \%$ & $11.4 \%$ \\
\hline Third Round & 4,443 & 4.35 & 4.26 & $4.9 \%$ & $14.2 \%$ \\
\hline Supplementary Round & 10,170 & 4.61 & 4.37 & $7.8 \%$ & $25.4 \%$ \\
\hline \multirow[t]{2}{*}{ Administrative Round } & 26,098 & 1.64 & 2.11 & $13.3 \%$ & $26.8 \%$ \\
\hline & \multicolumn{5}{|c|}{ B. Uncoordinated Mechanism - By Number of First Round Offers } \\
\hline No Offers & 36,464 & 2.80 & 3.12 & $10.4 \%$ & $24.4 \%$ \\
\hline One Offer & 21,328 & 3.89 & 3.85 & $7.1 \%$ & $13.8 \%$ \\
\hline \multirow[t]{2}{*}{ Two or More Offers } & 12,566 & 4.07 & 4.03 & $5.7 \%$ & $9.8 \%$ \\
\hline & \multicolumn{5}{|c|}{ C. Coordinated Mechanism - By Final Assignment Round } \\
\hline Overall & 66,921 & 4.05 & 3.91 & $6.4 \%$ & $11.4 \%$ \\
\hline Main Round & 54,577 & 4.02 & 3.86 & $6.1 \%$ & $9.9 \%$ \\
\hline Supplementary Round & 5,201 & 5.10 & 4.90 & $4.8 \%$ & $10.4 \%$ \\
\hline Administrative Round & 7,143 & 3.50 & 3.52 & $9.6 \%$ & $23.6 \%$ \\
\hline
\end{tabular}


Table 4. Ranked vs. Assigned Schools by Student Assignment Round

\begin{tabular}{|c|c|c|c|c|}
\hline & \multicolumn{2}{|c|}{ Uncoordinated Mechanism } & \multicolumn{2}{|c|}{ Coordinated Mechanism } \\
\hline & $\begin{array}{c}\text { Ranked Schools } \\
\text { (1) }\end{array}$ & $\begin{array}{c}\text { Assigned } \\
(2)\end{array}$ & $\begin{array}{c}\text { Ranked Schools } \\
\text { (3) }\end{array}$ & $\begin{array}{c}\text { Assigned } \\
\text { (4) }\end{array}$ \\
\hline & \multicolumn{4}{|c|}{ A. Main Round } \\
\hline Distance (in miles) & 4.82 & 4.30 & 5.10 & 4.00 \\
\hline High Math Achievement & 12.4 & 11.7 & 13.0 & 10.7 \\
\hline High English Achievement & 20.9 & 20.2 & 22.1 & 19.1 \\
\hline Percent Attending Four Year College & 49.1 & 47.1 & 50.6 & 48.3 \\
\hline Fraction Inexperienced Teachers & 45.3 & 45.6 & 46.6 & 43.8 \\
\hline Attendance Rate (out of 100) & 85.1 & 84.6 & 85.7 & 83.8 \\
\hline Percent Subsidized Lunch & 60.0 & 60.5 & 57.6 & 56.7 \\
\hline Size of 9 th grade & 694.3 & 698.8 & 675.0 & 819.2 \\
\hline \multirow[t]{2}{*}{ Percent White } & 15.1 & 14.7 & 16.7 & 17.8 \\
\hline & \multicolumn{4}{|c|}{ B. Supplementary Round } \\
\hline Distance (in miles) & 4.87 & 4.59 & 5.87 & 5.17 \\
\hline High Math Achievement & 11.8 & 9.3 & 16.6 & 14.2 \\
\hline High English Achievement & 19.9 & 15.8 & 26.5 & 20.0 \\
\hline Percent Attending Four Year College & 48.6 & 44.9 & 54.1 & 50.1 \\
\hline Fraction Inexperienced Teachers & 46.0 & 41.5 & 45.3 & 36.9 \\
\hline Attendance Rate (out of 100) & 85.1 & 82.2 & 87.4 & 83.2 \\
\hline Percent Subsidized Lunch & 62.0 & 61.8 & 53.5 & 51.0 \\
\hline Size of 9th grade & 685.3 & 908.0 & 638.5 & 1129.7 \\
\hline \multirow[t]{2}{*}{ Percent White } & 13.8 & 13.3 & 17.4 & 15.3 \\
\hline & \multicolumn{4}{|c|}{ C. Administrative Round } \\
\hline Distance (in miles) & 5.11 & 1.62 & 5.33 & 3.43 \\
\hline High Math Achievement & 14.9 & 10.5 & 14.3 & 10.7 \\
\hline High English Achievement & 24.3 & 17.5 & 24.2 & 19.2 \\
\hline Percent Attending Four Year College & 52.0 & 46.7 & 51.7 & 47.9 \\
\hline Fraction Inexperienced Teachers & 41.9 & 39.4 & 47.8 & 42.1 \\
\hline Attendance Rate (out of 100 ) & 85.8 & 80.8 & 86.7 & 82.9 \\
\hline Percent Subsidized Lunch & 53.8 & 50.4 & 57.2 & 53.1 \\
\hline Size of 9th grade & 760.6 & 1181.9 & 607.6 & 984.0 \\
\hline Percent White & 18.5 & 19.1 & 17.6 & 17.9 \\
\hline
\end{tabular}

Notes: Means unless otherwise noted. Analysis restricts the sample to students from the welfare sample with observed assignments. Uncoordinated mechanism refers to the 2002-03 mechanism and coordinated mechanism refers to the 2003-04 mechanism based on deferred acceptance. Main round in the uncoordinated mechanism corresponds to the first round. Rankings used are those submitted in the main round of the process. Student distance is calculated as road distance using ArcGIS. See Table 2 notes for details on school characteristics. 
Table 5. Offer Processing by Student Type

\begin{tabular}{|c|c|c|c|c|c|c|}
\hline & \multicolumn{3}{|c|}{ Uncoordinated Mechanism } & \multicolumn{3}{|c|}{ Coordinated Mechanism } \\
\hline & $\begin{array}{l}\text { Main Round } \\
\text { (1) }\end{array}$ & $\begin{array}{c}\text { Supplementary } \\
(2)\end{array}$ & $\begin{array}{c}\text { Administrative } \\
\text { (3) }\end{array}$ & $\begin{array}{l}\text { Main } \\
(4)\end{array}$ & $\begin{array}{c}\text { Supplementary } \\
\text { (5) }\end{array}$ & $\begin{array}{c}\text { Administrative } \\
(6)\end{array}$ \\
\hline Students & $48.5 \%$ & $14.5 \%$ & $37.1 \%$ & $81.6 \%$ & $7.8 \%$ & $10.7 \%$ \\
\hline Female & $51.0 \%$ & $14.3 \%$ & $34.7 \%$ & $82.1 \%$ & $7.7 \%$ & $10.2 \%$ \\
\hline Bronx & $53.3 \%$ & $20.2 \%$ & $26.5 \%$ & $81.7 \%$ & $6.7 \%$ & $11.6 \%$ \\
\hline Brooklyn & $49.8 \%$ & $16.2 \%$ & $33.9 \%$ & $82.9 \%$ & $8.0 \%$ & $9.1 \%$ \\
\hline Manhattan & $66.8 \%$ & $19.2 \%$ & $14.0 \%$ & $78.9 \%$ & $7.4 \%$ & $13.7 \%$ \\
\hline Queens & $43.1 \%$ & $8.3 \%$ & $48.6 \%$ & $79.2 \%$ & $10.0 \%$ & $10.8 \%$ \\
\hline Staten Island & $11.9 \%$ & $0.0 \%$ & $88.1 \%$ & $88.3 \%$ & $2.4 \%$ & $9.3 \%$ \\
\hline Asian & $46.1 \%$ & $5.4 \%$ & $48.5 \%$ & $82.3 \%$ & $7.3 \%$ & $10.3 \%$ \\
\hline Black & $53.2 \%$ & $18.4 \%$ & $28.4 \%$ & $81.3 \%$ & $8.7 \%$ & $10.0 \%$ \\
\hline Hispanic & $51.2 \%$ & $17.3 \%$ & $31.5 \%$ & $81.8 \%$ & $7.9 \%$ & $10.3 \%$ \\
\hline White & $31.5 \%$ & $3.8 \%$ & $64.7 \%$ & $81.4 \%$ & $5.0 \%$ & $13.6 \%$ \\
\hline High Baseline Math & $57.3 \%$ & $7.4 \%$ & $35.3 \%$ & $85.2 \%$ & $5.1 \%$ & $9.7 \%$ \\
\hline Low Baseline Math & $46.8 \%$ & $19.8 \%$ & $33.4 \%$ & $79.9 \%$ & $7.2 \%$ & $12.9 \%$ \\
\hline Subsidized Lunch & $51.8 \%$ & $15.9 \%$ & $32.3 \%$ & $82.7 \%$ & $7.7 \%$ & $9.6 \%$ \\
\hline Bottom Neighborhood Income Quartile & $55.4 \%$ & $23.3 \%$ & $21.3 \%$ & $81.8 \%$ & $7.2 \%$ & $11.0 \%$ \\
\hline Top Neighborhood Income Quartile & $41.3 \%$ & $8.1 \%$ & $50.6 \%$ & $80.8 \%$ & $7.4 \%$ & $11.8 \%$ \\
\hline Limited English Proficient & $46.9 \%$ & $16.3 \%$ & $36.8 \%$ & $81.8 \%$ & $7.6 \%$ & $10.7 \%$ \\
\hline Special Education & $38.9 \%$ & $18.8 \%$ & $42.3 \%$ & $71.8 \%$ & $0.0 \%$ & $28.2 \%$ \\
\hline SHSAT Test-taker & $61.9 \%$ & $10.3 \%$ & $27.8 \%$ & $82.6 \%$ & $7.3 \%$ & $10.0 \%$ \\
\hline
\end{tabular}

Notes: Uncoordinated mechanism refers to the 2002-03 mechanism and coordinated mechanism refers to the 2003-04 mechanism based on deferred acceptance. Table reports on final assignment round,

which is the round during which an offer to the final assigned school was accepted. Neighborhood income is median family income from the 2000 census. 
Table 6. School Characteristics by Rank of Student Choice

\begin{tabular}{|c|c|c|c|c|c|c|c|c|c|}
\hline Choice & Mechanism & 1 st & 2nd & $3 r d$ & 4th & 5 th & 6th & 9th & 12th \\
\hline & \multicolumn{9}{|c|}{ A. All Students } \\
\hline \multirow[t]{2}{*}{ Students Ranking Choice } & Coordinated & 69,907 & $93.4 \%$ & $88.7 \%$ & $82.8 \%$ & $76.2 \%$ & $69.1 \%$ & $49.7 \%$ & $20.3 \%$ \\
\hline & Uncoordinated & 59,277 & $93.5 \%$ & $85.8 \%$ & $71.7 \%$ & $46.7 \%$ & & & \\
\hline \multirow[t]{2}{*}{ Distance in Miles - Mean } & Coordinated & 4.43 & 4.81 & 5.05 & 5.21 & 5.38 & 5.49 & 5.65 & 5.12 \\
\hline & Uncoordinated & 4.80 & 4.91 & 4.94 & 4.88 & 4.79 & & & \\
\hline \multirow[t]{2}{*}{ Median } & Coordinated & 3.51 & 3.95 & 4.20 & 4.37 & 4.57 & 4.63 & 4.78 & 4.24 \\
\hline & Uncoordinated & 3.87 & 4.00 & 4.05 & 4.05 & 4.02 & & & \\
\hline \multirow[t]{2}{*}{ High Math Achievement } & Coordinated & 16.7 & 15.3 & 14.7 & 13.9 & 13.4 & 12.8 & 11.5 & 10.4 \\
\hline & Uncoordinated & 14.1 & 13.3 & 12.8 & 12.1 & 11.7 & & & \\
\hline \multirow[t]{2}{*}{ Fraction Subsidized Lunch } & Coordinated & 51.4 & 53.4 & 54.5 & 56.2 & 57.4 & 58.7 & 61.3 & 63.1 \\
\hline & Uncoordinated & 56.6 & 58.0 & 59.1 & 60.7 & 62.0 & & & \\
\hline \multirow[t]{2}{*}{ Size of 9th Grade } & Coordinated & 713.4 & 708.1 & 689.3 & 668.0 & 655.3 & 635.9 & 608.8 & 649.2 \\
\hline & Uncoordinated & 720.7 & 720.7 & 709.3 & 696.5 & 686.6 & & & \\
\hline \multirow[t]{2}{*}{ Percent White } & Coordinated & 19.1 & 16.7 & 15.7 & 14.4 & 13.3 & 12.2 & 10.4 & 9.0 \\
\hline & Uncoordinated & 14.6 & 13.4 & 12.5 & 11.4 & 10.8 & & & \\
\hline Split by High Math Achievement & \multicolumn{9}{|c|}{ B. Student Subgroups } \\
\hline \multirow[t]{2}{*}{ Students with Low Baseline Math } & Coordinated & 10.9 & 10.9 & 10.5 & 10.1 & 10.0 & 9.7 & 9.4 & 8.8 \\
\hline & Uncoordinated & 9.5 & 9.5 & 9.4 & 8.9 & 8.7 & & & \\
\hline \multirow[t]{2}{*}{ Students with High Baseline Math } & Coordinated & 26.0 & 21.4 & 20.5 & 19.1 & 18.2 & 17.3 & 15.2 & 12.8 \\
\hline & Uncoordinated & 21.5 & 19.0 & 17.8 & 16.9 & 16.1 & & & \\
\hline \multicolumn{10}{|l|}{ Split by Neighborhood Income } \\
\hline Students from Bottom Neighorhood & Coordinated & 11.4 & 10.9 & 10.5 & 10.4 & 10.1 & 9.9 & 9.6 & 8.7 \\
\hline Income Quartile & Uncoordinated & 9.5 & 9.6 & 9.5 & 9.1 & 8.7 & & & \\
\hline Students from Top Neighorhood & Coordinated & 23.3 & 20.7 & 19.6 & 18.7 & 17.7 & 16.8 & 15.0 & 12.7 \\
\hline Income Quartile & Uncoordinated & 21.4 & 18.5 & 17.6 & 16.5 & 16.1 & & & \\
\hline
\end{tabular}


Table 7. Select Preference Estimates for Different Demand Specifications

\begin{tabular}{|c|c|c|c|c|c|c|c|c|c|}
\hline \multirow[b]{3}{*}{ Specifications: } & & \multicolumn{2}{|c|}{ No Student Interactions } & \multicolumn{6}{|c|}{ School Characteristics $\times$ Student Characteristics } \\
\hline & & & & \multirow{2}{*}{\multicolumn{2}{|c|}{ Without Random Coefficients }} & \multicolumn{4}{|c|}{ Models with Random Coefficients } \\
\hline & & \multicolumn{2}{|c|}{ (1) } & & & \multicolumn{2}{|c|}{$\begin{array}{l}\text { All Choices } \\
\text { (3) }\end{array}$} & \multicolumn{2}{|c|}{$\begin{array}{l}\text { Choice Among Eligible Programs } \\
\text { (4) }\end{array}$} \\
\hline \multicolumn{2}{|l|}{ High Math Achievement } & & & & & & & & \\
\hline \multirow{2}{*}{\multicolumn{2}{|c|}{$\begin{array}{l}\text { Main effect } \\
\text { Baseline Math }\end{array}$}} & 0.016 & $(0.016)$ & 0.027 & $(0.014)$ & -0.029 & (0.018) & -0.058 & $(0.039)$ \\
\hline & & & & 0.031 & $(0.001)$ & 0.039 & $(0.001)$ & 0.050 & $(0.001)$ \\
\hline \multicolumn{10}{|l|}{ Percent Subsidized Lunch } \\
\hline Main effect & & -0.085 & $(0.007)$ & -0.057 & $(0.004)$ & -0.069 & $(0.009)$ & -0.113 & $(0.058)$ \\
\hline \multicolumn{10}{|l|}{ Size of 9th Grade (in 100s) } \\
\hline Main effect & & -0.164 & $(0.036)$ & -0.092 & $(0.032)$ & -0.113 & $(0.048)$ & -0.153 & $(0.178)$ \\
\hline \multicolumn{10}{|l|}{ Percent White } \\
\hline Main effect & & -0.002 & $(0.014)$ & 0.070 & $(0.012)$ & 0.062 & $(0.016)$ & 0.093 & $(0.062)$ \\
\hline Asian & & & & -0.054 & $(0.002)$ & -0.075 & $(0.003)$ & -0.100 & $(0.004)$ \\
\hline Black & & & & -0.084 & $(0.002)$ & -0.124 & $(0.002)$ & -0.189 & $(0.003)$ \\
\hline Hispanic & & & & -0.047 & $(0.002)$ & -0.084 & $(0.002)$ & -0.119 & $(0.003)$ \\
\hline Standard Deviation of $\varepsilon$ & & 7.226 & $(0.010)$ & 7.385 & $(0.011)$ & 7.858 & $(0.013)$ & 10.059 & $(0.022)$ \\
\hline Standard Deviation of $\xi$ & & 3.519 & $(0.121)$ & 2.954 & $(0.100)$ & 3.676 & $(0.129)$ & 5.151 & $(0.650)$ \\
\hline \multicolumn{10}{|c|}{ Random Coefficients (Covariances) } \\
\hline Size of 9th Grade (in 100s) & Size of 9th Grade (in 100s) & & & & & 1.584 & (0.009) & 1.837 & $(0.012)$ \\
\hline Size of 9th Grade (in 100s) & Percent White & & & & & -0.006 & $(0.001)$ & -0.009 & (0.001) \\
\hline Size of 9th Grade (in 100s) & Percent Subsidized Lunch & & & & & -0.002 & $(0.000)$ & -0.002 & $(0.000)$ \\
\hline Size of 9th Grade (in 100s) & High Math Achievement & & & & & -0.011 & $(0.001)$ & -0.015 & $(0.001)$ \\
\hline Percent White & Percent White & & & & & 0.008 & $(0.000)$ & 0.013 & $(0.000)$ \\
\hline Percent White & Percent Subsidized Lunch & & & & & -0.001 & $(0.000)$ & -0.002 & $(0.000)$ \\
\hline Percent White & High Math Achievement & & & & & 0.005 & $(0.000)$ & 0.007 & $(0.000)$ \\
\hline Percent Subsidized Lunch & Percent Subsidized Lunch & & & & & 0.002 & $(0.000)$ & 0.003 & $(0.000)$ \\
\hline Percent Subsidized Lunch & High Math Achievement & & & & & 0.000 & $(0.000)$ & -0.001 & $(0.000)$ \\
\hline \multirow[t]{5}{*}{ High Math Achievement } & High Math Achievement & & & & & 0.016 & $(0.000)$ & 0.022 & $(0.000)$ \\
\hline & & & & \multicolumn{2}{|c|}{$\mathrm{x}$} & \multicolumn{2}{|c|}{$\mathrm{x}$} & \multicolumn{2}{|c|}{$\mathrm{x}$} \\
\hline & & & & \multicolumn{2}{|c|}{$\mathrm{x}$} & \multicolumn{2}{|c|}{$\mathrm{x}$} & \multicolumn{2}{|c|}{$\mathrm{x}$} \\
\hline & & \multirow{2}{*}{\multicolumn{2}{|c|}{$\begin{array}{c}69,907 \\
542,666\end{array}$}} & \multirow{2}{*}{\multicolumn{2}{|c|}{$\begin{array}{c}69,907 \\
542,666\end{array}$}} & \multicolumn{2}{|c|}{69,907} & \multicolumn{2}{|c|}{69,907} \\
\hline & & & & & & & & & \\
\hline
\end{tabular}

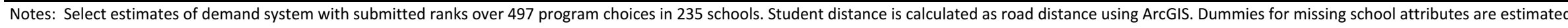
with separate coefficients. Column 1 contains no interactions between student and school characteristics. Column 2 contains interactions among school characteristics and baseline achievement, gender, race, special

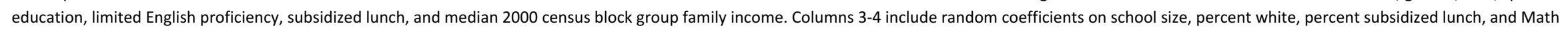

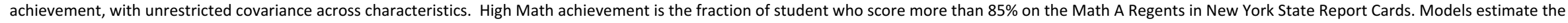

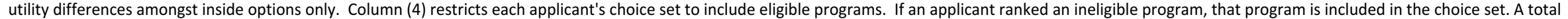
of 193 programs have eligibility restrictions and 3,854 students rank an ineligible program. Standard errors in parenthesis. 
Table 8. Welfare Comparison of Alternative Mechanisms Compared to Utilitarian Assignment

\begin{tabular}{|c|c|c|c|c|}
\hline \multirow{4}{*}{ Assignment Mechanism: } & \multirow{4}{*}{$\begin{array}{l}\text { Neighborhood } \\
\text { Assignment } \\
\text { (1) }\end{array}$} & \multicolumn{3}{|c|}{ School Choice } \\
\hline & & & Student-Optimal & Ordinal Pareto Efficient \\
\hline & & Coordinated Mechanism & Matching & Matching \\
\hline & & $(2)$ & (3) & $(4)$ \\
\hline All & -18.96 & -3.73 & -3.62 & -3.11 \\
\hline Female & -18.90 & -3.71 & -3.59 & -3.07 \\
\hline Black & -19.43 & -3.89 & -3.79 & -3.25 \\
\hline Hispanic & -19.37 & -3.80 & -3.67 & -3.10 \\
\hline White & -17.07 & -3.21 & -3.11 & -2.82 \\
\hline Bronx & -21.39 & -4.63 & -4.46 & -3.72 \\
\hline Brooklyn & -18.48 & -3.21 & -3.14 & -2.70 \\
\hline Queens & -18.02 & -3.39 & -3.29 & -2.96 \\
\hline Staten Island & -13.82 & -1.25 & -1.10 & -1.03 \\
\hline High Baseline Math & -18.53 & -3.29 & -3.18 & -2.61 \\
\hline Low Baseline Math & -19.40 & -4.28 & -4.18 & -3.63 \\
\hline Subsidized Lunch & -19.16 & -3.78 & -3.66 & -3.12 \\
\hline Bottom Neighborhood Income Quartile & -19.89 & -4.25 & -4.12 & -3.46 \\
\hline Top Neighborhood Income Quartile & -17.44 & -3.63 & -3.51 & -3.15 \\
\hline Special Education & -19.41 & -4.83 & -4.73 & -4.11 \\
\hline Limited English Proficient & -19.81 & -3.74 & -3.64 & -3.16 \\
\hline SHSAT Test-Takers & -19.13 & -4.17 & -4.05 & -3.41 \\
\hline
\end{tabular}

Notes: Utility from alternative assignments relative to utilitarian optimal assignment computed using actual preferences ignoring all school-side constraints except capacity. Utility computed using estimates in column 3 of Table 7. Mean utility from the utilitarian optimal assignment normalized to zero. Column 1 is computed by running the student-proposing deferred acceptance algorithm where applicants simply rank schools in order of distance. Column 2 is from 100 lottery draws of student-proposing deferred acceptance with single tiebreaking using the demand estimation sample. If a student is unassigned, we mimic the Supplementary Round by assigning students according to a serial dictatorship using preferences drawn from the preference distribution estimated in column 3 of Table 7. Student optimal matching in column 3 computed by taking each deferred acceptance assignment and applying the Erdil-Ergin (2008) stable improvement cycles algorithm to find a student-optimal matching. Ordinal Pareto Efficient Matching in column 4 computed by applying Gale's top trading cycles to the economy where the student-optimal matching determine student endowments, followed by the Abdulkadiroglu-Sonmez (2003) version of top trading cycles with counters. 


\begin{tabular}{|c|c|c|c|c|}
\hline & \multicolumn{2}{|c|}{ Change in Utility Net Distance (in miles) } & \multicolumn{2}{|c|}{ Change in Distance (in miles) } \\
\hline & $\begin{array}{l}\text { Assignment } \\
\text { (1) }\end{array}$ & $\begin{array}{c}\text { Enrollment } \\
\text { (2) }\end{array}$ & $\begin{array}{l}\text { Assignment } \\
\text { (3) }\end{array}$ & $\begin{array}{c}\text { Enrollment } \\
\text { (4) }\end{array}$ \\
\hline All Students & 10.62 & 9.25 & 0.69 & 0.38 \\
\hline Female & 10.01 & 8.59 & 0.68 & 0.37 \\
\hline Asian & 11.91 & 10.11 & 0.63 & 0.33 \\
\hline Black & 8.97 & 7.83 & 0.74 & 0.45 \\
\hline Hispanic & 10.21 & 9.11 & 0.66 & 0.39 \\
\hline White & 15.46 & 13.03 & 0.56 & 0.22 \\
\hline Bronx & 9.46 & 8.54 & 0.93 & 0.64 \\
\hline Brooklyn & 10.57 & 9.49 & 0.52 & 0.33 \\
\hline Manhattan & 5.10 & 4.33 & 0.00 & -0.09 \\
\hline Queens & 11.30 & 8.78 & 1.13 & 0.57 \\
\hline Staten Island & 22.62 & 22.42 & 0.34 & 0.00 \\
\hline High Baseline Math & 8.85 & 6.85 & 0.53 & 0.20 \\
\hline Low Baseline Math & 10.61 & 9.83 & 0.57 & 0.33 \\
\hline Subsidized Lunch & 10.13 & 8.93 & 0.65 & 0.38 \\
\hline Bottom Neighborhood Income Quartile & 8.81 & 8.18 & 0.57 & 0.42 \\
\hline Top Neighborhood Income Quartile & 12.02 & 9.71 & 0.71 & 0.25 \\
\hline Special Education & 10.30 & 9.10 & 0.76 & 0.43 \\
\hline Limited English Proficient & 11.62 & 10.58 & 0.60 & 0.38 \\
\hline SHSAT Test-Takers & 6.91 & 5.51 & 0.55 & 0.25 \\
\hline
\end{tabular}

Notes: Utilities are in distance units (miles) averaged across students in the mechanism comparison sample in Table 1 using preference estimates in column 3 of Table 7. Utility estimates assume truthful reports. Assignment is the school assigned the conclusion of the high school assignment process. Enrollment is the school student in which the student enrolls in October following application. If a student enrolls in the assigned school, we use the assigned program to compute the utility of enrollment. If a student enrolls at another school, we use the program-size weighted average of utilities from all programs at that school. 2002-03 offer process reports the fraction of students with row characteristic first offered school finally assigned in the Main round (rounds 1-3), the Supplementary round, or the Administrative round. Student distance calculated as road distance using ArcGIS. High baseline math students score above the 75th percentile for 7th grade relative to citywide distribution; low baseline math students score below the 25 th percentile. Subsidized lunch, not available preassignment, comes from enrolled students as of the 2004-05 school year. Neighborhood income is median census block group family income from the 2000 census. 
Table 10. Welfare Comparison for Alternative Selection Rules

\begin{tabular}{|c|c|c|c|}
\hline \multirow{3}{*}{$\begin{array}{l}\text { Optimal Reporting Computed from Choice Menu } \\
\text { Consisting of: }\end{array}$} & \multicolumn{3}{|c|}{ Difference in Expected Utility from Truthful Reporting } \\
\hline & \multirow{2}{*}{$\begin{array}{l}\text { Top } 10 \\
\text { (1) }\end{array}$} & \multirow{2}{*}{$\begin{array}{c}\text { Top } 15 \\
\text { (2) }\end{array}$} & \multirow{2}{*}{$\begin{array}{c}\text { Top } 20 \\
\text { (3) }\end{array}$} \\
\hline & & & \\
\hline All Students & 1.57 & 1.94 & 2.08 \\
\hline Female & 1.51 & 1.85 & 1.98 \\
\hline Asian & 2.18 & 2.68 & 2.86 \\
\hline Black & 1.39 & 1.73 & 1.87 \\
\hline Hispanic & 1.39 & 1.71 & 1.84 \\
\hline White & 2.07 & 2.52 & 2.66 \\
\hline Bronx & 1.43 & 1.76 & 1.89 \\
\hline Brooklyn & 1.66 & 2.07 & 2.21 \\
\hline Manhattan & 1.24 & 1.52 & 1.63 \\
\hline Queens & 1.77 & 2.19 & 2.36 \\
\hline Staten Island & 1.56 & 1.82 & 1.90 \\
\hline High Baseline Math & 1.60 & 1.91 & 2.01 \\
\hline Low Baseline Math & 1.53 & 1.93 & 2.10 \\
\hline Subsidized Lunch & 1.49 & 1.83 & 1.97 \\
\hline Bottom Neighborhood Income Quartile & 1.29 & 1.59 & 1.71 \\
\hline Top Neighborhood Income Quartile & 1.81 & 2.22 & 2.36 \\
\hline Special Education & 1.56 & 1.96 & 2.12 \\
\hline Limited English Proficient & 1.62 & 2.01 & 2.16 \\
\hline SHSAT Test-Takers & 1.60 & 1.94 & 2.05 \\
\hline \multicolumn{4}{|c|}{$\begin{array}{l}\text { 2003-04. } 11.6 \% \text { of applicants have the same application from truthful reporting as optimal reporting optimizing over a choice menu with the applicant's top } 10 \\
\text { choices. } 55.8 \% \text { of applicants have the same application from optimal reporting optimizing over a choice menu with the applicant's top } 10 \text { choices and the } \\
\text { applicant's top } 15 \text { choices. } 75.5 \% \text { of applicants have the same application from optimal reporting optimizing over a choice menu with the applicant's top } 15 \\
\text { choices and the applicant's top } 20 \text { choices. }\end{array}$} \\
\hline
\end{tabular}



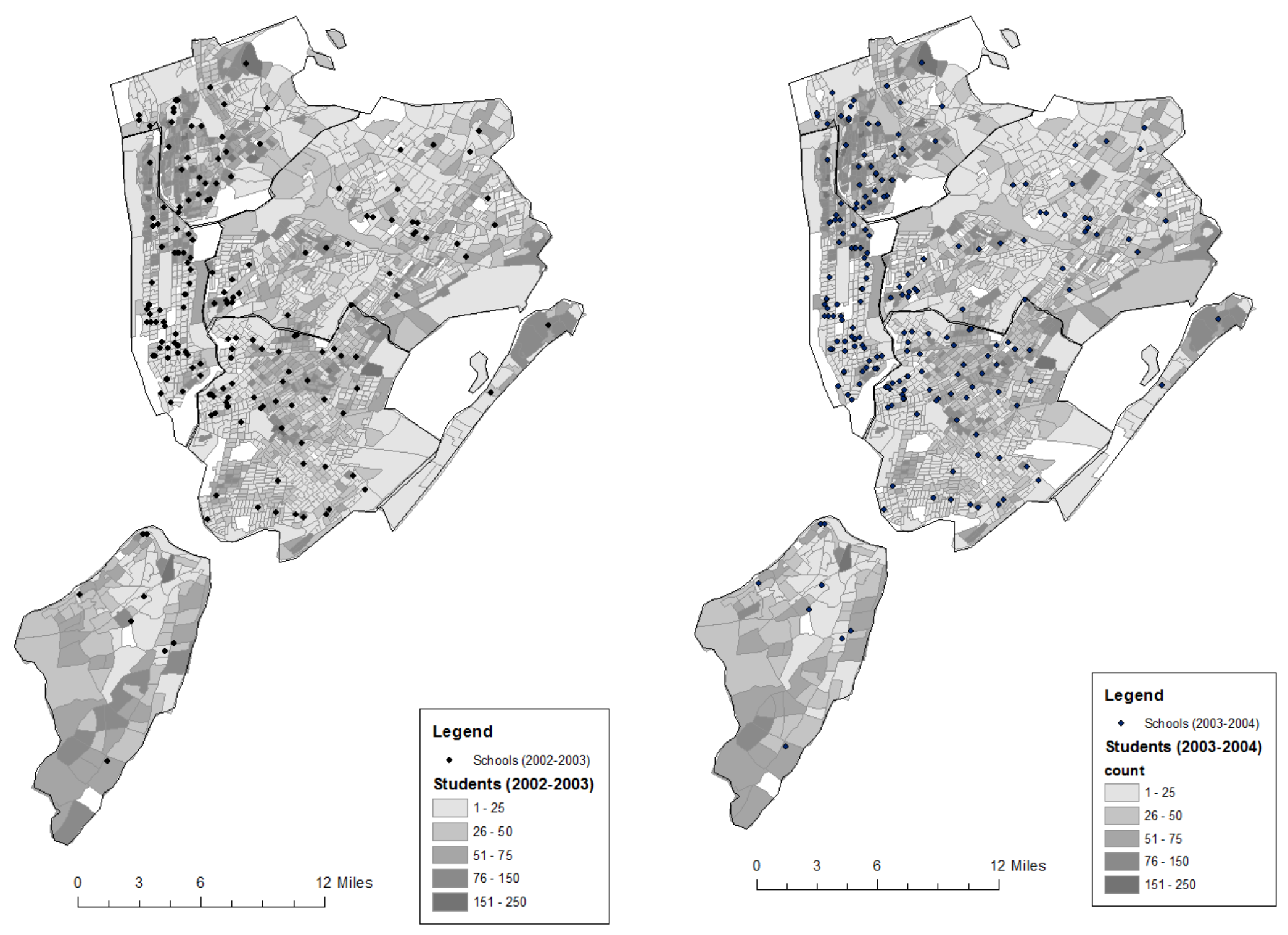

Figure 1. School Locations and Students by New York City Census Tract in 2002-03 and 2003-04 


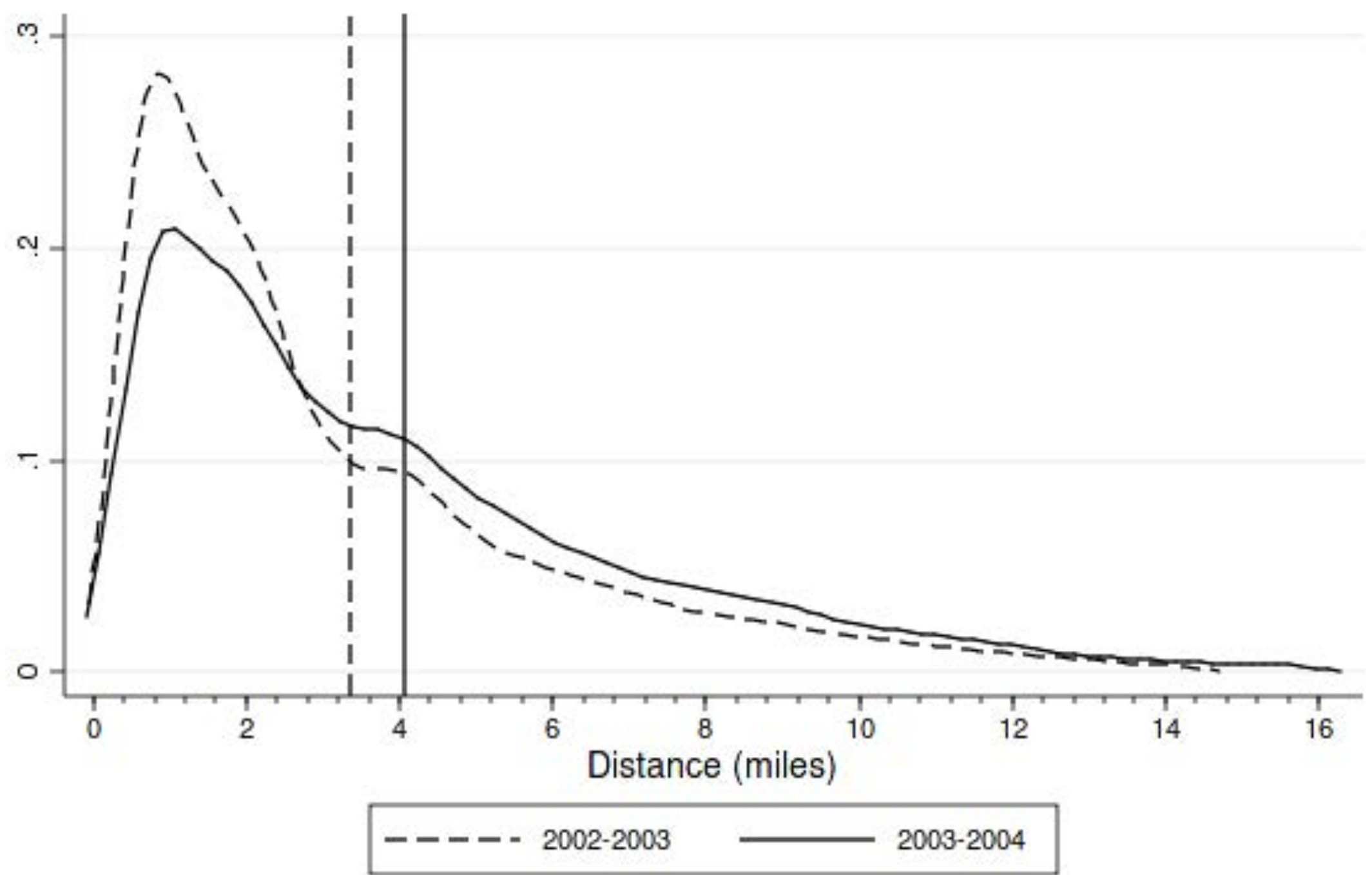

Figure 2. Distribution of Distance to Assigned School in Uncoordinated (2002-03) and Coordinated (2003-04) Mechanism

Mean (median) travel distance is 3.36 (2.25) miles in 2002-03 and 4.05 (3.04) miles in 2003-04. Top and bottom 1\% are not shown in figure. Line fit from Gaussian kernel with bandwidth chosen to minimize mean integrated squared error using STATA's kdensity command. 


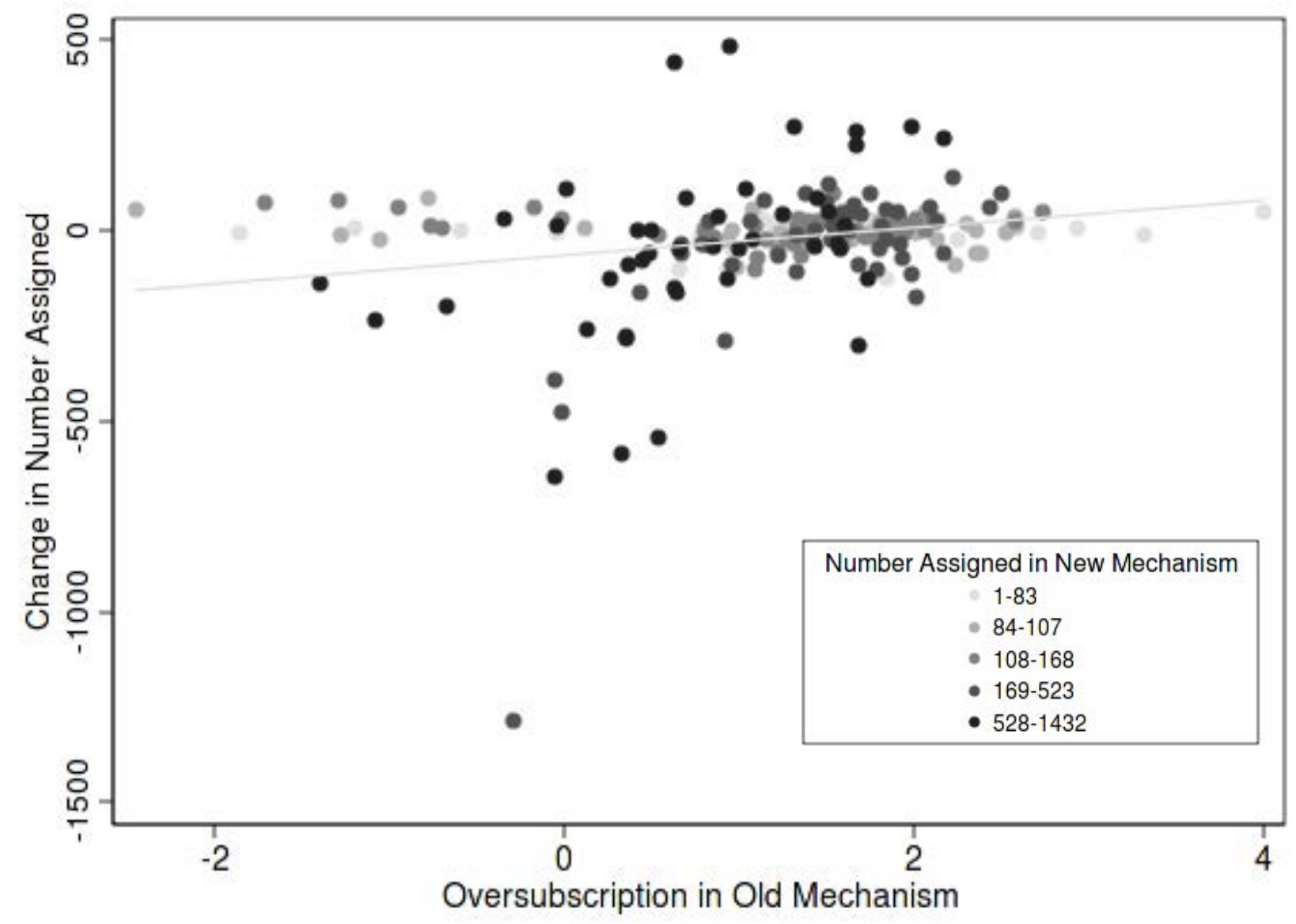

Figure 3. Change in Number Assigned by Oversubscription in Uncoordinated Mechanism

The figure shows the change in the number of students assigned to the school in the new mechanism minus the old mechanism (on the vertical axis) compared to oversubscription in the uncoordinated mechanism (on the horizontal axis). Oversubscription is measured as the log of the number of applications divided by the number assigned to the program. 


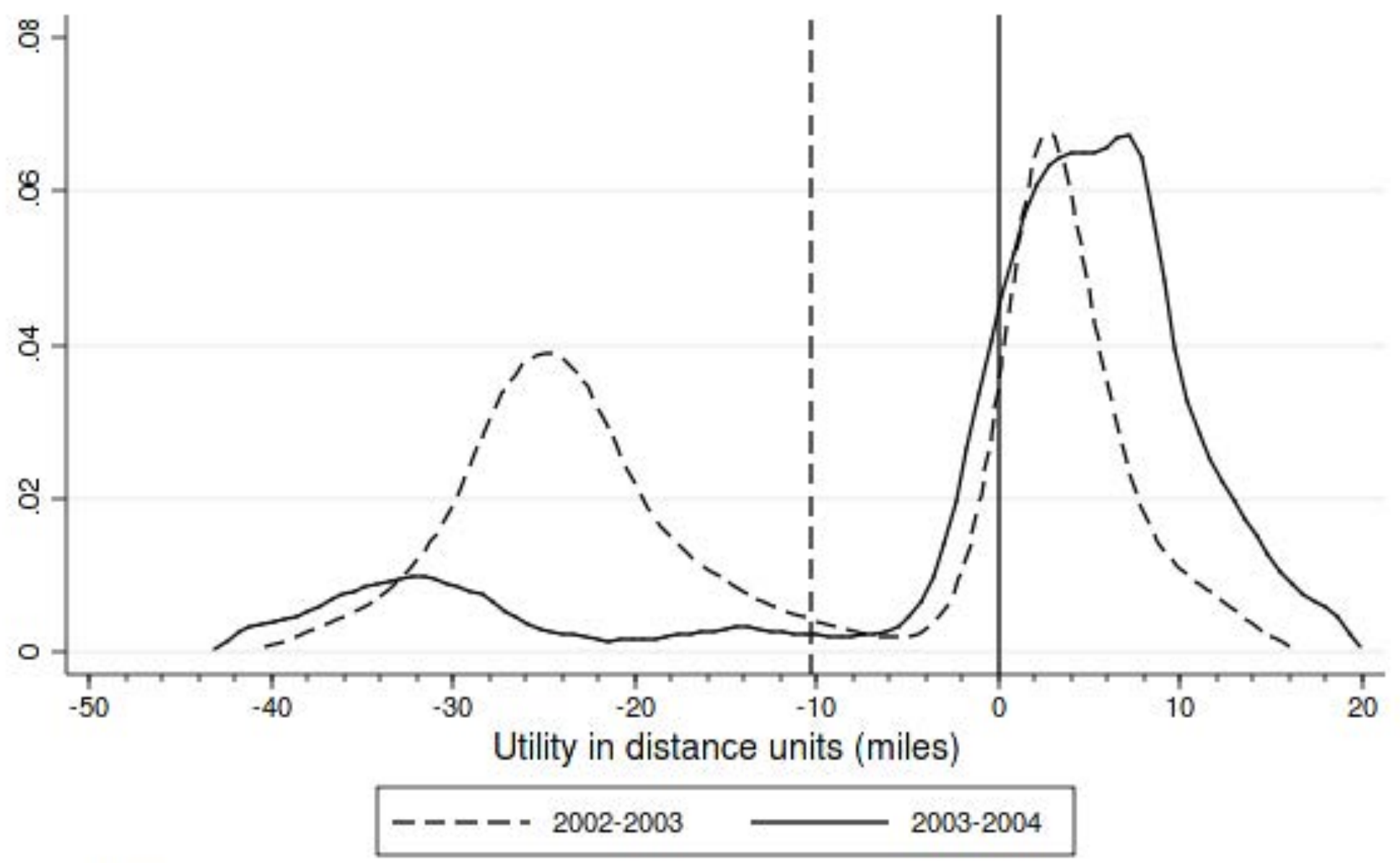

Figure 4. Student Welfare from Uncoordinated and Coordinated Mechanism

Distribution of utility (measured in distance units) from assignment based estimates in column 3 of Table A1 with mean utility in 2003-04 normalized to 0 . Top and bottom 1\% are not shown in figure. Line fit from Gaussian kernel with bandwidth chosen to minimize mean integrated squared error using STATA's kdensity command. 


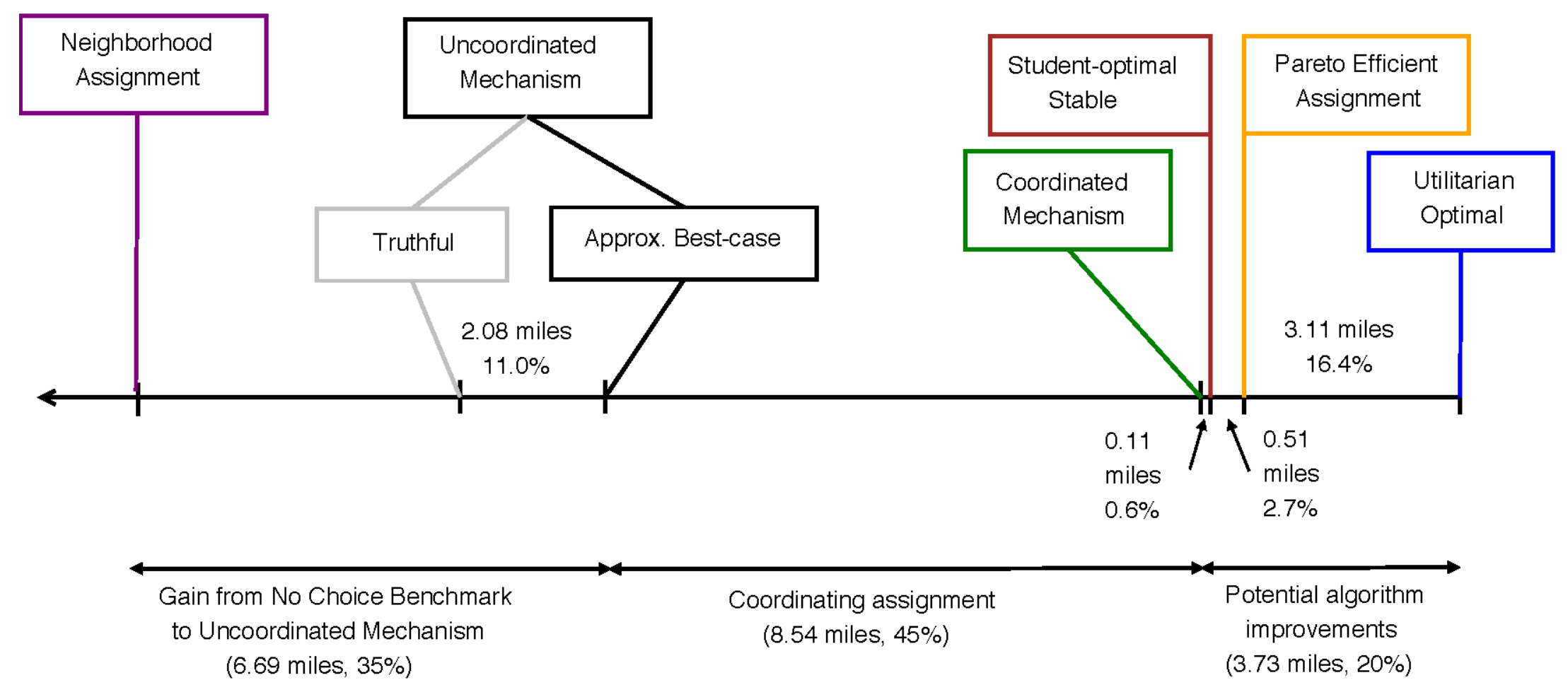

Figure 5. Coordinating Assignments vs. Algorithm Improvements 


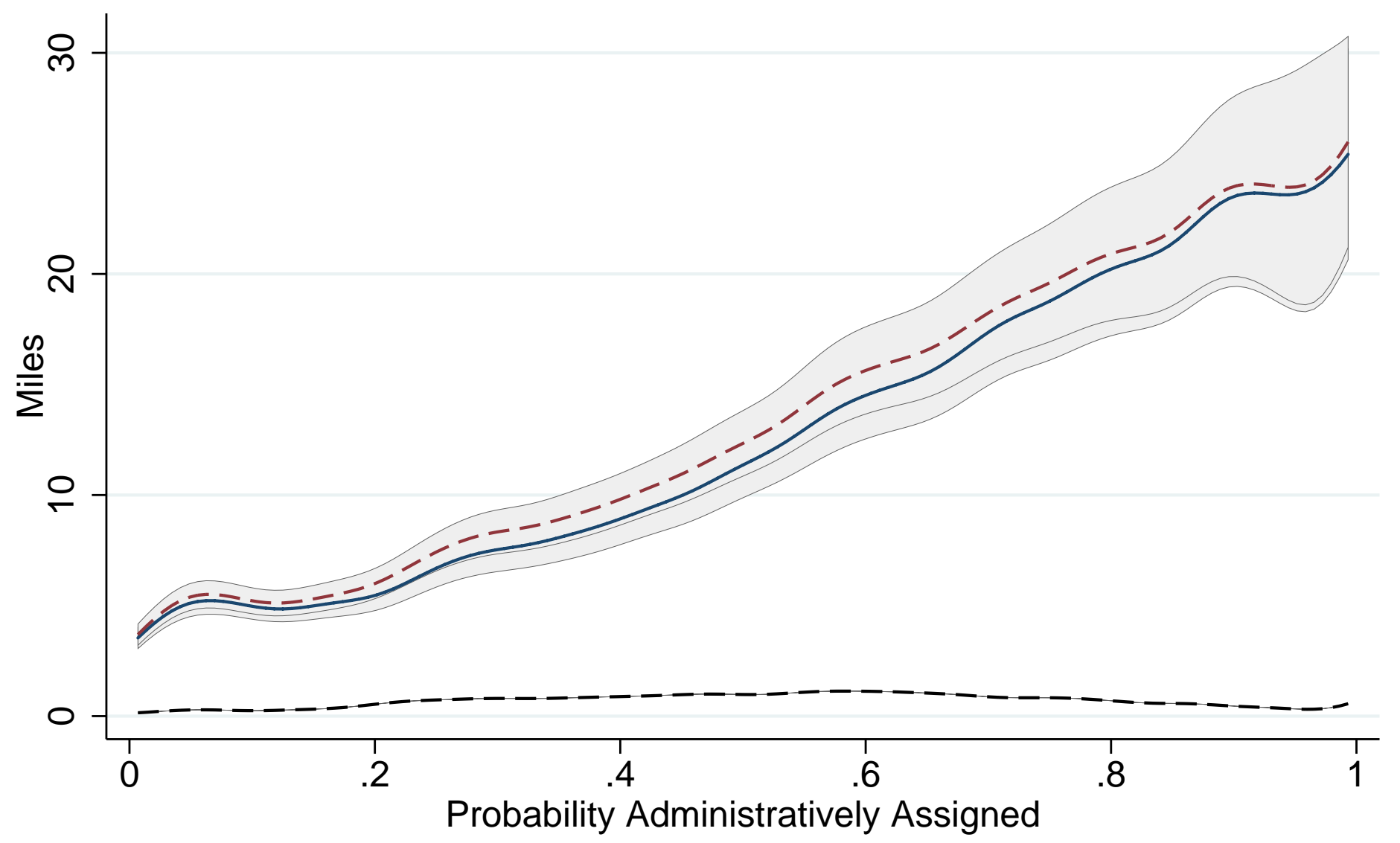

\begin{tabular}{|c|c|}
\hline$-\Delta$ Utility (incl. distance) & $----\Delta$ Utility (net distance) \\
\hline - - - $\Delta$ Distance & 95\% Confidence Interval \\
\hline
\end{tabular}

\section{Figure 6. Change in Student Welfare by Propensity to be Administratively Assigned in the Uncoordinated Mechanism}

Probability of administrative assignment estimated from probit of administrative assignment indicator on student census tract dummies and all student characteristics in the demand model except for distance in the uncoordinated mechanism. If student lives in a tract where either all or no students are administratively assigned, all students from those tracts are coded as administratively assigned. For a grid of points of administrative assignment propensity, we plot the difference between local linear regression fits of utility including distance and net of distance from coordinated and uncoordinated mechanism computed as in Table 9. Bandwidth is twice STATA's kdensity optimal bandwidth. Standard errors constructed using 100 draws of parameter values taken from the posterior distribution and re-estimated utility distributions. For each draw of the parameter, we updated $\xi$ and obtained utility draws consistent with observed rank-ordered data using a Gibbs' sampler. Programs that are not ranked by anyone are assigned a draw of $\xi$ from its unconditional distribution. 


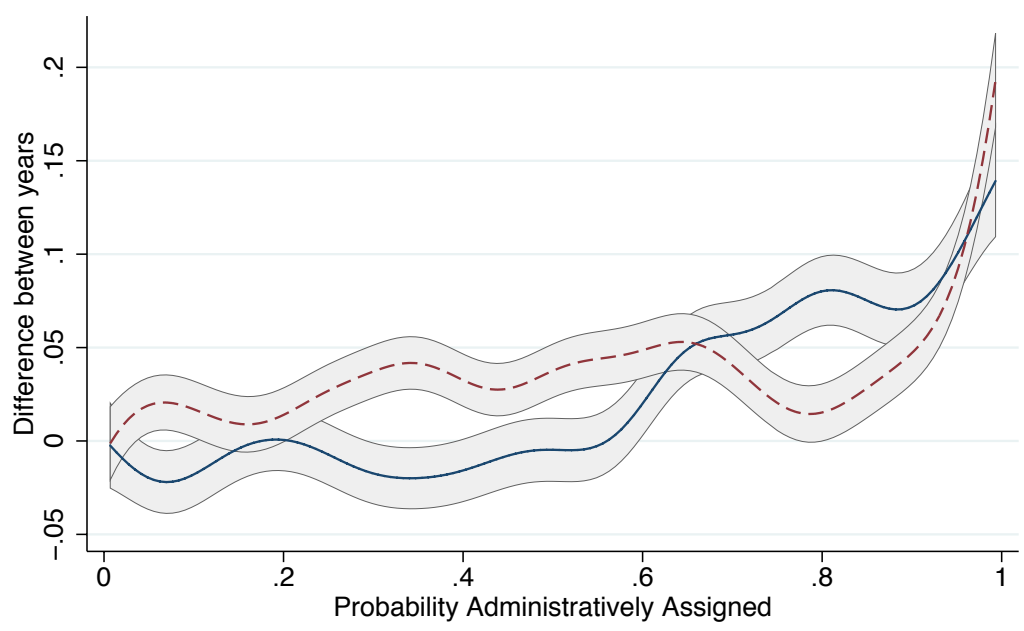

$\Delta$ Regents Math

95\% Confidence Interval

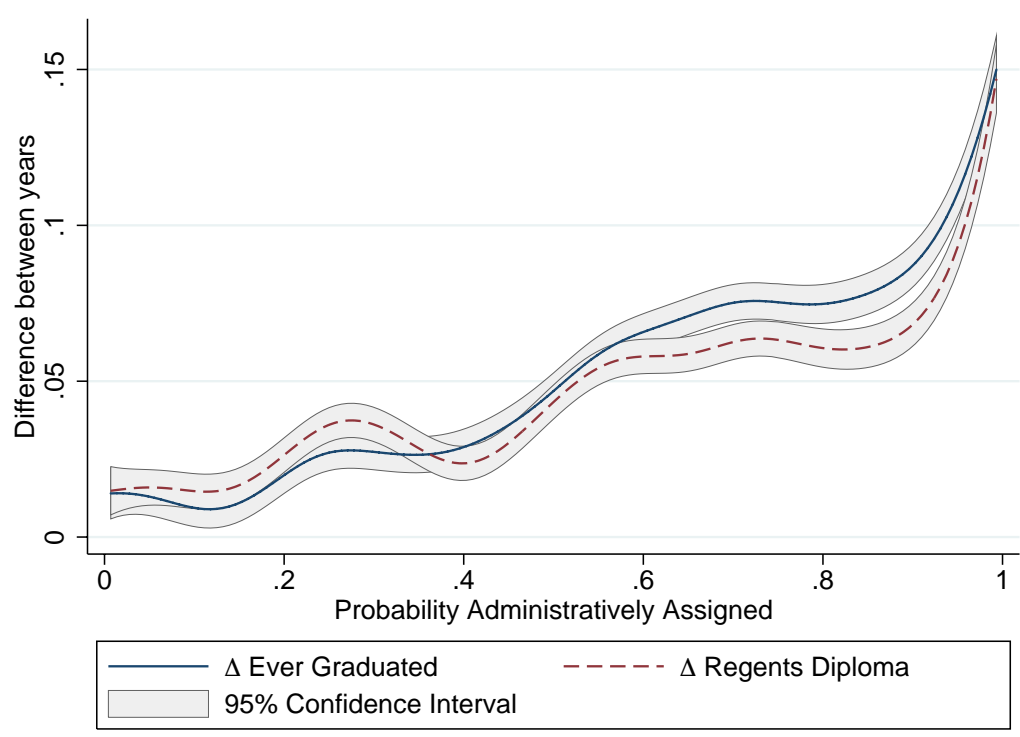

Figure 7. Change in Student Achievement and Graduation by Propensity to be Administratively Assigned in the Uncoordinated Mechanism

Probability of administrative assignment estimated from probit of administrative assignment indicator on student census tract dummies and all student characteristics in the demand model except for distance in uncoordinated mechanism. If student lives in a tract where either all or no students are administratively assigned, all students from those tracts are coded as administratively assigned. For a grid of points of administrative assignment propensity, we plot the difference between local linear regression fits of Regents Math, English, and graduation outcomes from coordinated and uncoordinated mechanisms. Bandwidth is twice STATA's kdensity optimal bandwidth. Data appendix contains details on Regents and graduation outcomes. 


\section{References}

AbdulkadiroĞlu, A., J. Angrist, and P. Pathak (2014): "The Elite Illusion: Achievement Effects at Boston and New York Exam Schools," Econometrica, 82(1), 137-196.

AbdulkadiroĞlu, A., J. D. Angrist, S. M. Dynarski, T. J. Kane, and P. A. Pathak (2011): "Accountability and Flexibility in Public Schools: Evidence from Boston's Charters and Pilots," Quarterly Journal of Economics, 126(2), 699-748.

AbdulkadiroĞlu, A., Y.-K. Che, P. Pathak, A. Roth, and O. Tercieux (2017): "Minimizing Justified Envy in School Choice: The Design of New Orleans OneApp," NBER Working Paper Working Paper 23265.

AbdulkadiroĞlu, A., Y.-K. Che, and Y. Yasuda (2015): "Expanding "Choice" in School Choice," American Economic Journal: Microeconomics, 7(1), 1-42.

AbdulkadiroĞlu, A., P. A. Pathak, and A. E. Roth (2005): "The New York City High School Match," American Economic Review, Papers and Proceedings, 95(2), 364-367.

(2009): "Strategy-proofness versus Efficiency in Matching with Indifferences: Redesigning the New York City High School Match," American Economic Review, 99(5), 1954-1978.

AbdulkadiroĞlu, A., P. A. Pathak, A. E. Roth, and T. Sönmez (2006): "Changing the Boston Public School Mechanism: Strategy-proofness as Equal Access," NBER Working paper, 11965.

AbdulkadiroĞLu, A., And T. Sönmez (2003): "School Choice: A Mechanism Design Approach," American Economic Review, 93(3), 729-747.

AbulkadiroĞlu, A., W. Hu, and P. A. Pathak (2013): "Small High Schools and Student Achievement: Lottery-Based Evidence from New York City," NBER Working Paper, 19576.

Agarwal, N., And P. Somaini (2014): "Demand Analysis using Strategic Reports: An Application to a School Choice Mechanism," NBER Working Paper, 20775.

AJAYI, K. (2017): "School Choice and Educational Mobility: Lessons from Secondary School Applications in Ghana," Unpublished working paper, Boston University.

Arvidsson, T. S., N. Fruchter, and C. Mokhtar (2013): "Over the Counter, Under the Radar: Inequitably Distributing New York City's Late-Enrolling High School Students," Annenberg Institute for School Reform at Brown University, Available at: http://annenberginstitute.org/publication/over-counter-under-radar-inequitablydistributing-new-york-city\%E2\%80\%99s-late-enrolling-high-sc, Last accessed: October 2013.

Balinski, M., And T. Sönmez (1999): "A Tale of Two Mechanisms: Student Placement," Journal of Economic Theory, 84, 73-94. 
Berry, S., J. Levinsohn, and A. Pakes (2004): "Differentiated Products Demand Systems from a Combination of Micro and Macro Data: The New Car Market," Journal of Political Economy, 112(1), 68-105.

Bogomolnaia, A., And H. Moulin (2001): "A New Solution to the Random Assignment Problem," Journal of Economic Theory, 100, 295-328.

Briesch, R., P. Chintagunta, and R. Matzkin (2002): "Semiparametric Estimation of Brand Choice Behavior," Journal of the American Statistical Association, 97, 973-982.

Budish, E., And E. Cantillon (2012): "The Multi-Unit Assignment Problem: Theory and Evidence from Course Allocation at Harvard," American Economic Review, 102(5), 2237-2271.

Budish, E., Y.-K. Che, F. Kojima, and P. Milgrom (2013): "Designing Random Allocation Mechanisms: Theory and Applications," American Economic Review, 103(2), 585-623.

Burgess, S., E. Greaves, A. Vignoles, and D. Wilson (2015): "What Parents Want: School Preferences and School Choice," Economic Journal, 125(587), 1262-1289.

Calsamiglia, C., C. Fu, and M. Guell (2014): "Structural Estimation of a Model of School Choices: the Boston Mechanism vs. Its Alternatives," Unpublished paper, UAB.

Calsamiglia, C., G. Haeringer, and F. Kluin (2010): "Constrained School Choice: An Experimental Study," American Economic Review, 100(4), 1860-1874.

Chen, Y., And T. Sönmez (2006): "School Choice: an Experimental Study," Journal of Economic Theory, 127, 202-231.

Dee, T. S., B. A. Jacob, J. McCrary, and J. Rockoff (2016): "The Causes and Consequences of Test Score Manipulation Evidence from the New York Regents Examination," NBER Working Paper 22165.

Deming, D. J., J. S. Hastings, T. J. Kane, and D. O. Staiger (2014): "School Choice, School Quality and Postsecondary Attainment," American Economic Review, 104(3), 9911013.

DOE (2002): "Directory of the New York City Public High Schools: 2002-2003," New York City Department of Education.

Dubins, L. E., And D. A. Freedman (1981): "Machiavelli and the Gale-Shapley algorithm," American Mathematical Monthly, 88, 485-494.

Ekmekci, M., And M. B. Yenmez (2016): "Integrating Schools for Centralized Assignment," Working paper, Boston College.

Epple, D., and R. Romano (1998): "Competition Between Private and Public Schools, Vouchers, and Peer Group Effects," American Economic Review, 88(1), 33-62. 
Erdil, A., And H. Ergin (2008): "What's the Matter with Tie-Breaking? Improving Efficiency in School Choice," American Economic Review, 98(3), 669-689.

Fack, G., J. Grenet, and Y. He (2015): "Beyond Truth-telling: Preference Estimation with Centralized School Choice," Working paper, Rice University.

Fox, J. C. (2015): "Plan would simplify Boston public school enrollments," Boston Globe, Metro Section, September 17.

Gale, D., And L. S. Shapley (1962): "College Admissions and the Stability of Marriage," American Mathematical Monthly, 69, 9-15.

Gelman, A., And D. Rubin (1992): "Inference from Iterative Simulation Using Multiple Sequences," Statistical Science, 7(4), 457-472.

Gendar, A. (2000): "Simpler HS Entry Eyed Ed Board Aims to Trim Selection Process, Improve Schools," New York Daily News, October 21.

Haeringer, G., And F. Klijn (2009): "Constrained School Choice," Journal of Economic Theory, 144(5), 1921-1947.

Hastings, J., T. J. Kane, and D. O. Staiger (2009): "Heterogenous Preferences and the Efficacy of Public School Choice," Working paper, Yale University.

Hastings, J., and J. M. Weinstein (2008): "Information, School Choice and Academic Achievement: Evidence from Two Experiments," Quarterly Journal of Economics, 123(4), 1373-1414.

He, Y. (2012): "Gaming the Boston Mechanism in Beijing," Unpublished mimeo, Toulouse.

He, Y., A. Miralles, M. Pycia, and J. Yan (2015): "A Psuedo-Market Approach to Allocation with Priorities," Working paper, UCLA.

Hemphill, C. (2007): New York City's Best Public High Schools: A Parent's Guide, Third Edition. Teachers College Press.

Hemphill, C., And K. Nauer (2009): "The New Marketplace: How Small-School Reforms and School Choice have Reshaped New York City's High Schools," Center for New York City Affairs, Milano the New School for Management and Urban Policy.

Herszenhorn, D. M. (2004): "Council Members See Flaws in School-Admissions Plan," New York Times, Metropolitan Desk, November 19.

Hoxby, C. (2003): "School Choice and School Productivity (Or, Could School Choice be a Rising Tide that Lifts All Boats)," in The Economics of School Choice, ed. by C. Hoxby. Chicago: University of Chicago Press.

Hwang, S. I. M. (2014): "A Robust Redesign of High School Match," University of Chicago, Working Paper. 
IChimura, H., And T. S. Thompson (1998): "Maximum Likelihood Estimation of a Binary Choice Model with Random Coefficients of Unknown Distribution," Journal of Econometrics, 86(2), 269-295.

Jacob, B., And L. Lefgren (2007): "What Do Parents Value in Education? An Empirical Investigation of Parents' Revealed Preferences for Teachers," Quarterly Journal of Economics, 122(4), 1603-1637.

Kapor, A., C. Neilson, and S. Zimmerman (2016): "Heterogeneous Beliefs and School Choice," Working paper, Princeton University.

Kerr, P. (2003): "Parents Perplexed by High School Admissions Rule: Reply," New York Times, November 3.

Kesten, O. (2010): "School Choice with Consent," Quarterly Journal of Economics, 125(3), $1297-1348$.

Kesten, O., and M. Kurino (2012): "On the (im)possibility of improving upon the studentproposing deferred acceptance mechanism," WZB Discussion Paper SP II 2012-202.

Klemperer, P. (2002): "What Really Matters in Auction Design," Journal of Economic Perspectives, 16(1), 169-189.

Kojima, F., and P. A. Pathak (2009): "Incentives and Stability in Large Two-Sided Matching Markets," American Economic Review, 99(3), 608-627.

LEWBeL, A. (2000): "Semiparametric qualitative response model estimation with unknown heteroscedasticity or instrumental variables," Journal of Econometrics, 97(1), 145-177.

Milgrom, P. R. (2004): Putting Auction Theory to Work. Cambridge University Press, Cambridge.

NARITA, Y. (2016): "Match or Mismatch: Learning and Inertia in School Choice," Working paper, MIT.

NeIlson, C. (2014): "Targeted Vouchers, Competition among Schools and the Academic Achievement of Poor Students," Unpublished working paper, Yale University.

Niederle, M., And A. E. Roth (2003): "Unraveling reduced mobility in a labor market: Gastroenterology with and without a centralized match," Journal of Political Economy, 111(6), $1342-1352$.

Nobel (2012): "Scientific Background on the Svergies Riksbank Prize in Economic Sciences in Memory of Alfred Nobel: Stable Allocations and the Practice of Market Design," Compiled by the Economic Sciences Prize Committee of the Royal Swedish Academy of Sciences.

Pathak, P. A., And P. Shi (2014): "Demand Modeling, Forecasting, and Counterfactuals, Part I," NBER Working Paper, 19859. 
Pathak, P. A., And T. Sönmez (2008): "Leveling the Playing Field: Sincere and Sophisticated Players in the Boston Mechanism," American Economic Review, 98(4), 1636-1652.

Rossi, P. E., G. M. Allenby, and R. McCulloch (2005): Bayesian Statistics and Marketing. Wiley.

Rossi, P. E., R. E. McCulloch, and G. M. Allenby (1996): "The Value of Purchase History Data in Target Marketing," Marketing Science, 15(4), 321-340.

Roth, A. E. (1982): "The Economics of Matching: Stability and Incentives," Mathematics of Operations Research, 7, 617-628.

(2015): Who Gets What - And Why: The New Economics of Matchmaking and Market Design. Eamon Dolan.

Roth, A. E., And X. Xing (1997): "Turnaround Time and Bottlenecks in Market Clearing: Decentralized Matching in the Market for Clinical Psychologists," Journal of Political Economy, 105(2), 284-329.

Rothstein, J. (2006): "Good Principals or Good Peers: Parental Valuation of School Characteristics, Tiebout Equilibrium, and the Incentive Effects of Competition Among Jurisdictions," American Economic Review, 96(4), 1333-1350.

Shapley, L., And H. Scarf (1974): "On Cores and Indivisibility," Journal of Mathematical Economics, 1, 23-28.

Sönmez, T. (1997): "Manipulation via Capacities in Two-Sided Matching Markets," Journal of Economic Theory, 77, 197-204.

(2013): "Bidding for Army Career Specialties: Improving the ROTC Branching Mechanism," Journal of Political Economy, 121(1), 186-219.

Train, K. (2009): Discrete Choice Methods with Simulation. Cambridge University Press.

Tullis, T. (2014): "How Game Theory Helped Improve New York City's High School Application Process," NY Times, December 5.

Urquiola, M. (2005): "Does school choice lead to sorting? Evidence from Tiebout variation," American Economic Review, 95(4), 1310-1326.

VAN Der VaArT, A. W. (2000): Asymptotic Statistics. Cambridge Series in Statistical and Probabilistic Mathematics.

VAznis, J. (2013): "Barros Proposes Single Application for City, Charter Schools," Boston Globe, Education Desk, June 5.

Walters, C. (2014): "The Demand for Effective Charter Schools," NBER Working Paper 20640. 
Table A1. Model Fit of Correlation between Choices across Demand Specifications

\begin{tabular}{|c|c|c|c|c|c|c|c|c|}
\hline \multirow[b]{3}{*}{ School Characteristic } & \multirow{2}{*}{\multicolumn{2}{|c|}{ Correlation between }} & \multicolumn{3}{|c|}{$\begin{array}{c}\text { Coordinated Mechanism (2003-04) } \\
\text { Specification }\end{array}$} & \multicolumn{3}{|c|}{$\begin{array}{c}\text { Coordinated Mechanism (2004-05) } \\
\text { Specification }\end{array}$} \\
\hline & & & & Main & No Student & & Main & No Student \\
\hline & $\begin{array}{c}\text { Choice } \\
\text { (1) }\end{array}$ & $\begin{array}{c}\text { Choice } \\
\text { (2) }\end{array}$ & $\begin{array}{c}\text { Observed } \\
\text { (3) }\end{array}$ & $\begin{array}{c}\text { Specification } \\
(4)\end{array}$ & $\begin{array}{c}\text { Interactions } \\
\text { (5) }\end{array}$ & $\begin{array}{c}\text { Observed } \\
(6)\end{array}$ & $\begin{array}{c}\text { Specification } \\
(7)\end{array}$ & $\begin{array}{c}\text { Interactions } \\
\text { (8) }\end{array}$ \\
\hline \multirow[t]{3}{*}{ Distance } & 1 & 2 & 0.47 & 0.16 & 0.09 & 0.50 & 0.17 & 0.07 \\
\hline & 1 & 3 & 0.39 & 0.15 & 0.09 & 0.41 & 0.16 & 0.07 \\
\hline & 2 & 3 & 0.44 & 0.17 & 0.12 & 0.47 & 0.16 & 0.07 \\
\hline \multirow[t]{3}{*}{ High Math Performance } & 1 & 2 & 0.35 & 0.39 & 0.03 & 0.39 & 0.42 & 0.03 \\
\hline & 1 & 3 & 0.32 & 0.36 & 0.03 & 0.35 & 0.38 & 0.03 \\
\hline & 2 & 3 & 0.34 & 0.33 & 0.03 & 0.39 & 0.36 & 0.03 \\
\hline \multirow[t]{3}{*}{ Percent Free Lunch } & 1 & 2 & 0.61 & 0.49 & 0.30 & 0.66 & 0.49 & 0.34 \\
\hline & 1 & 3 & 0.54 & 0.46 & 0.28 & 0.60 & 0.47 & 0.33 \\
\hline & 2 & 3 & 0.55 & 0.43 & 0.26 & 0.62 & 0.45 & 0.31 \\
\hline \multirow[t]{3}{*}{ Percent White } & 1 & 2 & 0.55 & 0.55 & 0.29 & 0.60 & 0.56 & 0.37 \\
\hline & 1 & 3 & 0.47 & 0.52 & 0.26 & 0.54 & 0.54 & 0.36 \\
\hline & 2 & 3 & 0.48 & 0.48 & 0.24 & 0.56 & 0.51 & 0.35 \\
\hline \multirow[t]{3}{*}{ Size of 9th Grade } & 1 & 2 & 0.29 & 0.60 & 0.07 & 0.34 & 0.59 & 0.09 \\
\hline & 1 & 3 & 0.21 & 0.58 & 0.06 & 0.24 & 0.57 & 0.09 \\
\hline & 2 & 3 & 0.27 & 0.56 & 0.06 & 0.33 & 0.56 & 0.08 \\
\hline
\end{tabular}

Notes: Table reports the observed correlation between the school characteristic of the choice in column 1 with the choice in column 2 for the main specification (shown in column 3 of Table

7) and the specification with no student interactions (shown in column 1 of Table 7). 
Table A2. Welfare Comparisons for Alternative Demand Specifications

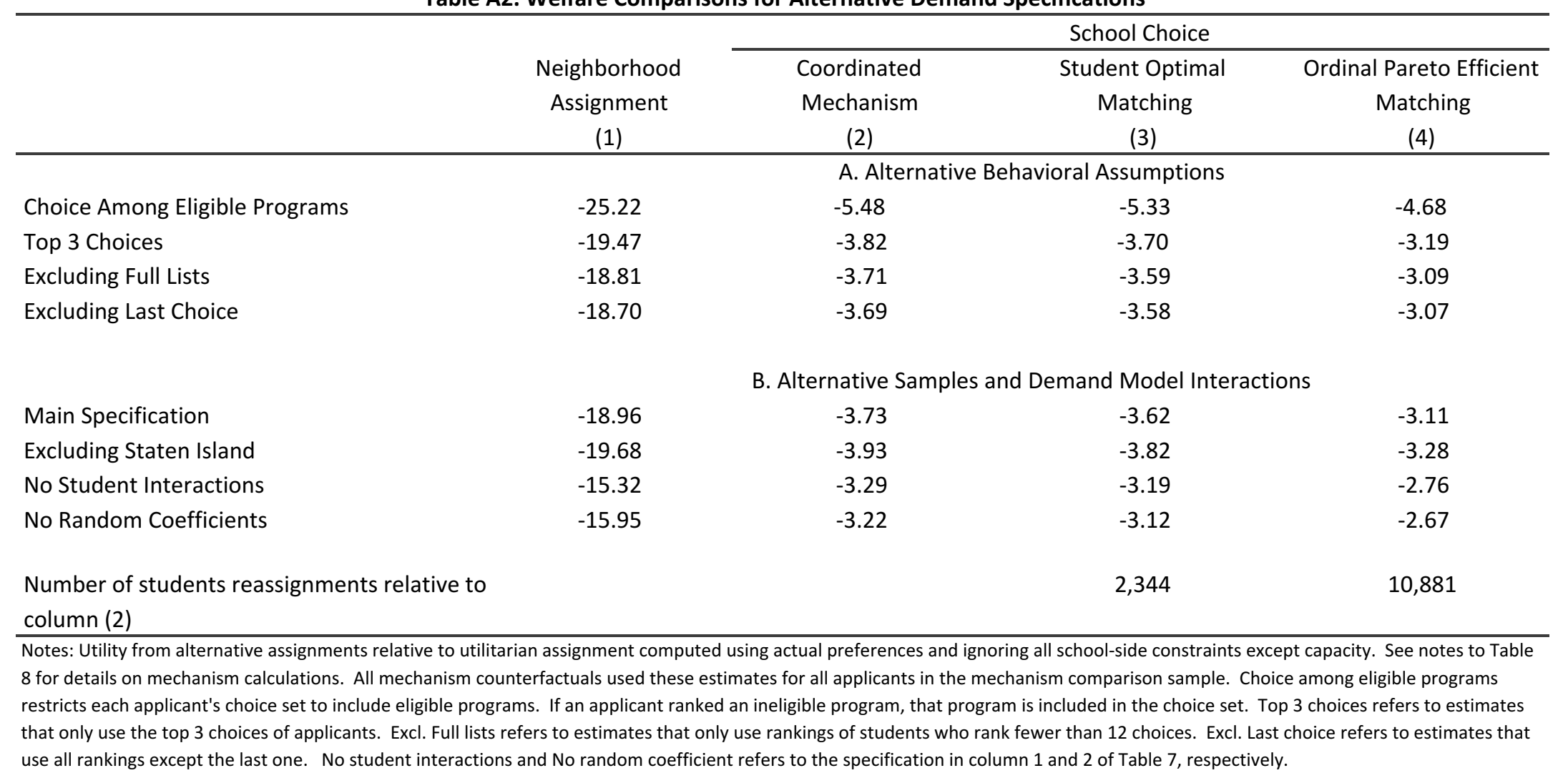


Table A3. Posterior Means of Preference Estimates for Alternative Demand Specifications

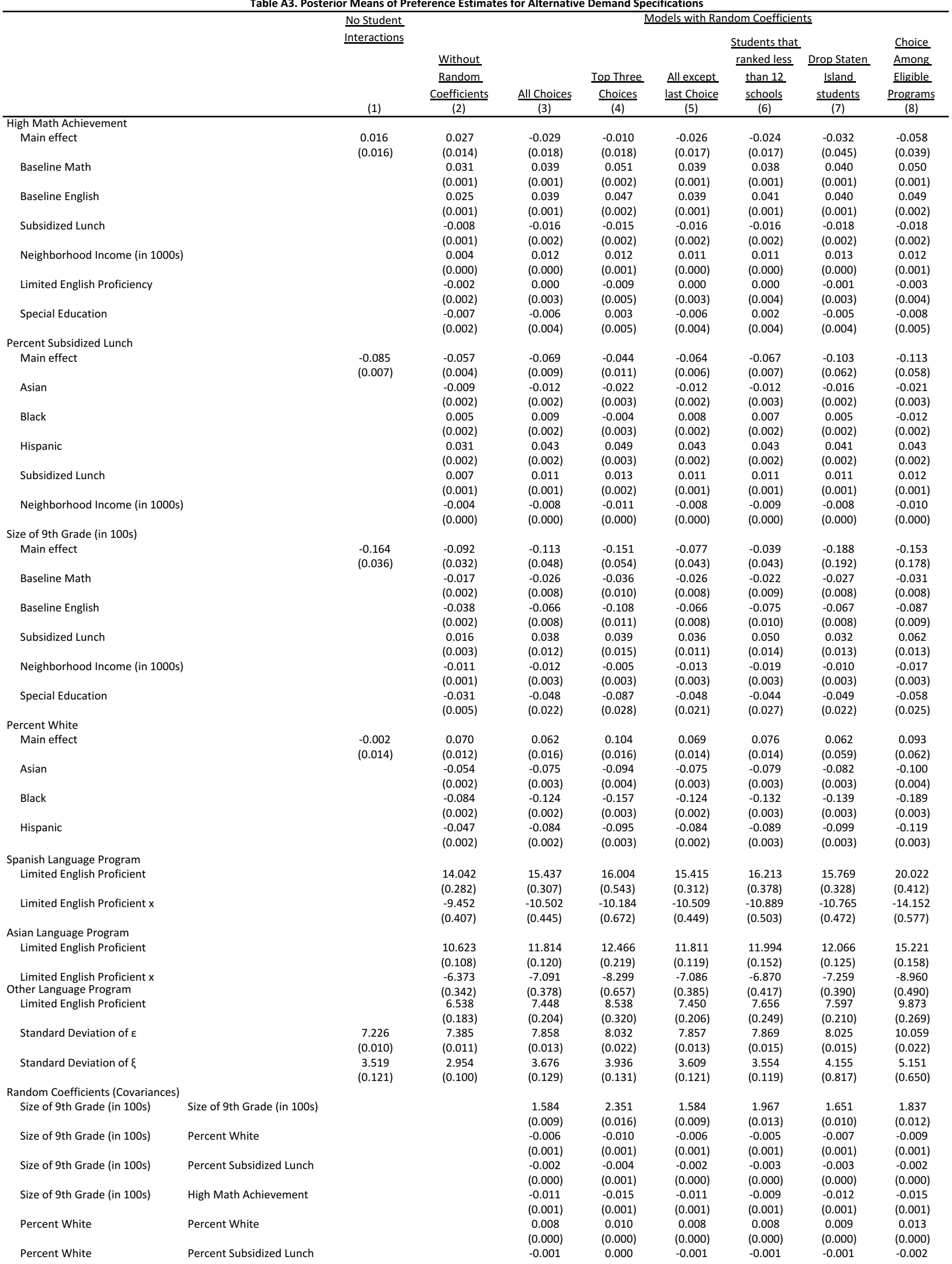




\begin{tabular}{|c|c|c|c|c|c|c|c|c|c|}
\hline & & & & $(0.000)$ & $(0.000)$ & $(0.000)$ & $(0.000)$ & $(0.000)$ & $(0.000)$ \\
\hline \multirow[t]{2}{*}{ Percent White } & \multirow{2}{*}{\multicolumn{3}{|c|}{ High Math Achievement }} & 0.005 & 0.006 & 0.005 & 0.004 & 0.005 & 0.007 \\
\hline & & & & $(0.000)$ & $(0.000)$ & $(0.000)$ & $(0.000)$ & $(0.000)$ & $(0.000)$ \\
\hline \multirow[t]{2}{*}{ Percent Subsidized Lunch } & \multirow{2}{*}{\multicolumn{3}{|c|}{ Percent Subsidized Lunch }} & 0.002 & 0.005 & 0.002 & 0.003 & 0.003 & 0.003 \\
\hline & & & & $(0.000)$ & $(0.000)$ & $(0.000)$ & $(0.000)$ & $(0.000)$ & $(0.000)$ \\
\hline \multirow[t]{2}{*}{ Percent Subsidized Lunch } & \multirow{2}{*}{\multicolumn{3}{|c|}{ High Math Achievement }} & 0.000 & 0.000 & 0.000 & 0.000 & 0.000 & -0.001 \\
\hline & & & & $(0.000)$ & $(0.000)$ & $(0.000)$ & $(0.000)$ & $(0.000)$ & $(0.000)$ \\
\hline \multirow[t]{2}{*}{ High Math Achievement } & \multirow{2}{*}{\multicolumn{3}{|c|}{ High Math Achievement }} & 0.016 & 0.021 & 0.016 & 0.016 & 0.017 & 0.022 \\
\hline & & & & $(0.000)$ & $(0.000)$ & $(0.000)$ & $(0.000)$ & $(0.000)$ & $(0.000)$ \\
\hline \multicolumn{4}{|l|}{ Program Type Dummies } & $x$ & $x$ & $x$ & $x$ & $x$ & $x$ \\
\hline \multicolumn{4}{|l|}{ Program Specialty Dummies } & $x$ & $x$ & $x$ & $x$ & $x$ & $x$ \\
\hline \multirow{2}{*}{\multicolumn{2}{|c|}{ Number of Students }} & 69907 & 69907 & 69907 & 69907 & 69907 & 55695 & 65518 & 69907 \\
\hline & & 542666 & 542666 & 542666 & 197245 & 55323 & 372122 & 530861 & 542666 \\
\hline
\end{tabular}

Notes: Estimates of demand system with submitted ranks over 497 program choices in 235 schools. All columns use all students. See Table 7 and Table A2 for additional details. 
a) Percent Subsidized lunch

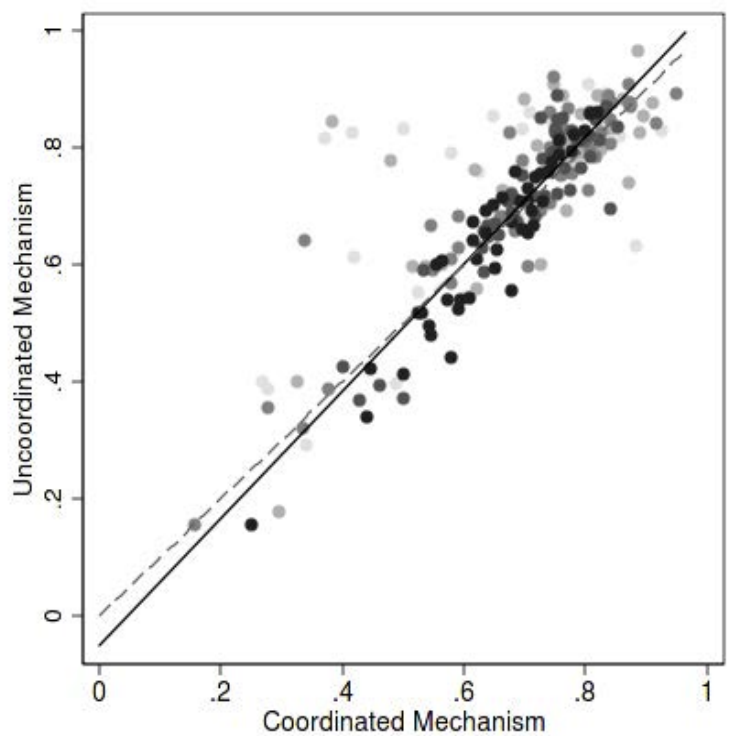

c) Baseline Math Standardized Score

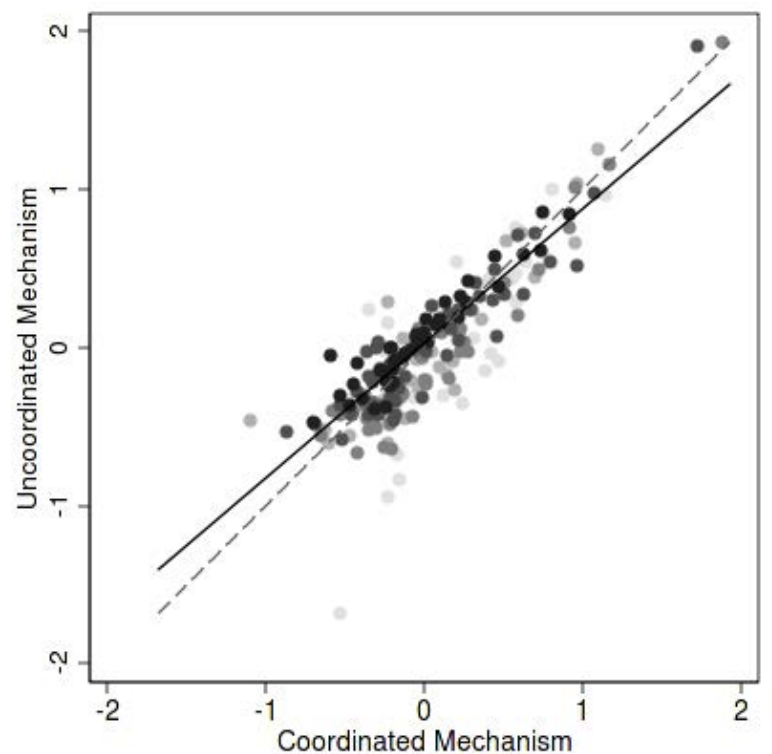

b) Percent white

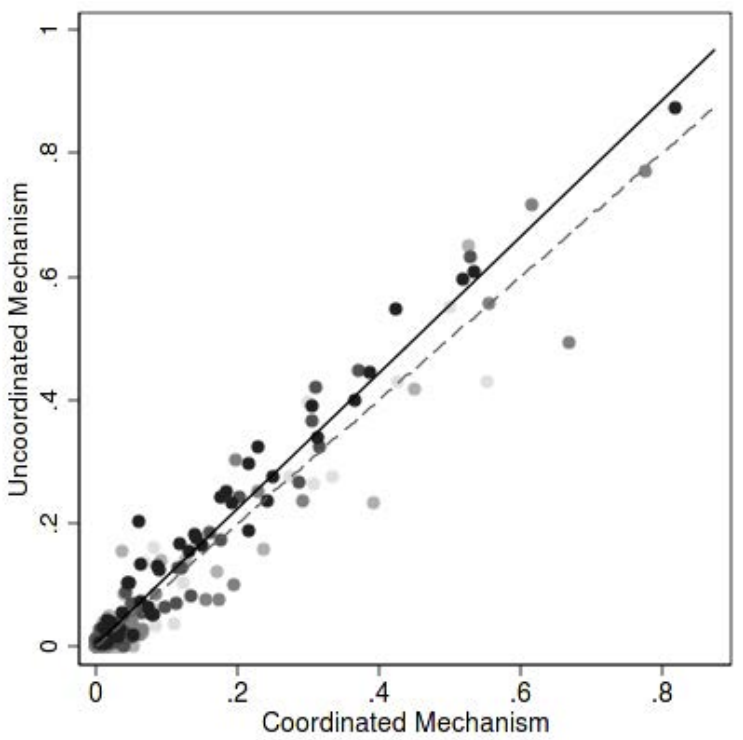

d) Distance

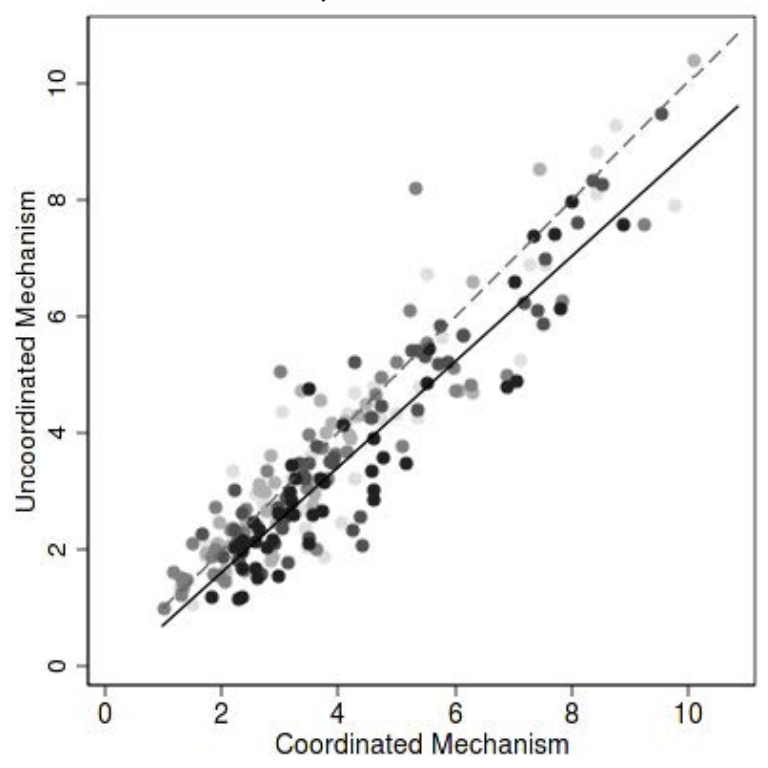

Number Assigned in New Mechanism $1-83$

- 84-107

- $108-168$

- $169-523$

- 528-1432

\section{Figure A1. Comparison of Characteristics of Enrolled Students at Each School between Uncoordinated and Coordinated Mechanism}

This figure reports school characteristics measured by the attributes of students enrolled at each school across mechanisms.

The dotted line is the 45 degree line; the solid line is the least squares line fit. 


\section{a) High Math Achievement}

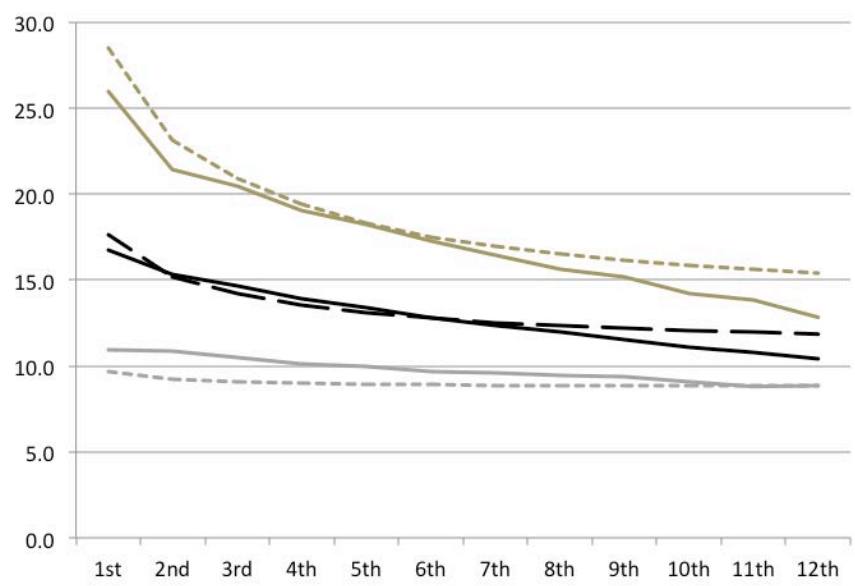

c) Percent White

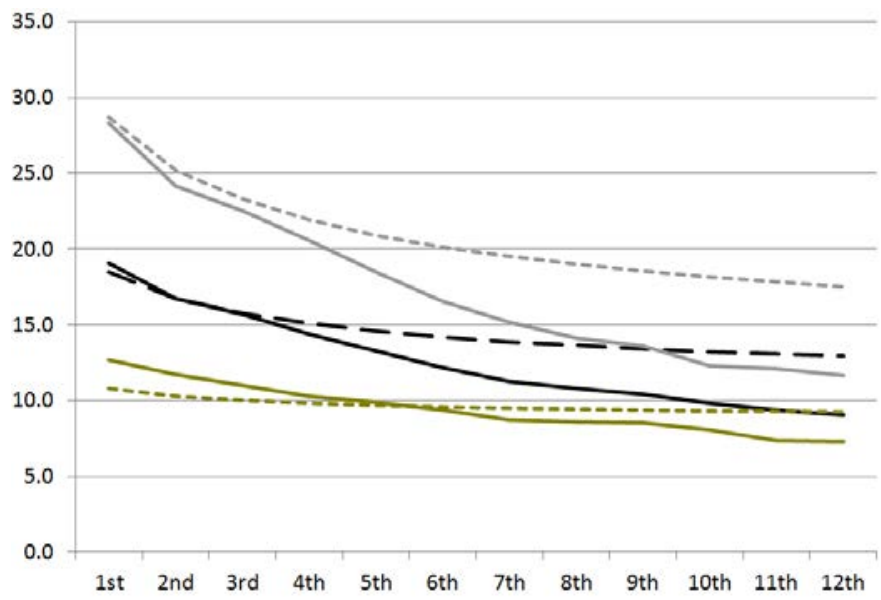

b) Percent Subsidized Lunch

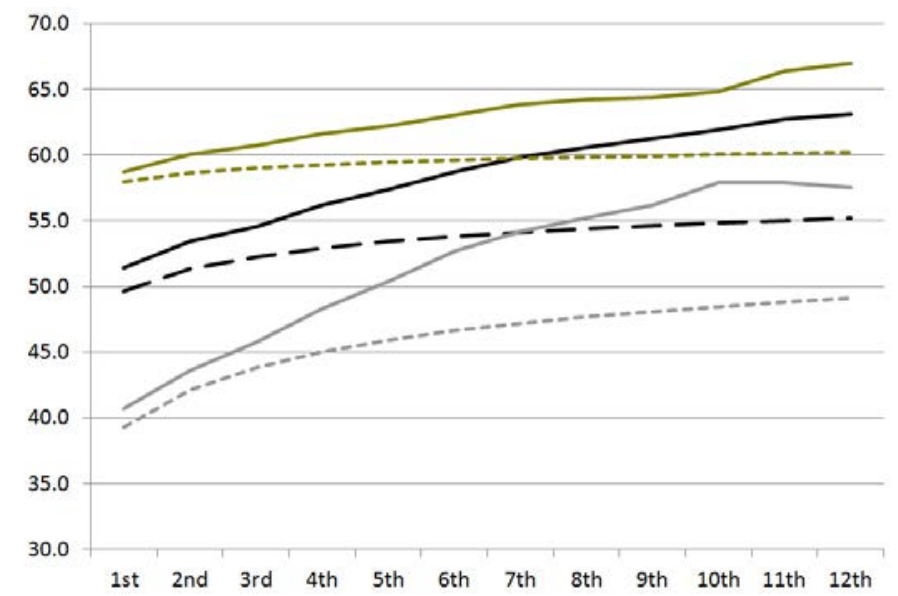

d) Distance

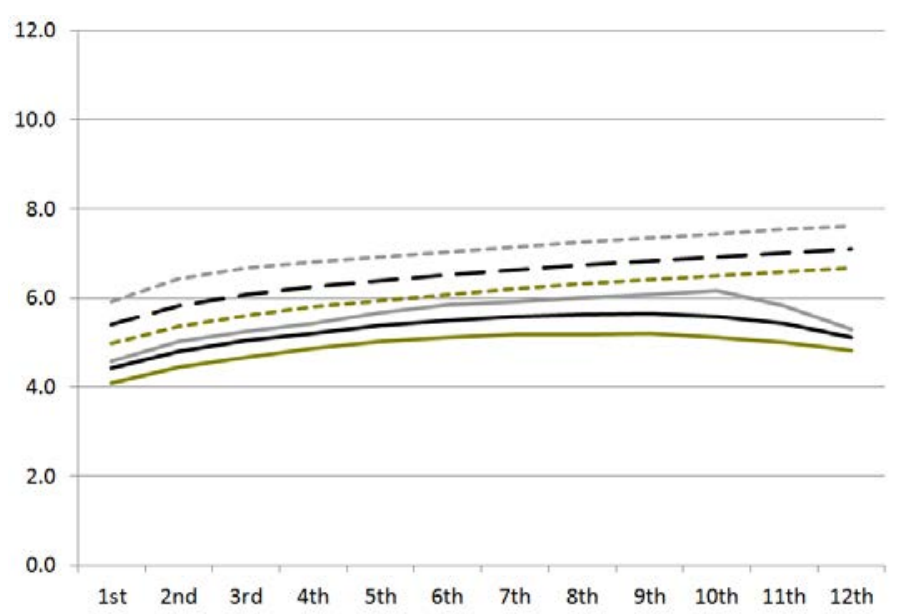

—observed

- Simulated

—observed for High Baseline

---.Simulated for High Baseline

—observed for Low Baseline

---Simulated for Low Baseline

\section{Figure A2. Model Fit}

This figure reports the observed and estimated school characteristics for different student ranked choices The estimates are from the main specification in column 3 of Table 7. 


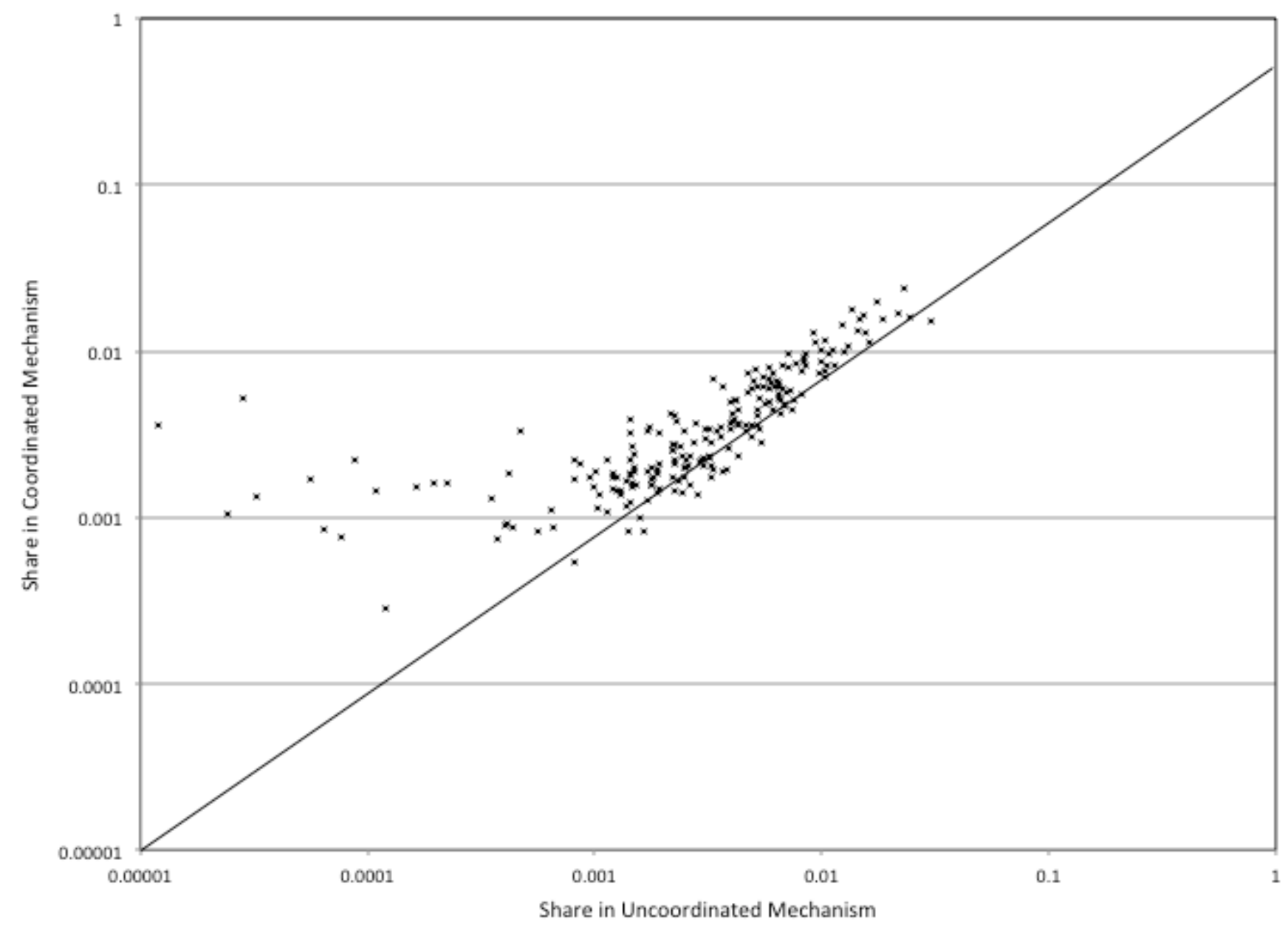

Figure A3. Comparison of School Market Shares between 2002-03 Uncoordinated Mechanism and 2003-04 Coordinated Mechanism

This figure plots school market shares defined as the count of applicants ranking a program at a given school divided by the total number of choices expressed for schools to which students can apply to in 2002-03 and 2003-04. Market shares are normalized within this set to sum to 1 . 


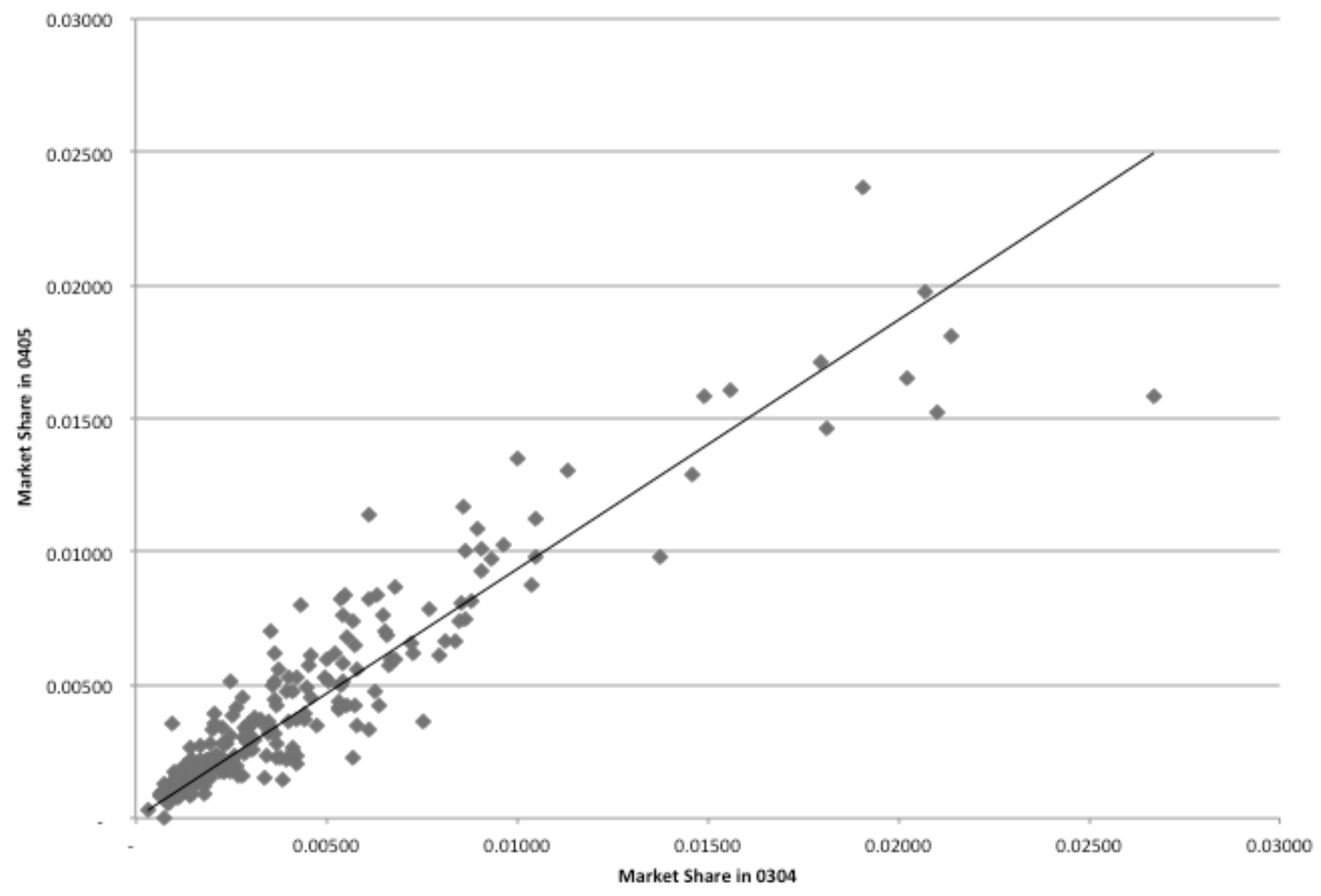

Figure A4. Comparison of School Market Shares between 2003-04 Coordinated Mechanism and 2004-05 Coordinated Mechanism

This figure plots school market shares defined as the count of applicants ranking a program at a given school divided by the total number of choices expressed for schools to which students can apply in 2003-04 and 2004-05. Market shares are normalized within this set to sum to 1 . The slope of the line fit is 0.93 and the $R 2$ is 0.86 . 


\section{Online Appendix for \\ "The Welfare Effects of Coordinated Assignment: \\ Evidence from the New York City High School Match"}

Atila Abdulkadiroğlu Nikhil Agarwal Parag A. Pathak

November 2016

\section{A Appendix: Computational (Not for Publication)}

The demand model is an ordered version of the model in Rossi, McCulloch, and Allenby (1996). We assume that the utility for student $i$ for program $j$ can be written as:

$$
\begin{aligned}
u_{i j} & =\delta_{j}+\sum_{l} \alpha^{l} z_{i}^{l} x_{j}^{l}+\sum_{k} \gamma_{i}^{k} x_{j}^{k}-d_{i j}+\varepsilon_{i j}, \\
\text { with } \quad \delta_{j} & =x_{j} \beta+\xi_{j} .
\end{aligned}
$$

We parametrize the random coefficients as follows:

$$
\gamma_{i} \sim \mathcal{N}\left(0, \Sigma_{\gamma}\right), \quad \xi_{j} \sim \mathcal{N}\left(0, \sigma_{\xi}^{2}\right), \quad \varepsilon_{i j} \sim \mathcal{N}\left(0, \sigma_{\varepsilon}^{2}\right)
$$

The priors for $\beta, \alpha, \Sigma_{\gamma}, \sigma_{\xi}^{2}$, and $\sigma_{\varepsilon}^{2}$ are as follows:

$$
\begin{gathered}
\beta \sim \mathcal{N}\left(0, \bar{\Sigma}_{\beta}\right), \quad \alpha \sim \mathcal{N}\left(0, \bar{\Sigma}_{\alpha}\right) \\
\Sigma_{\gamma} \sim \operatorname{IW}\left(\bar{\Sigma}_{\gamma}, \nu_{\gamma}\right), \quad \sigma_{\xi}^{2} \sim \operatorname{IW}\left(\bar{\sigma}_{\xi}^{2}, \nu_{\xi}\right), \quad \text { and } \quad \sigma_{\varepsilon}^{2} \sim \operatorname{IW}\left(\bar{\sigma}_{\varepsilon}^{2}, \nu_{\varepsilon}\right),
\end{gathered}
$$

where IW is the inverse Wishart distribution. Following Chapter 5 of Rossi, Allenby, and McCulloch (2005), we set diffuse priors as follows: the prior variances of $\beta$ and $\alpha$ are 100 times the identity matrix, and

$$
\begin{gathered}
\left(\bar{\Sigma}_{\gamma}, \nu_{\gamma}\right)=\left(\left(3+\operatorname{dim}\left(\gamma_{i}\right)\right) I_{\operatorname{dim}\left(\gamma_{i}\right)}, 3+\operatorname{dim}\left(\gamma_{i}\right)\right), \\
\left(\bar{\sigma}_{\xi}^{2}, \nu_{\xi}\right)=(1,2) \quad \text { and } \quad\left(\bar{\sigma}_{\varepsilon}^{2}, \nu_{\varepsilon}\right)=(3+J, 3+J),
\end{gathered}
$$

where $I_{k}$ is the identity matrix of dimension $k$.

The Gibbs sampler iterates through the following steps (where, for notational simplicity, we omit conditioning on the observed data and the priors). First, we iterate through the observed rank-ordered lists to update the values of $u_{i j}$. We then draw utilities for the unranked options by observing that their indirect utility must be at most the indirect utility of the lowest ranked option. This step can be written as

$$
u_{i j} \mid u_{i-j}, \mathbf{r}_{i}, \beta, \xi, \gamma_{i}, \alpha,
$$

where each simulation is from a (two-sided) truncated normal. 
Given the utilities, the posteriors of $\xi, \beta$ and $\alpha$ are multivariate normal distributions that can be computed as follows:

$$
\begin{array}{c|c}
\xi & u, \gamma, \beta, \alpha, \sigma_{\xi}^{2}, \\
\beta & u, \gamma, \xi, \alpha, \bar{\Sigma}_{\beta}, \\
\alpha & u, \gamma, \beta, \alpha, \bar{\Sigma}_{\alpha},
\end{array}
$$

where $u$ and $\gamma$ stack the utilities and random coefficients for all students. We then update the student-specific random coefficients:

$$
\gamma_{i} \mid u_{i}, \beta, \xi, \alpha, \Sigma_{\gamma}
$$

The priors and distribution of $\varepsilon_{i j}$ imply that a posterior is a multivariate normal distribution for each student. Finally, we sample from the posteriors $\sigma_{\varepsilon}^{2}\left|\varepsilon, \sigma_{\xi}^{2}\right| \xi$ and $\Sigma_{\gamma} \mid \gamma$, which are given by inverse Wishart distributions.

For the Full sample estimates in the main specification, we iterate through the Markov Chain 1.25 million times, and discard the first 0.75 million draws as "burn in" to ensure mixing. We diagnosed mixing by examining trace plots and computing the Potential Scale Reduction Factor (PSRF) following Gelman and Rubin (1992). Because of computational constraints in drawing from separate chains, we split the draws after the burn-in period into three equally sized continguous pieces and computed the PSRF using the first and third pieces. The PSRFs for almost all parameters were within 1.1 and were within 1.3 for all parameters. Trace plots for the few parameters with PSRFs higher than 1.1 did not indicate any obvious convergence issues.

Estimates of the $10 \%$ samples were computed by iterating through the Markov Chain 1 million times and discarding the first 0.75 million draws. We obtained estimates from three distinct chains initiated from dispersed starting values. We compared variances within each chain and the variance between chains, by computing both within and across PSRF chain values. For nearly all parameters, the PSRF is close to one, which suggests we have reached the target distribution.

Our estimates report the posterior mean and standard deviations. We examined the histograms of the marginal distributions of the posteriors to assess the skew. These histograms indicate that the means, modes and medians of the parameters in the main specification are similar. 


\section{B Appendix: Subway Distances (Not for Publication)}

In New York, high school students who live within 0.5 miles of a school are not eligible for transportation. If a student lives between 0.5 and 1.5 miles from a school, the Metropolitan Transit Authority provides them with a half-fare student Metrocard that works only for bus transportation. If they reside 1.5 miles or more from a school, they obtain full-fare transportation with a student Metrocard that works for subways and buses and is issued by the school transportation office.

Since subway is a common mode of transportation in New York City, this appendix assesses how the driving distance measure we utilize in the paper differs from commuting distance using NYC's subway system. Subway distance is defined as the sum of distance on foot to the student's nearest subway station, travel distance on the subway network to a school's nearest subway station, and the distance on foot from that station to the school. To compute these distances, we used ESRI's ArcGIS software and information on the NYC subway system from GIS files downloaded from Metropolitan Transit Authority's website. Details on these sources are in the Data appendix.

The overall correlation between driving distance and total commuting distance for all studentprogram pairs is 0.96. A regression of commuting distance on driving distance yields a coefficient of 0.77. Table B2 provides a summary of the correlations by the student and school borough. The correlations are higher than 0.84, except for schools in Staten Island, where the subway system is not quite as extensive as in other boroughs. In fact, it may be that driving distances are a more accurate measure than subway distance of Staten Island.

Panels B and $\mathrm{C}$ show that most students are assigned to schools in their borough in both the uncoordinated and coordinated mechanisms. In both mechanisms, a very small number of

students who do not live in Staten Island are assigned to schools there, and conversely, only a small number of students living in Staten Island are assigned to schools in a different borough. 
Table B1. Offer Processing in the Second Year of the Coordinated Mechanism (2004-05)

Distance to School (in miles)

Number of Students

Assignment

\begin{tabular}{lccc} 
& $(1)$ & $(2)$ & $(3)$ \\
\hline
\end{tabular}

(2)

(3)

Schools

In NYC Public, but at

Exit from NYC Public School Other than

Assigned

match. Final assignment round is the round during which an offer to the final assigned school is first made. 
Table B2. Subway and Driving Distance and Cross-Borough Travel

\begin{tabular}{|c|c|c|c|c|c|c|}
\hline \multirow[b]{2}{*}{ Student Borough } & \multicolumn{5}{|c|}{ School Borough } & \multirow[b]{2}{*}{$\begin{array}{c}\text { Total } \\
(6)\end{array}$} \\
\hline & $\begin{array}{c}\text { Bronx } \\
\text { (1) }\end{array}$ & $\begin{array}{c}\text { Brooklyn } \\
\text { (2) }\end{array}$ & $\begin{array}{c}\text { Manhattan } \\
\text { (3) }\end{array}$ & $\begin{array}{c}\text { Queens } \\
\text { (4) }\end{array}$ & $\begin{array}{c}\text { Staten Island } \\
\text { (5) }\end{array}$ & \\
\hline & \multicolumn{6}{|c|}{ A. Correlation between Subway and Driving Distance } \\
\hline Bronx & 0.90 & 0.93 & 0.97 & 0.91 & 0.76 & $\ldots$ \\
\hline Brooklyn & 0.90 & 0.91 & 0.95 & 0.91 & 0.92 & $\ldots$ \\
\hline Manhattan & 0.96 & 0.95 & 0.98 & 0.95 & 0.76 & $\cdots$ \\
\hline Queens & 0.91 & 0.91 & 0.95 & 0.87 & 0.85 & $\ldots$ \\
\hline \multirow[t]{2}{*}{ Staten Island } & 0.84 & 0.92 & 0.85 & 0.89 & 0.73 & $\ldots$ \\
\hline & \multicolumn{6}{|c|}{ B. Cross-Borough Travel in Uncoordinated Mechanism } \\
\hline Bronx & 15,187 & 41 & 1,382 & 66 & 1 & 16,677 \\
\hline Brooklyn & 13 & 20,877 & 1,073 & 502 & 12 & 22,477 \\
\hline Manhattan & 89 & 42 & 8,604 & 24 & 1 & 8,760 \\
\hline Queens & 15 & 493 & 586 & 16,498 & 0 & 17,592 \\
\hline \multirow[t]{2}{*}{ Staten Island } & 2 & 13 & 59 & 4 & 4,774 & 4,852 \\
\hline & \multicolumn{6}{|c|}{ C. Cross-Borough Travel in Coordinated Mechanism } \\
\hline Bronx & 13,335 & 85 & 2,049 & 84 & 8 & 15,561 \\
\hline Brooklyn & 39 & 20,035 & 1,858 & 846 & 40 & 22,818 \\
\hline Manhattan & 238 & 108 & 7,492 & 52 & 7 & 7,897 \\
\hline Queens & 26 & 584 & 1,028 & 14,972 & 9 & 16,619 \\
\hline Staten Island & 3 & 37 & 69 & 4 & 3,913 & 4,026 \\
\hline
\end{tabular}


Table B3. Main Round Assignments in Coordinated Mechanism, by Length of Rank Order List

\begin{tabular}{|c|c|c|c|c|c|c|c|c|c|c|c|c|c|}
\hline \multirow[b]{2}{*}{ Choice Assigned } & \multirow[b]{2}{*}{ All } & \multicolumn{12}{|c|}{ Length of Rank Order List } \\
\hline & & 1 & 2 & 3 & 4 & 5 & 6 & 7 & 8 & 9 & 10 & 11 & 12 \\
\hline Total & 69,907 & 4,597 & 3,282 & 4,128 & 4,622 & 4,952 & 4,776 & 4,406 & 4,390 & 4,558 & 6,135 & 9,849 & 14,212 \\
\hline 1 & $31.9 \%$ & $88.6 \%$ & $40.7 \%$ & $35.2 \%$ & $31.9 \%$ & $27.9 \%$ & $28.6 \%$ & $27.1 \%$ & $25.7 \%$ & $25.6 \%$ & $25.4 \%$ & $26.2 \%$ & $25.2 \%$ \\
\hline 2 & $15.0 \%$ & & $39.8 \%$ & $17.7 \%$ & $15.1 \%$ & $14.8 \%$ & $14.6 \%$ & $13.7 \%$ & $13.9 \%$ & $13.9 \%$ & $15.2 \%$ & $14.7 \%$ & $14.6 \%$ \\
\hline 3 & $10.2 \%$ & & & $24.3 \%$ & $11.6 \%$ & $11.6 \%$ & $10.6 \%$ & $10.0 \%$ & $10.8 \%$ & $9.9 \%$ & $10.4 \%$ & $10.4 \%$ & $10.5 \%$ \\
\hline 4 & $7.3 \%$ & & & & $18.0 \%$ & $9.3 \%$ & $8.1 \%$ & $7.9 \%$ & $8.0 \%$ & $7.6 \%$ & $7.6 \%$ & $7.8 \%$ & $8.2 \%$ \\
\hline 5 & $5.4 \%$ & & & & & $12.8 \%$ & $7.0 \%$ & $7.0 \%$ & $6.3 \%$ & $6.1 \%$ & $6.6 \%$ & $6.2 \%$ & $6.7 \%$ \\
\hline 6 & $3.9 \%$ & & & & & & $10.2 \%$ & $5.7 \%$ & $4.9 \%$ & $5.0 \%$ & $4.9 \%$ & $4.8 \%$ & $5.3 \%$ \\
\hline 7 & $2.9 \%$ & & & & & & & $8.1 \%$ & $4.3 \%$ & $4.4 \%$ & $4.0 \%$ & $4.1 \%$ & $4.3 \%$ \\
\hline 8 & $2.0 \%$ & & & & & & & & $5.8 \%$ & $3.4 \%$ & $3.3 \%$ & $2.9 \%$ & $3.5 \%$ \\
\hline 9 & $1.5 \%$ & & & & & & & & & $4.0 \%$ & $2.8 \%$ & $2.7 \%$ & $2.8 \%$ \\
\hline 10 & $1.1 \%$ & & & & & & & & & & $3.2 \%$ & $2.3 \%$ & $2.6 \%$ \\
\hline 11 & $0.8 \%$ & & & & & & & & & & & $2.6 \%$ & $2.2 \%$ \\
\hline 12 & $0.5 \%$ & & & & & & & & & & & & $2.5 \%$ \\
\hline Unassigned & $17.5 \%$ & $11.4 \%$ & $19.5 \%$ & $22.8 \%$ & $23.3 \%$ & $23.6 \%$ & $20.9 \%$ & $20.6 \%$ & $20.3 \%$ & $20.1 \%$ & $16.7 \%$ & $15.3 \%$ & $11.6 \%$ \\
\hline
\end{tabular}

Notes: This table reports choices assigned after the main round in the coordinated mechanism in 2003-04. 
Table B4. Assignment and Enrollment Decisions of Students in Coordinated Mechanism by Rank Order List Length

\begin{tabular}{|c|c|c|c|c|c|c|c|c|c|c|c|c|c|}
\hline & \multirow[b]{2}{*}{ All } & \multicolumn{12}{|c|}{ Length of Rank Order List } \\
\hline & & 1st & 2nd & $3 \mathrm{rd}$ & 4th & 5th & 6th & 7th & 8th & 9th & 10th & 11th & 12th \\
\hline & \multicolumn{13}{|c|}{ A. Students Offered Assignment in Main Round } \\
\hline Number of Students & 57,658 & 4,072 & 2,641 & 3,187 & 3,545 & 3,782 & 3,776 & 3,497 & 3,499 & 3,642 & 5,113 & 8,340 & 12,564 \\
\hline Average Rank of Assignment & 3.00 & 1.00 & 1.49 & 1.86 & 2.21 & 2.53 & 2.76 & 3.04 & 3.20 & 3.35 & 3.49 & 3.60 & 3.93 \\
\hline Accept Main Round Assignment & $92.7 \%$ & $91.2 \%$ & $88.5 \%$ & $88.4 \%$ & $90.2 \%$ & $91.2 \%$ & $92.3 \%$ & $91.9 \%$ & $93.0 \%$ & $93.6 \%$ & $94.5 \%$ & $94.6 \%$ & $94.3 \%$ \\
\hline Enroll in Private School & $2.5 \%$ & $6.9 \%$ & $7.4 \%$ & $6.1 \%$ & $4.5 \%$ & $2.9 \%$ & $2.4 \%$ & $2.1 \%$ & $1.9 \%$ & $1.2 \%$ & $1.0 \%$ & $0.7 \%$ & $1.0 \%$ \\
\hline Remain in Current School & $1.2 \%$ & $1.2 \%$ & $2.0 \%$ & $2.3 \%$ & $1.9 \%$ & $2.1 \%$ & $1.4 \%$ & $1.8 \%$ & $1.4 \%$ & $1.2 \%$ & $0.9 \%$ & $0.7 \%$ & $0.6 \%$ \\
\hline Attend Specialized or Alternative School & $0.1 \%$ & $0.0 \%$ & $0.0 \%$ & $0.0 \%$ & $0.0 \%$ & $0.1 \%$ & $0.1 \%$ & $0.2 \%$ & $0.1 \%$ & $0.1 \%$ & $0.2 \%$ & $0.1 \%$ & $0.0 \%$ \\
\hline \multirow[t]{2}{*}{ Participate in Supplementary Round } & $0.3 \%$ & $0.1 \%$ & $0.2 \%$ & $0.2 \%$ & $0.4 \%$ & $0.5 \%$ & $0.6 \%$ & $0.3 \%$ & $0.6 \%$ & $0.3 \%$ & $0.3 \%$ & $0.2 \%$ & $0.3 \%$ \\
\hline & \multicolumn{13}{|c|}{ B. Students Unassigned after Main Round } \\
\hline Number of Students & 12,249 & 525 & 641 & 941 & 1,077 & 1,170 & 1,000 & 909 & 891 & 916 & 1,022 & 1,509 & 1,648 \\
\hline Participate in Supplementary Round & $52.6 \%$ & $26.1 \%$ & $44.8 \%$ & $54.0 \%$ & $54.1 \%$ & $56.2 \%$ & $55.6 \%$ & $55.7 \%$ & $52.7 \%$ & $46.5 \%$ & $43.5 \%$ & $49.6 \%$ & $68.2 \%$ \\
\hline Enroll at Supplementary Round Assignment & $72.9 \%$ & $73.0 \%$ & $85.0 \%$ & $76.0 \%$ & $75.5 \%$ & $77.8 \%$ & $73.0 \%$ & $75.9 \%$ & $74.5 \%$ & $68.8 \%$ & $71.7 \%$ & $69.5 \%$ & $66.3 \%$ \\
\hline Enroll in Private School & $2.8 \%$ & $6.7 \%$ & $6.1 \%$ & $4.7 \%$ & $3.5 \%$ & $3.8 \%$ & $2.2 \%$ & $1.7 \%$ & $1.6 \%$ & $1.9 \%$ & $2.2 \%$ & $1.4 \%$ & $1.9 \%$ \\
\hline Remain in Current School & $3.2 \%$ & $6.7 \%$ & $6.2 \%$ & $5.6 \%$ & $5.3 \%$ & $4.4 \%$ & $3.2 \%$ & $3.3 \%$ & $2.5 \%$ & $2.0 \%$ & $1.5 \%$ & $0.9 \%$ & $1.8 \%$ \\
\hline Attend Specialized or Alternative School & $0.3 \%$ & $0.8 \%$ & $0.5 \%$ & $0.6 \%$ & $0.2 \%$ & $0.1 \%$ & $0.3 \%$ & $0.3 \%$ & $0.3 \%$ & $0.1 \%$ & $0.2 \%$ & $0.5 \%$ & $0.1 \%$ \\
\hline
\end{tabular}

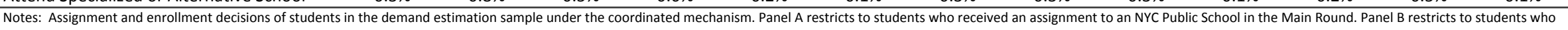
did not receive an assignment in the Main Round. 


\section{Appendix: Data (Not for Publication)}

The data for this study come from the NYC Department of Education (DOE), the 2000 US Census, ArcGIS Business Analyst toolbox, and GFTS NYC subway data from the NYC Metropolitan Transit Authority. These sources provide us with data on students, schools, the rank-order lists submitted by students, assignments of students to schools, or the distance between students and schools on either the road network or the subway system. Students and programs are uniquely identified by a number that can be used to populate fields and merge across DOE datasets. We geocode student and school addresses to merge with geo-spatial data.

We use three samples of students in our analysis: one sample to estimate demand and two to infer the welfare effects of the mechanism change. The welfare samples consist of public middle school students who matriculate into NYC Public High Schools in the academic years 2003-04 and 2004-05. The demand sample consists of public middle school students who participated in the Main round of the mechanism in 2003-04. The demand sample and the welfare sample from 2003-04 are not nested because students participating in the mechanism may choose to enroll in schools outside the NYC Public School system, whereas other students may be assigned to public schools outside the main assignment process.

\section{C.1 Students}

\section{Assignment and Rank Data}

Data on the assignment system come from the DOE's enrollment office. The files indicate all final assignments of students in both analysis years. We use these assignments as the basis of our baseline welfare calculations. In addition, the assignment system also provides separate files that detail the rank orders, applications, or processes through which a student is assigned to a given school.

We use the records from the Main round in the new mechanism to obtain the rank-order lists submitted by students and the assignment proposed by the mechanism. A total of 87,355 students participated in the main round.

For the old mechanism, the assignment system provides student choice and decision files for the Main round. The former contains the ranked applications submitted by the students and the latter provides the school decisions to accept/reject/waitlist students and the students' responses to these offers, if any. A total of 84,272 students participated in the Main round.

The old assignment system also contains several files documenting the supplementary variable assignment process (VAS) round.

\section{Assignment Rounds and Offers in the Old Mechanism}

The files in the old mechanism do not contain direct information on how students were assigned to their programs. However, we are able to determine whether a student applied to a particular program/school in the Main process or the supplementary VAS process. We first append fields indicating whether a student applied to her assigned program in the main process. We also append a field indicating whether a student applied to her assigned school in the supplementary 
VAS process. It turns out that no final assignment appears in both the Main and the VAS files. We therefore categorize the former assignments as Main-round assignments and the latter as VAS assignments. We assume all other assignments occur in the Administrative round. Based on conversations with DOE officials, we surmise that students were typically assigned to the school closest to home that had open seats. Our understanding is that most students who participated in the VAS process did not have a default local school. Analyzing the geographic distribution if students assigned administratively, as per our definition, supports this; many parts of NYC have no students assigned administratively.

Finally, we also append the number of offers made to a particular student using a file with the initial school response to the student application.

\section{Assignment Rounds in the New Mechanism}

We use the NYC assignment files described above to determine the process through which a student was assigned a given school.

The assignment files in the new mechanism contain, for every student program-pair ranked in either the Main or the Supplementary round, two fields indicating whether the student is eligible for the school and if the student was assigned to that school. A final assignment is treated as a Main round assignment if it appears as an eligible assignment in the Main round. Assignments not made in the Main round are treated as Supplementary round assignments if they appear in the Supplementary round files. All other assignments are treated as Administrative assignments.

\section{Student Characteristics}

The records from the NYC Department of Education contain students' street address, previous and current grade, gender, ethnicity, and whether the student was enrolled in a public middle school. Each student is identified by a unique number that allows us to merge these data with additional NYC DOE data on student scores in middle school standardized tests, Limited English Proficiency status, and Special Education status. A separate file indicates subsidized lunch status as of the 2004-05 enrollment. If a student is not in that file, we code the student as not receiving a subsidized lunch.

There are several standardized tests taken by middle school students in NYC. To avoid the concern that two different tests may not be comparable indicators of student achievement, we identify the modal standardized math and reading tests taken by students in our sample. These are the May tests with codes CTB and TEM respectively. Of the students who did not take either of these tests in May, at most $10 \%(<2 \%$ of the full sample) took a different standardized test in the same subject while in middle school. We verify that test score distribution and support

are similar across the two years in our sample. Some students took the test multiple times. The highest score obtained by a student was used in these instances.

In 2002-03, the math and reading scores are missing for $13.56 \%$ and $17.55 \%$ of students, respectively, from our final sample. For the 2003-04 welfare sample, scores are missing for $8.29 \%$ and $13.57 \%$ students, respectively, for math and reading. In the demand sample the corresponding fractions are $7.13 \%$ and $12.56 \%$. 


\section{Geographic Data}

We use the 2000 US Census to obtain block group family income. Student home address and distances to school were calculated using ArcGIS. Corrections to the addresses, when necessary, were made using Google Map Tools followed by manual checks and corrections.

The final address set was geocoded using ArcGIS geocoder with the address-set in the Business Analyst toolbox (ver. 10.0). We first used an exact match to determine if a student's address can be geocoded precisely to a rooftop. If the results were unreliable, we coded the student to the zip code centroid. The vast majority of students were rooftop geocoded. The OD Cost matrix tool in the Network Analyst toolbox was used to compute the distance by road for each student-school pair. The road network is also obtained from Business Analyst.

Our computation of subway distances assumes that a student first walks to the closest subway stop, then uses the subway system to travel to the subway stop closest to the school, and finally walks from the subway to the school. The Subway stop locations are taken from the GTFS and geodata data on the NYC Metropolitan Transit Authority website. The Network Analyst toolbox is used to compute the walking distance and the GTFS data is used to compute the distance on the subway system between every pair of subway stops.

\section{Merging Student Records}

Assignment and other DOE files are matched using the unique student identifier linking these data. Each 8th-grade non-private middle school student in the Department of Education records could be merged uniquely with a student in the NYC assignment records. Less than $0.45 \%$ of students with known assignments in the records of the NYC assignment system records could not be merged with a student in the DOE records. These students were not included in the analysis.

\section{C.2 Applicant Sample Construction}

Our goal is to consider first-time applicants to the NYC public (unspecialized) high school system who live in New York City and attend a public middle school in 8th grade. Below, we describe the procedure used to construct the samples. The selection procedure is also summarized in Table B1.

\section{Welfare Sample}

The welfare samples are constructed from the NYC DOE's records for all students enrolling in 9th grade at a high school in the academic years 2003-04 and 2004-05.

Because our choice set in the demand analysis will be restricted to unspecialized, non-charter high schools in the public school system, the welfare sample does not include students who matriculated to such schools.

Of the 92,623 8th grade students matriculating into 9th grade at a NYC public school in 2002$03,11,790(12.73 \%)$ students went to a private middle school and were dropped. Another 8,051 $(8.69 \%)$ students were not included in the analysis because their assignments were unknown, or 
because they matriculated to either a Specialized high school or a charter school. Finally, we exclude students in schools that were closed (i.e. no assignments in the new system).

In 2003-04, about $1.3 \%$ of students had also participated in the old mechanism, presumably because these students repeated 8th grade. These students were considered part of the 2002-03 sample and only their 2002-03 high school assignment is considered in our analysis. We also drop private middle school students and those not assigned to public school. These fractions were similar to the $2002-03$ numbers, at $12.21 \%$ and $8.13 \%$ respectively. We also drop students who were assigned to new schools.

These selections into the sample leave us with 70,358 students in 2002-03 and 66,921 students in 2003-04. Students who may have been assigned to a high school program through a process other than the Main round are included in these samples.

\section{Demand Sample}

This sample is sourced from the NYC Assignment system's records on the participants in the Main round of the mechanism. As discussed in the text, we use data only from the Main round of the mechanism because this round has the most desirable incentive properties.

We do not want to exclude students on the basis of final assignment to avoid selecting on the choice to leave the public school system. In order to most closely match welfare sample construction, we select the demand sample only on characteristics that can be considered as exogenous at the time of participation.

Since we focus on first-time applicants in 8 th grade, we exclude 747 students who were part of the 2002-03 files and 5,311 students who were 9th graders. Presumably, these students were held back in 8th or 9th grade. This leaves us with a sample of 81,297 8th grade students.

Of the 8th-grade participants, 9,301 (11.44\%) students were from private middle schools and were dropped. We also excluded students designated as belonging to the top $2 \%$ of their middle school classes because these students are prioritized at education option schools, creating incentives to misreport their preferences. These are $2.5 \%$ of the non-private 8 th grade population.

A total of 216 students did not rank any public schools in our sample. After excluding these students, a total of 69,907 students remain in the sample we use for the demand analysis.

\section{C.3 Programs/Schools}

\section{NYC Department of Education School Report Cards}

The school characteristics were taken from the report card files provided by the NYC Department of Education. These data provide information on a school's enrollment statistics, racial composition of student body, attendance rates, suspensions, teacher numbers and experience, and graduating class Regents Math and English performance. A unique identifier for each school allows these data to be merged with data from our other sources.

There were significant differences in the file formats and field names across the years. To keep the school characteristics constant across years, we use the data from the 2003-04 report cards as the primary source. This corresponds to information from school years prior to the

new assignment mechanism. Except for data on the math and reading achievement, variable 
descriptions were comparable across years. For these comparable variables, we used the 2002-03 data only when the 2003-04 data were not available. The coverage of the characteristics for the school sample is enumerated in Table B2.

\section{Assignment System and DOE files}

Assignment data contain a list of all school programs in the public school system along with an identifier for the associated high school. The DOE provided a separate file with data on the school addresses and identifiers that allows us to merge that information with the assignment system database. A second identifier can be used to merge these data with other fields in the department of education records described above.

Across the two years, the high school identifiers in the files were inconsistent for a small number of schools in our sample. These were matched by school name and address. One school moved from Brooklyn to Manhattan and was investigated to ensure the records were appropriately matched.

\section{Program Characteristics}

Program characteristics are taken from the DOE's High School Directory, which is made available to students before the application process. Reliable data on program types were not available in 2002-03. The 2002-03 program types were imputed from the 2003-04 program types if the program was present in both years. Otherwise, the program was categorized as a general program.

The numerous program types were aggregated into fewer broad categories. The items in the list below are the aggregated categories that include all the subcategories described by the data.

1. Arts: Dance, Instrument Performance, Musical Theater, Performing and Visual, Performing Arts, Theater, Theater Tech, Visual Arts, Vocal Performance.

2. Humanities/Interdisciplinary: Education, Humanities/Interdisciplinary.

3. Business/Accounting: Accounting, Business, Business Law, Computer Business, Finance, International Business, Marketing, Travel Business.

4. Math/Science: Engineering, Engineering - Aerospace, Engineering - Electrical, Environmental, Math and Science, Science and Math.

5. Career: Architecture, Computer Tech, Computerized Mech, Cosmetology, Journalism, Veterinary, Vision Care Technology.

6. Vocational: Auto, Aviation, Clerical, Construction, Electrical Construction, Health, Heating, Hospitality, Plumbing, Transportation.

7. Government/law: Law, Law Enforcement, Law and Social Justice, Public Service.

8. Other: Communication, Expeditionary, Preservation, Sports.

9. Zoned 


\section{General: General, Unknown.}

Finally, some programs adopt a language of instruction other than English. We categorized the languages as Spanish, English, Asian Languages, and Other.

\section{C.4 School Sample Construction}

We consider NYC public middle school 8th grade students assigned to public high schools that are not charters, specialized or parochial. Our analysis uses two school samples, one for each year in our analysis.

To construct these samples, we started with the set of schools and programs in the assignment records. To analyze rank data, we added the set of school programs that were ranked by any student in our demand sample. This initial set consists of 743 (301) programs (schools) in 2002-03 and 677 (293) programs (schools) in 2003-04.

In 2003-04, this list contained 62 parochial school programs. We verified that each of the 130 students matriculating to these school programs were private middle-schoolers. These schools were dropped from the analysis because private middle-schoolers are not in the population of interest. Subsequently, we dropped all charter and specialized high school programs and other school programs that do not have assignments and were not ranked by any student in our sample.

A total of 9 continuing student programs accepted students only from their associated middle school. Since these programs cannot be chosen by students who were not in those schools in 8th grade, we combine these programs with a generic program (e.g., unscreened, English, general/humanities/math). Rank-order lists for students who ranked both the continuing students' only program and the associated program were modified as described below.

Finally, we dropped new and closed schools from the analysis. Closed schools were ones that admitted students in 2002-03 but not in 2003-04. The set of new schools was collected from a separate DOE directory of new schools. These schools were not well advertised and very few students ranked them, making calculations with those schools unreliable.

The number of schools and programs at each stage of our selection procedure is also summarized in Table B2.

\section{C.5 Program Capacities}

Program capacities are not provided separately in the data files. We have estimated program capacities from the actual match files and students' final assignments. The capacity of each program is initially set to zero. If a student in our demand sample is assigned a program at the end of the assignment process, the capacity of the program is increased by one. Otherwise, if the student is assigned a program in the Main round, the capacity of the program is increased by one. Finally, if a student is not assigned in the Main round and is assigned a program in the Supplementary round, the capacity of the program is increased by one.

Education Option programs are divided into six buckets: High Select, High Random, Middle Select, Middle Random, Low Select and Low Random. Bucket capacities are calculated as above by taking into account the category of the assigned student. For example, if a student of High category is assigned an Education Option program, then the capacity of a High Select bucket is 
increased by one. If the current capacity of the High Select bucket is less than or equal to that of High Random, then the capacity of the High Select bucket is increased, otherwise the capacity of the High Random bucket is increased.

\section{C.6 Program Priorities}

Program type determines how students are priority-ordered. The data contains a list of all programs with program-specific information, including type, building number, street address, etc. When students have the same priority, the tie is broken randomly. The random numbers are generated by computer during our simulations.

The assignment data contains several fields that determine a student's priority order in programs. Priority group is a number assigned by the NYC DOE depending on students' home addresses, program location, etc. High school rank is a number assigned by each program. This number may reflect a student's ranking among all applicants to an Education Option program, whether a student attended the information session of a limited unscreened program, etc. These fields are provided for every program every student ranked. Students applying to Educational Option programs are placed into one of three categories based on their score on the 7th grade reading test: top 16 percent (high), middle 68 percent (middle), and bottom 16 percent (low). Student categories are included in the assignment data.

Unscreened programs order students based on their random numbers only. Limited unscreened and formerly zoned programs order students first by priority group and then by random number within the priority group. Screened programs order students by priority group and then by high school rank. Each Education Option program orders all applicants for each of six buckets, High Select, High Random, Middle Select, Middle Random, Low Select and Low Random. A High Bucket orders high category students first, then middle category students, then low category students. A Middle Bucket orders middle category students first, then high category students, then low category students. A Low Bucket orders low category students first, then high category students, then middle category students. A Select bucket orders students within each category by priority order and then by high school rank. A Random bucket orders students within each category by priority order.

\section{C.7 Regents Test and Graduation Outcomes}

\section{Regents}

The NYC Regents test file contains the date and raw score for each tested student from 2004 to 2010. Regents exams are mandatory state examinations on which performance determines whether a student is eligible for a Regents high school diploma in New York. There are Regents examinations in English, Global History, US History, and multiple exams in Math and Science. A Regents exam typically has a multiple choice section and a long answer or essay component, and each exam usually lasts for three hours. The English exam, however, consists of two three-hour pieces over two days. The exam has a locally-graded component and Dee, Jacob, McCrary, and Rockoff (2016) illustrate how test scores bunch near performance thresholds.

The New York State Board of Regents governs and designs the Regents exams. Starting in 
2005, they started to modify the math exams. At the beginning of our sample, the two math exams were Elementary Algebra and Planar Geometry (Math A) and Intermediate Algebra and Trigonometry (Math B). Two new math exams, Integrated Algebra I (Math E) and Geometry (Math G), have since been phased in. Since students typically either take Math A or Math E, we focus on the score on the test taken first, taking the Math A score when both are contemporaneous. There are Regents science exams in Earth Science, Living Environment, Chemistry, and Physics. The science outcome we focus on is Living Environment because it is the most commonly taken Regents science exam. English and US History Regents exams are typically taken in 11 th grade.

The Regents file does not have the test date, and instead only has a variable indicating the term ("termcd"). Based on discussions with the DOE, we convert term to fall if the termcd is "1", "5", "a", or "A" and to spring if the termcd is "2", "3", "4", "6", or "7." The DOE indicated exceptions at the following school DBNs where the termcd of "2" refers to the fall semester: 79M573, 79M612, 32K564, 02M560, 10X319, 02M575, 22K585, 12X480, 03M505, 02M570, 21K525, 21K540, 19K409, 17K489, 15K698, 14K454, 14K640, 07X379, 11X265, 15K529, 08X377, 05M285, 21K728, 02M303, 25Q792, 18K578, 24Q520, and 19K431. If the student takes a subject before 9th grade, that subject is dropped for that student. If a student takes the test more than once after 9th grade, we used the test score from the earliest date. There are a small number of cases where there is more than one score on the same date, and this date is the first date after entering 9 th grade. In some of these cases, there are two different test codes, where one code ends with a "2". We used the score corresponding to the test that does not end with a "2". Otherwise, we treated the score as missing.

We focus on the results in the Mathematics and English tests. Given the existence of multiple Math tests we take the earliest test between Math A and Math B, which are the two most common tests. If a student takes both tests in the same school year and term we use the Math A result.

For each subject, we standardized scores to have mean zero and standard deviation within subject for each cohort of test-takers by year and test time.

\section{Graduation}

The Graduation file contains the discharge status of all public school students from 2005 to the Spring 2012. For application cohorts 2002-03 and 2003-04, students should start school in Fall 2003 and Fall 2004 and graduate on-time in Spring 2007 and Spring 2008, respectively. To code graduation type, we use the following discharge codes: a) 26, 30, and 61 (discharge codes for a local diploma)?b) 27, 46, and 60 (discharge codes for a Regents diploma) c) 28, 47, and 62 (discharge codes for an Advanced Regents diploma).

It is possible for students to graduated with several different discharge files. We classify students as having received or not any diploma (local or Regents) and we distinguish among students who received any Regents diploma or not.

\section{C.8 Miscellaneous Issues}

\section{Modifications to the rank-order list}


1. In the Main round, some students ranked programs that were either charter schools or Specialized High Schools. These programs are not in the sample of schools we consider and were likely ranked by in error the students. In such cases, programs were removed from the rank-order lists and rank-order lists were made contiguous where all programs ranked below a program not in the sample were moved up in the rank-order lists. These programs were observed a total of 795 times in the data. Thirty students ranked only charter or specialized programs.

2. The rank-order lists of students who ranked continuing student programs were modified as follows: First, the lists of all students who ranked only the continuing student programs were modified so that the student ranked the associated generic program instead. When students ranked both the generic program and the associated continuing student program, the list was modified so that only the associated program was ranked, and it was ranked at the highest of the two ranked positions. All programs ranked at positions below the lower-ranked of the two programs were moved up by one. A total of 46 students ranked both the continuing program and the generic program, to which we mapped the continuing program to. In 17 cases, these ranks were not consecutive. 
Table C1. Student Sample Selection

\begin{tabular}{|c|c|c|c|}
\hline & \multicolumn{3}{|c|}{ Mechanism Comparison } \\
\hline & \multirow{3}{*}{$\begin{array}{c}\text { Uncoordinated } \\
2002-2003 \\
\text { (1) }\end{array}$} & \multicolumn{2}{|c|}{ Coordinated } \\
\hline & & 2003-2004 & 2004-2005 \\
\hline & & (2) & (3) \\
\hline Number of students in the NYC DOE student file & 100,669 & 97,569 & 96,327 \\
\hline \multicolumn{4}{|l|}{ Number of students in the rank data } \\
\hline Excluding students in both $2002-03$ and $2003-04$ files from $2003-04$ & & 96,275 & \\
\hline Excluding 9th grade students & 92,623 & 89,062 & 90,250 \\
\hline Excluding private middle school students & 80,833 & 78,183 & 80,093 \\
\hline Excluding students with addresses outside the five boroughs & 80,725 & 78,089 & 79,977 \\
\hline Total number of students with known assignments to sample schools & 75,515 & 73,989 & 75,049 \\
\hline Excluding students attending specialized high schools & 72,725 & 70,992 & 71,861 \\
\hline Excluding students attending charter schools & 72,681 & 70,886 & 71,749 \\
\hline Excluding students in closed and new schools & 70,358 & 66,921 & 69,013 \\
\hline \multicolumn{4}{|l|}{ Excluding top $2 \%$ students } \\
\hline Excluding students that did not rank any sample schools & & & \\
\hline
\end{tabular}


Table C2. Construction of School Sample

\begin{tabular}{|c|c|c|c|c|c|c|}
\hline & \multirow{2}{*}{\multicolumn{2}{|c|}{$\begin{array}{c}\text { Uncoordinated } \\
2002-2003\end{array}$}} & \multicolumn{4}{|c|}{ Coordinated } \\
\hline & & & \multicolumn{2}{|c|}{ 2003-2004 } & \multicolumn{2}{|c|}{ 2004-2005 } \\
\hline & $\begin{array}{c}\text { Programs } \\
\text { (1) } \\
\end{array}$ & $\begin{array}{c}\text { Schools } \\
(2)\end{array}$ & $\begin{array}{c}\text { Programs } \\
\text { (3) } \\
\end{array}$ & $\begin{array}{c}\text { Schools } \\
(4)\end{array}$ & $\begin{array}{c}\text { Programs } \\
\text { (5) } \\
\end{array}$ & $\begin{array}{c}\text { Schools } \\
(6)\end{array}$ \\
\hline Programs where NYC public school students assigned & 743 & 301 & 669 & 293 & 658 & 322 \\
\hline Adding additional programs ranked by students & & & 677 & 294 & 764 & 338 \\
\hline Excluding parochial schools & 681 & 239 & 677 & 294 & 752 & 331 \\
\hline Excluding specialized schools & 669 & 232 & 665 & 287 & 750 & 329 \\
\hline Excluding charter schools & 667 & 230 & 663 & 285 & 702 & 315 \\
\hline Excluding programs with no assignments or ranking & 637 & 225 & 648 & 284 & 691 & 313 \\
\hline Combining continuing education programs & 637 & 225 & 639 & 284 & 691 & 313 \\
\hline Excluding closed schools & 612 & 215 & 639 & 284 & 691 & 313 \\
\hline Excluding schools opened after HS directory printed* & 612 & 215 & 558 & 235 & 661 & 283 \\
\hline Programs/schools ranked by students in sample & & & 497 & 234 & 660 & 283 \\
\hline
\end{tabular}

Notes: 13 continuining student programs were merged with a generic program at host school. Parochial schools in 2002-03 only have private middle school students assigned to them and are not ranked by students in the demand sample. *A total 20 schools and 23 programs opened before HS directory printed are included in 2003-04. 
Table C3. Coverage of School Characteristics

\begin{tabular}{|c|c|c|c|}
\hline & $\begin{array}{c}\text { Uncoordinated } \\
2002-03 \\
(1) \\
\end{array}$ & $\begin{array}{c}\text { Coordinated } \\
2003-04 \\
(2) \\
\end{array}$ & $\begin{array}{l}\text { Both } \\
\text { Years } \\
\text { (3) }\end{array}$ \\
\hline Total number of schools in the sample & 215 & 234 & 215 \\
\hline 9th grade enrollment & 196 & 199 & 189 \\
\hline Race & 196 & 199 & 189 \\
\hline Attendance Rate & 196 & 199 & 189 \\
\hline Percent Free Lunch & 196 & 198 & 189 \\
\hline Percent of teachers less than 2 years experience & 219 & 223 & 212 \\
\hline High Math Achievement & 198 & 200 & 191 \\
\hline High English Achievement & 180 & 177 & 173 \\
\hline Percent Attending College & 171 & 167 & 165 \\
\hline
\end{tabular}

Notes: Table reports the number of schools with the characteristics from New York State Report cards. 